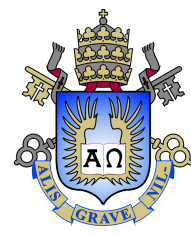

Tamires Pereira Pinto da Silva

\title{
Permeability estimation in turbidite channels constrained by well-testing
}

Dissertation presented to the Programa de Pós-Graduação em Matemática da PUC-Rio in partial fulfillment of the requirements for the degree of Mestre em Matemática .

Advisor

Prof. Sinésio Pesco

Co-advisor: Prof. Abelardo Borges Barreto Junior 


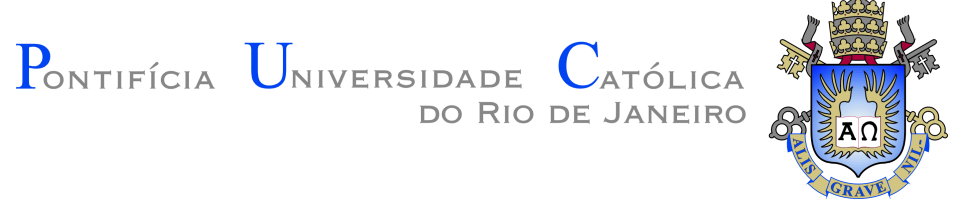

Tamires Pereira Pinto da Silva

\section{Permeability estimation in turbidite channels constrained by well-testing}

Dissertation presented to the Programa de Pós-Graduação em Matemática da PUC-Rio in partial fulfillment of the requirements for the degree of Mestre em Matemática. Approved by the undersigned Examination Committee.

Prof. Sinésio Pesco

Advisor

Departamento de Matemática - PUC-Rio

Prof. Abelardo Borges Barreto Junior

Co-advisor

Departamento de Engenharia Mecânica - PUC-Rio

Prof. Márcio da Silveira Carvalho

Departamento de Engenharia Mecânica - PUC-Rio

Prof. Luiz Fernando Araujo Oliveira CENPES - Petrobras

Prof. Márcio da Silveira Carvalho

Vice Dean of Graduate Studies

Centro Técnico Científico - PUC-Rio

Rio de Janeiro, September 14th, 2018 
All rights reserved.

Tamires Pereira Pinto da Silva

Graduated in mathematics by Universidade Federal Fluminense de Niterói (UFF) in 2016.

Bibliographic data

Pereira Pinto da Silva, Tamires

Permeability estimation in turbidite channels constrained by well-testing / Tamires Pereira Pinto da Silva; advisor: Sinésio Pesco; co-advisor: Abelardo Borges Barreto Junior. - Rio de janeiro: PUC-Rio, Departamento de Matemática, 2018.

v., 67 f: il. color. ; $30 \mathrm{~cm}$

Dissertação (mestrado) - Pontifícia Universidade Católica do Rio de Janeiro, Departamento de Matemática .

Inclui bibliografia

1. Matemática Aplicada - Teses. 2. Computação Gráfica - Teses.

3. Teste de pressão;. 4. Modelo geológico;. 5. Modelagem baseada em objetos;. 6. Geoestatística;. 7. Simulação de fluxo..

I. Pesco, Sinésio. II. Borges Barreto Junior, Abelardo. III. Pontifícia Universidade Católica do Rio de Janeiro. Departamento de Matemática. IV. Título. 


\section{Acknowledgments}

I would like to dedicate this achievement to my family for the support and affection, especially to my parents who with unparalleled love and union have made me who I am. I would like to thank my greatest friend, Everson Esteves, who helped me to overcome all the challenges that I faced during my journey.

I would like to thank all my professors Dirce Pesco, Luciana Pena, Katia Frensel and Wanderley Rezende for their encouragement to follow in the postgraduate.

My deep and sincere gratitude to my advisor Sinésio Pesco for the dialogue, guidelines and advices that served as motivation for my academic development and my co-advisor Abelardo Barreto for the long conversations, availability and continuous optimism that helped me to complete this work.

Then I wish to thank the Departamento de Matemática - PUC-Rio and Creuza, Orlando, Katia, Carlos and Mariana for their support and attention.

Besides I am forever thankful to my postgraduate friends for the reception and exchange of knowledge, especially the students of room 850: Tiago Novello, Gabrielle Saller, Pêdra Andrade, Letícia Alves, Marcelo Santos, Makson Salles and Renan Vieira. Also, to my friends who collaborated for my development and who shared several happy moments with me: Thiago Menezes, João Marcos, Rafael Sanabria, Viviana Vargas, Tahyz Pinto, Paulo Roberto and Mayara Antunes.

This study was financed in part by the Coordenação de Aperfeiçoamento de Pessoal de Nível Superior - Brasil (CAPES) - Finance Code 001 and by Petrobras. 


\section{Abstract}

Pereira Pinto da Silva, Tamires; Pesco, Sinésio (Advisor); Borges Barreto Junior, Abelardo (Co-Advisor). Permeability estimation in turbidite channels constrained by well-testing. Rio de Janeiro, 2018. 67p. Dissertação de Mestrado

- Departamento de Matemática, Pontifícia Universidade Católica do Rio de Janeiro.

The main objective of this work is to populate turbidite channels with some petrophysical property such as permeability. These channels are geometrically constrained by turbidite lobes creating a simulated depositional system. Numerical simulations are used to try to fit the permeability field to a reference case through an objective function. A conventional finite difference simulator was used to compare the reference data to the simulations, obtaining close results.

\section{Keywords}

Well testing; Geological model; Object-based modeling; Geostatistics; Fluid-flow simulation. 


\section{Resumo}

Pereira Pinto da Silva, Tamires; Pesco, Sinésio; Borges Barreto Junior, Abelardo. Estimativa da permeabilidade em canais turbidíticos usando dados de teste de formação. Rio de Janeiro, 2018. 67p. Dissertação de Mestrado - Departamento de Matemática , Pontifícia Universidade Católica do Rio de Janeiro.

O principal objetivo deste trabalho é preencher canais turbidíticos com alguma propriedade petrofísica, como a permeabilidade. Estes canais são geometricamente limitados por lobos turbidíticos, gerando a simulação de um sistema deposicional. Simulações numéricas são usadas para tentar ajustar a permeabilidade a um caso de referência por meio de uma função objetivo. Um simulador convencional de diferenças finitas foi usado para comparar os dados de referência com as simulações, obtendo resultados próximos.

\section{Palavras-chave}

Teste de pressão; $\quad$ Modelo geológico; $\quad$ Modelagem baseada em objetos; Geoestatística; Simulação de fluxo. 


\section{Table of contents}

1 Introduction $\quad 10$

1.1 Work Sketch 11

1.2 Dissertation Outline 12

2 Geological Model $\quad 13$

2.1 Modeling of Geological Bodies 13

2.1.1 Turbidite Lobe 14

$\begin{array}{ll}2.1 .2 & \text { Bottom Surface } \\ 2.1 .3 & 15\end{array}$

$\begin{array}{ll}2.1 .3 \text { Channel System } & 16\end{array}$

$\begin{array}{ll}2.2 \text { Depositional System Modeling } & 17\end{array}$

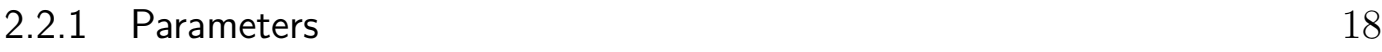

$\begin{array}{ll}2.2 .2 \text { Simulated Cases } & 20\end{array}$

3 Petrophysical Characterization $\quad 22$

3.1 Permeability 22

3.2 Areal Permeability Distribution 22

3.3 Vertical Permeability Distribution 25

3.4 Properties Generation 25

3.4.1 The Areal Permeability Grid 27

3.4.2 The Vertical Permeability Grid 29

4 Permeability Adjust Constrained by Well Test Data 31

4.1 Well-Testing 31

4.2 Input File IMEX 32

4.2.1 Average Permeability 33

4.3 Output File IMEX $\quad 35$

$\begin{array}{ll}\text { 4.3.1 Effective Wellbore Radius } & 37\end{array}$

$\begin{array}{lll}4.4 & \text { Optimization Process } & 39\end{array}$

4.4.1 Objective Function 39

4.4.2 Auxiliary Function and Secant Method 40

5 Results $\quad 42$

5.1 Approximation to the Reference Case 42

5.2 Approximation to the Reference Case with Noise 52

6 Conclusions $\quad 61$

$\begin{array}{ll}\text { Bibliography } & 62\end{array}$

A Example of Input File $\quad 64$

B NULL.txt $\quad 66$

$\begin{array}{lll}C & \text { PERM.txt } & 67\end{array}$ 


\section{List of figures}

Figure 2.1 Sediments deposition scheme - Reprinted from Esquema de Deposição dos Sedimentos do Reservatório do Campo de Marlim, modified by Arienti etal, July 25 2018, retrieved from http://www.drm.rj.gov.br/admin_fotos/bacia_de_campos/ Copyright 2018 by Departamento de Recursos Minerais - RJ.

Figure 2.2 Parameters for the creation of the lobe. These images are an adaptation of figures from [3].

Figure 2.3 Monterey bay. This image is from [4]. 15

$\begin{array}{lll}\text { Figure 2.4 Both of figures are from of [5] } & 16\end{array}$

2.4(a) Training image. $\quad 16$

2.4(b) Training skeleton obtained from the Fig. 2.4(a). 16

$\begin{array}{ll}\text { Figure 2.5 } & 17\end{array}$

2.5(a) The bottom surface. 17

2.5(b) Lobe with the bottom surface. 17

$\begin{array}{ll}\text { Figure 2.6 } & 18\end{array}$

2.6(a) Skeleton simulation. 18

2.6(b) Channel system. 18

$\begin{array}{lll}\text { Figure 2.7 Image corresponds to table 2.1. } & 19\end{array}$

$\begin{array}{lll}\text { Figure 2.8 } & \text { Image corresponds to table 2.2. } & 19\end{array}$

Figure 2.9 Image corresponds to table 2.3. 20

Figure 2.10 The depositional system with 2 layers. 21

Figure 2.11 The depositional system with 3 layers. 21

Figure 3.1 Marks inserts into the edges of Skeleton. 23

$\begin{array}{lll}\text { Figure } 3.2 & \text { Areal flow illustration. } & 23\end{array}$

Figure 3.3 Graph of function $f$. 24

Figure 3.4 Graph of function $g . \quad 24$

Figure 3.5 Graph of function $h$. 24

Figure 3.6 An example of grain depositions. 25

Figure 3.7 An example of a channel formed by an edge E with dimension $\mathrm{w}$ and $\mathrm{h}$. 25

Figure 3.8 Generation process of a grid with permeability. 26

Figure 3.9 (a)Region of channel intersections. (b) The channel on the right of the bifurcation point overlaps the channel on the left. $\quad 26$

Figure 3.10 An example of the areal permeability grid filled with output function given by Eq. 3.1. 27

Figure 3.11 Permeability distribution function for the areal flow. $\quad 28$

3.9 (a) 28

3.9 (b) 28

Figure 3.12 Three channel systems within the areal permeability data. 28

Figure 3.13 An example of the vertical permeability grid filled with output function given by Eq. 3.2. 29

Figure 3.14 Permeability distribution function for the vertical flow. $\quad 30$

Figure 3.15 The channel system within the vertical permeability data. 30 
Figure 4.1 $\Delta p \times \Delta t$ and $\Delta p^{\prime} \times \Delta t . \quad 35$

Figure 4.2 Pressure variation at the end of well test. 36

Figure 4.3 An example of the refinement process result. 38

Figure 4.4 Graph of $\Delta p, \Delta p^{\prime}$ and $\Delta p^{\prime}$ with refinement. 39

Figure 4.5 The Secant Method [14] 41

Figure 5.1 Graphs correspond to Table 5.1. 43

Figure 5.2 $\Delta p^{\prime} \times$ Time for each iteration. 44

Figure 5.3 Areal permeability distribution. 44

Figure 5.4 Vertical permeability distribution. 45

Figure 5.5 $\bar{k} \times$ iteration. $\quad 46$

Figure 5.6 $f_{o b j} \times$ iteration. $\quad 47$

Figure 5.7 Production log of the case with 2 lobes. 47

$\begin{array}{lll}\text { Figure 5.8 } \Delta p^{\prime} \times \text { Time. } & 48\end{array}$

$\begin{array}{lll}\text { Figure 5.9 Areal permeability field. } & 48\end{array}$

Figure 5.10 Vertical permeability field. 49

Figure 5.11 Graphs correspond to Table 5.3. 50

Figure 5.12 Production log of the case with 3 lobes. 51

Figure 5.13 $\Delta p^{\prime} \times$ Time. $\quad 51$

Figure 5.14 Areal permeability distribution. $\quad 52$

Figure 5.15 Vertical permeability distribution. $\quad 52$

Figure 5.16 Graphs correspond to table 5.4. 53

Figure $5.17 \Delta p^{* \prime} \times$ Time. $\quad 54$

Figure 5.18 Areal permeability distribution. $\quad 54$

Figure 5.19 Vertical permeability distribution. 54

Figure 5.20 Graphs correspond to table 5.5. 55

Figure 5.21 Production log of the case with 2 lobes and noise. 56

Figure $5.22 \Delta p^{* \prime} \times$ Time. 56

Figure 5.23 Areal permeability distribution. $\quad 57$

Figure 5.24 Vertical permeability distribution. $\quad 57$

Figure 5.25 Graphs correspond to table 5.6. 58

Figure 5.26 Production log of the case with 3 lobes and noise. 58

Figure $5.27 \Delta p^{* \prime} \times$ Time. $\quad 59$

Figure 5.28 Areal permeability distribution. $\quad 59$

Figure 5.29 Vertical permeability distribution. $\quad 59$ 


\section{Introduction}

Turbidity currents are sediment flows induced by gravity, whose overall fluid density is greater than the water surrounding the flow [1]. They are characterized by moving at high speed carrying out a sediment transfer process. Thus, this current is a transport mechanism of particles (sandstones) to the deep domain in a very efficient way. The deposits of that currents are commonly called Turbidites [2].

Since these currents are deposits of sandstones related to oil reservoirs and an important part of the world's oil reservoirs is formed by turbidites, the study and creation of a possible scenario through object-based simulation could be a great tool for the development of oil research.

Therefore, the geometry used to build the geological bodies aims to approximate the fluid flow model to the conceptual one. This assignment is based on three previous thesis: the turbidite lobe created by Cardona [3], the bottom surface computed by Silva [4] and a channel system obtained by immersing an one-dimensional object, called the Skeleton developed by Grajales [5].

The goal of this work is to fill out this channel system with petrophysical properties. In addition to this objective, we aim to test the results of this modeling to a reference case that was built constrained by well pressure data obtained in well tests and we adjust the petrophysical characterization to it.

The simulation process is divided in three-stages. First, the complex morphology is simulated. The simulation algorithm uses random variables to build the model. The second stage involves modeling of petrophysical properties into turbidite channels. For this, the morphological model is converted to a three-dimensional grid, prioritizing the most recent channel (from the top to bottom) to the oldest one. Each channel of the system is associated to a distribution law, respecting the assumptions considered for the reservoir modeling. Then the images of this petrophysical property are generated.

In the last stage, the optimization process is carried out, starting with the allocation of the well in some channel and then building a reference case. This process is based on adjusting the pressure data answer of our model to the 
reference case through an objective function. Thus, property into the turbidite channels is estimated as an inverse problem.

\section{1}

Work Sketch

This flow chart corresponds to the steps in our model.

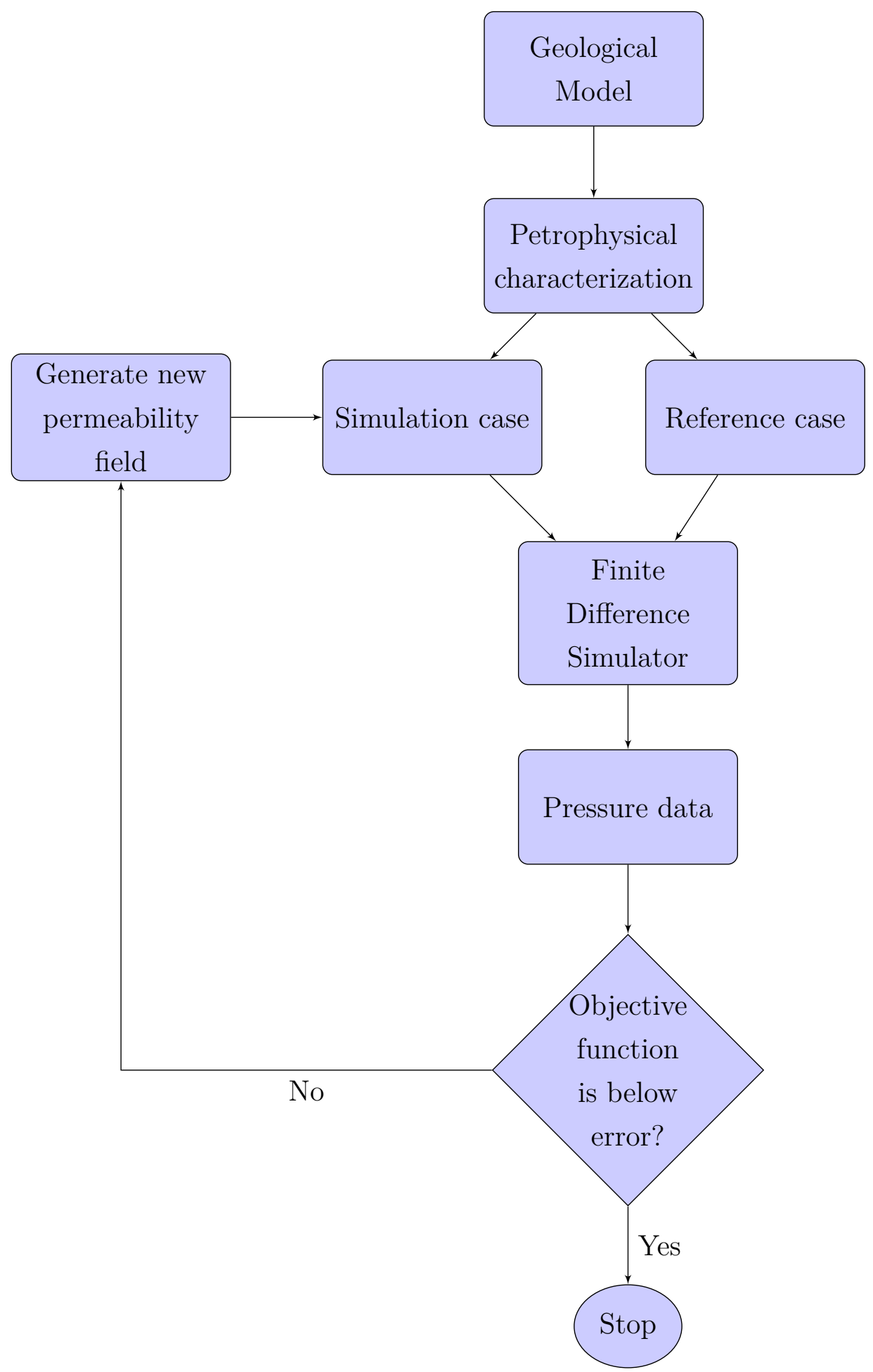


First the modeling of geological bodies is done. After, the channel system is filled with permeability. And this data is used to compare the simulation to the reference case from pressure data extracted from the commercial simulator. If this function is below the error, the simulation stops. Otherwise, the permeability value is modified according to the auxiliary function. This optimization process continues until the objective function achieves a value less than the error.

\section{2}

\section{Dissertation Outline}

This thesis is organized as follows.

- In the chapter 2 , the three objects used in our geological model based on turbidity currents are presented.

- The distribution of the rock properties in channel system, attributing a petrophysical characterization to the model built in previous chapter is described in the chapter 3 .

- In the chapter 4 , the process of permeability adjust to the reference case is presented.

- The obtained results is discussed in the chapter 5 . 


\section{2}

\section{Geological Model}

Our depositional modeling system aims to build an environment similar to the sediments deposition scheme illustrated in Fig. 2.1 that presents: a non-uniform bottom surface in color green, a region limited by turbidites in yellow and a channels system for each turbidite lobe that presents a systematic segregation of grain-sizes within the channels.

Therefore, the geometry used to build the depositional environment aims to approximate the simulated model to the conceptual one.

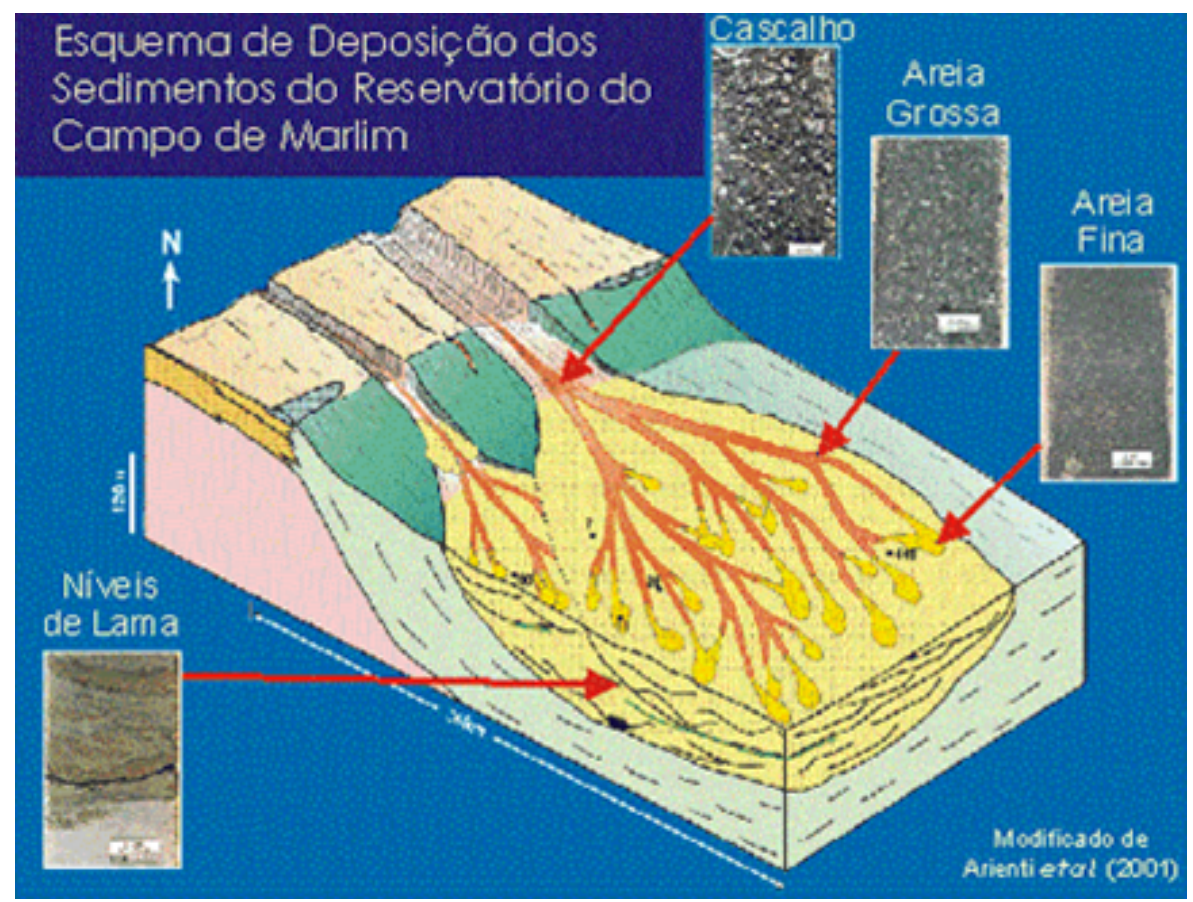

Figure 2.1: Sediments deposition scheme - Reprinted from Esquema de Deposição dos Sedimentos do Reservatório do Campo de Marlim, modified by Arienti etal, July 25 2018, retrieved from http://www.drm.rj.gov.br/admin_fotos/bacia_de_campos/ Copyright 2018 by Departamento de Recursos Minerais - RJ.

\section{1}

\section{Modeling of Geological Bodies}

In this section, it will be presented the main objects considered for depositional modeling system, which are: the turbidite lobe (see [3]) and channel system formed by the skeletons described in [5]. Also, the turbidite 
lobe is limited by a similar bottom surface, less than the translations and rotations of the surface used in [4].

\subsection{1}

\section{Turbidite Lobe}

The turbidite lobe is generated by prolonged events of turbidity currents, resulting from by the continued deposition of sediment in a region. In this work, we considered that the reservoir is formed by a composition of at most three turbidite lobes. The choice of the number of layers for the simulation was arbitrary.

According to Cardona [3], the shape of each lobe isIn this section, it will be presented the main objects considered for modeling of the depositional system, which are: the turbidite lobe (see [3]) and channel system formed by the Skeletons described in [5]. Also, the turbidite lobe is limited by a similar bottom surface, less than the translations and rotations of the used surface in the work in [4]. determined by the following parameters: an origin point $\left(x_{0}, y_{0}, z_{0}\right)$, a flow direction of the turbidity current $(d)$, length $(l)$, width $(w)$ and thickness $(t)$ of the turbidite.

In the plane $z=z_{0}$, the center axis of lobe is the line that passes through the origin point and it has direction $d$. This axis is used as a reference to define the maximum values for width and thickness. In the width's case, the dimension is divided in two parameters: the width at right $\left(w_{r}\right)$ and the width at left $\left(w_{l}\right)$, enabling the creation of non-symmetrical lobes with respect to the central axis, see Fig. 2.2(a). In the same way, it is done for the thickness: there's a lower thickness $\left(t_{\text {inf }}\right)$ and a upper thickness $\left(t_{\text {sup }}\right)$ (see Fig. 2.2(b)).

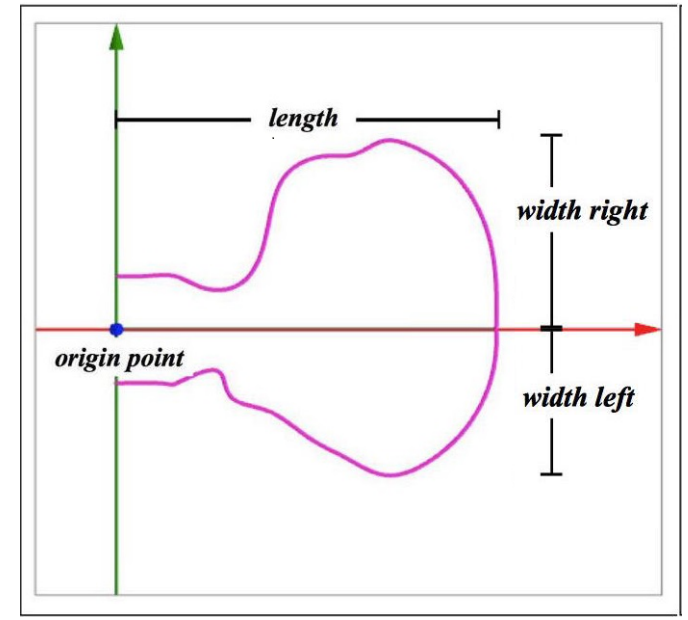

(a)

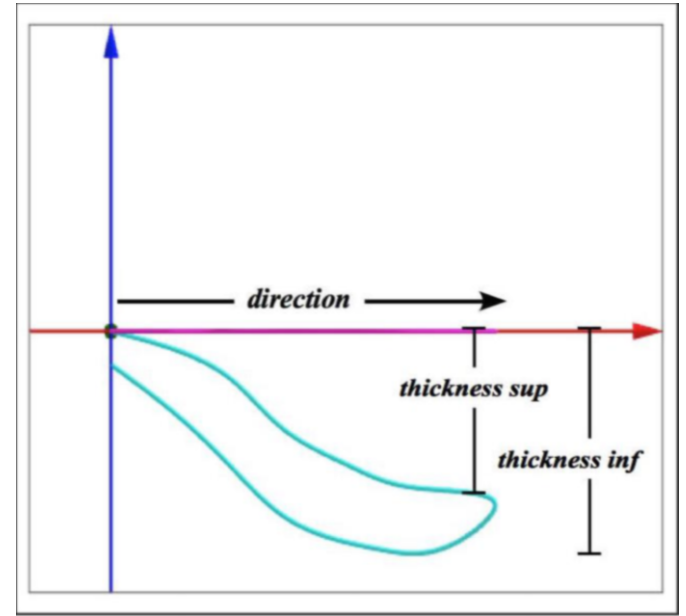

(b)

Figure 2.2: Parameters for the creation of the lobe. These images are an adaptation of figures from [3]. 
Often, when vertical sediment deposition is obtained from the bottom of ocean, many turbidites are found superposed. Because of that, in the process of reservoir creation, the parameters of the deepest lobe are defined first. Then, the two other lobes have been generated in such a way that the upper lobe has the parameters (width, length and thickness) smaller than the one below, which makes it impossible to overlap the lobes. B-Spline curves are used to generate this lobes and the formation's lobe process is described with detail in [3].

\subsection{2}

\section{Bottom Surface}

Due to the assumption that reservoir modeling is based on turbidity currents, the region where the sediments (sandstones) are deposited in the sea floor has a non-uniform appearance. A fundamental characteristic of these gravity driven is that the local direction of mass flow is strongly controlled by topographic variations on the sea floor. A modeling based on this approach can be found in [6].

Thus, to obtain a realistic modeling of such architectures, it was necessary to implement a bottom surface to represent the local topographical relief. The surface used for such modeling is based on the undersea relief of the Monterey Bay canyon (Fig. 2.3). For building this surface, it is used a set of 19,266 points of $\mathbb{R}^{3}$, obtained by Seafloor Mapping Lab through bathymetry.

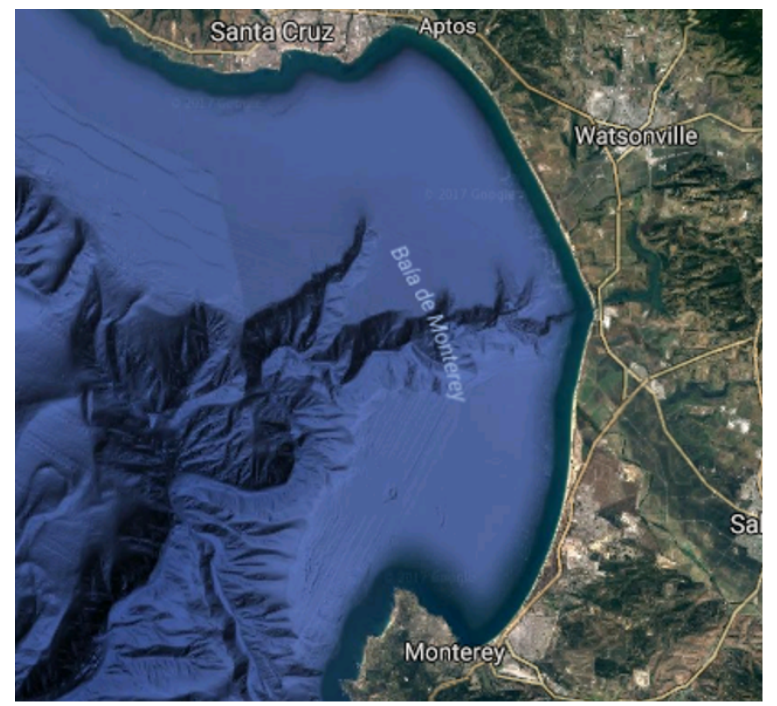

Figure 2.3: Monterey bay. This image is from [4].

The given set of points only contemplates the beginning of the canyon, but it is enough to build an environment close to the real one. The surface is obtained by interpolation of these points, using the 
Shepard interpolation method [7]. All the content about the implementation of this surface is described in [4].

\subsection{3}

\section{Channel System}

For each lobe, a channel system is obtained from a one-dimensional object dip in a three-dimensional grid, called Skeleton. This object is a graph formed by edges and nodes in the plane, where the edges represent the channels and the nodes correspond to channel's bifurcations. Then, a skeleton consists basically in two sets: the edges $E$ and the nodes $N$.

That sets are based on the informations extracted from a 2D binary training image, seemed the illustration presented in Fig. 2.4(a). The generation process of a training skeleton (see Fig. 2.4(b)) and the method used to extract data from this image are explained in greater detail in [5].

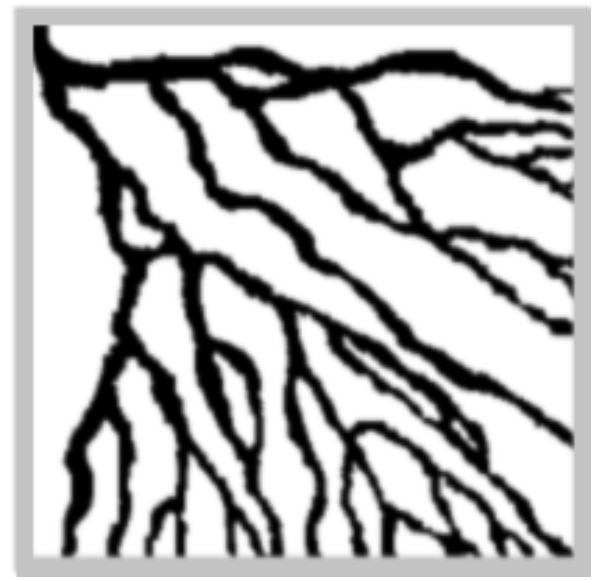

2.4(a): Training image.

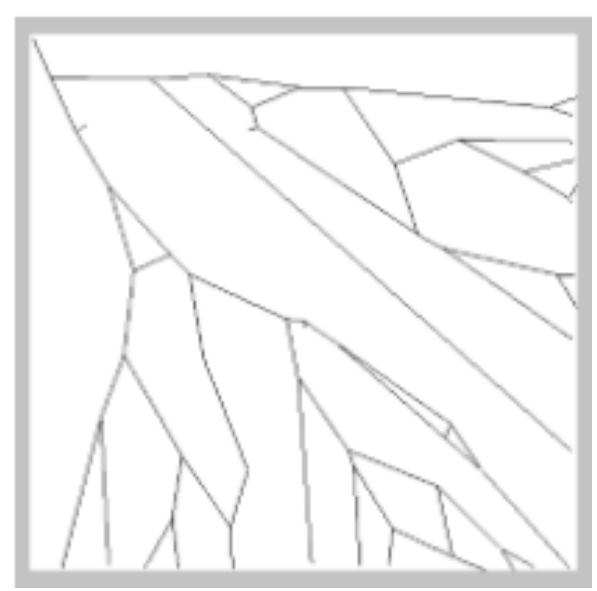

2.4(b): Training skeleton obtained from the Fig. 2.4(a).

Figure 2.4: Both of figures are from of [5]

Following Grajales [5], "a node $N$ is an object formed by 3 elements: a point $p \in \mathbb{R}^{2}$, a vector $\alpha_{n} \in \mathbb{R}^{2}$ and an integer $M_{n} \in \mathbb{N}$. The point $p_{n}$ is the initial or final point of one or more edges $\in E$. $\alpha_{n}$ contains the directions of the edges that arrive at the point $p_{n}$, it can be one or two edges. $M_{n}$ is the number of edges that arrive or left the point $p_{n}$, it is called the mark of the node."

Besides these elements, to insert any property in the model, it is necessary to add two marks to the edges in $E$ : one to identify the level of each edge, which means to know the oldest channel; and another to put the distribution function in each channel according to bifurcation angle. These modifications do not change in any way the generation process of the channel system done in [5], because these elements are only used in the petrophysical property modeling. 


\section{2}

\section{Depositional System Modeling}

In this section, it will be shown the model that was used to create the depositional system, which is divided in three cases with 1,2 and 3 layers that corresponds to one, two and three lobes respectively. These models are associated to distinct scenarios for the petrophysical characterization.

In this way, the environment used to create these depositional systems is a three-dimensional regular grid, which is a partition by parallelepipeds of a domain in $\mathbb{R}^{3}$. In order to create a scenario capable of replicating petrophysical properties in the channel systems, the simulations of this thesis are performed in a grid with dimension $100 \times 100 \times 100$.

The modeling of geological bodies in all cases is divided into four stages. First, the bottom surface is computed (Fig. 2.5(a)). After, the turbidite lobe is generated and the lobe's cells below the bottom surface are not considered (Fig. 2.5(b)). So, the skeleton is simulated in the plane $x y$ conditioned to the limits given by the B-splines curves in the same plane (see Fig. 2.6(a)).

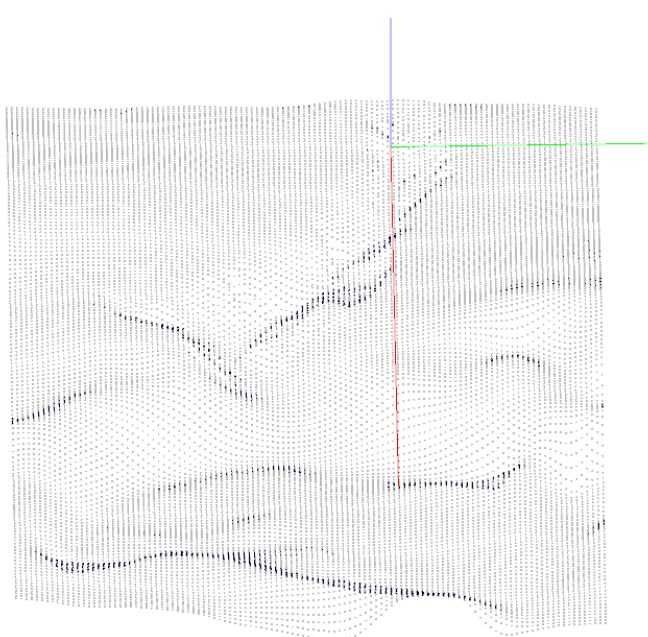

2.5(a): The bottom surface.

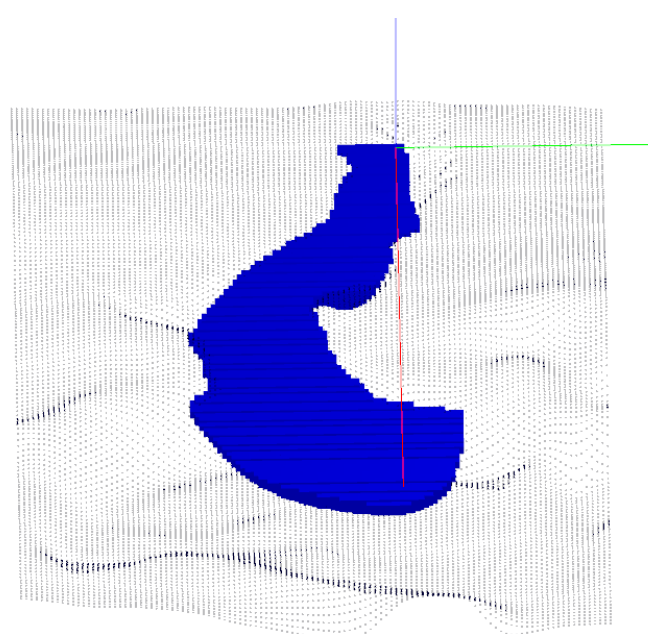

2.5(b): Lobe with the bottom surface.

Figure 2.5

Then, the channel system is obtained through the simulation of a skeleton inside the lobe, respecting the bottom surface. Each edge of the skeleton is the center line of a channel associated to it. The cross section orthogonal to direction of the edge is a half-ellipse. The values for width and length of the half-ellipse is inversely proportional to the distance of origin point of turbidite lobe (Fig. 2.6(b)). 


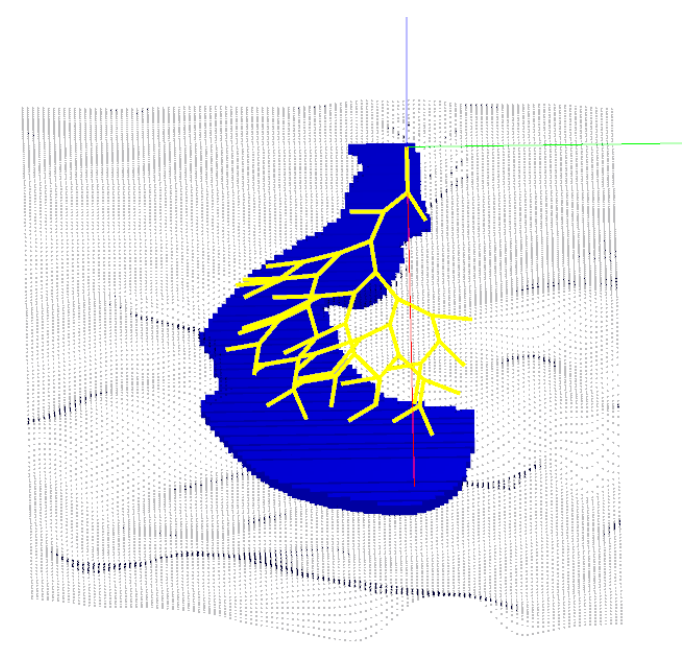

2.6(a): Skeleton simulation.

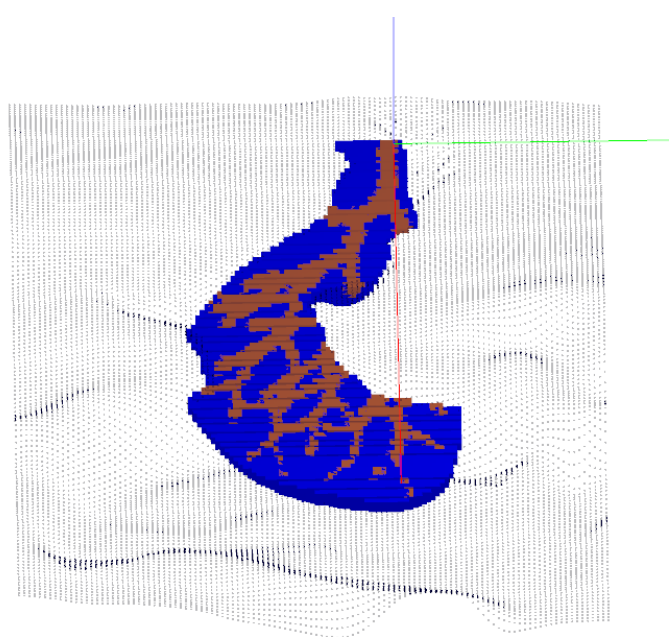

2.6(b): Channel system.

Figure 2.6

\subsection{1}

\section{Parameters}

The simulation algorithm uses random variables to define the parameters for the construction of geological bodies. But as soon as these parameters are determined, they are not modified. In this work, we do not estimate the geometric parameters that characterize the depositional system, since we only be interested in estimating the permeability into the channel system.

The parameters used to generate the turbidite lobes will be shown in the tables: $2.1-2.3$ and the simulated model associated to them in the figures: 2.7 - 2.9. Simplifying the simulation process, we consider that the origin point of the channel system being the same point of the turbidite lobe.

Table 2.1: Lower Lobe Parameters

\begin{tabular}{cc}
\hline Parameter & Value \\
\hline Origin point & $(0,0,0)$ \\
$d$ & 0 \\
$w_{l}$ & 4.00 \\
$w_{r}$ & 2.69 \\
$t_{\text {in }}$ & 0.79 \\
$t_{\text {sup }}$ & 1.15 \\
$l$ & 8.75 \\
\hline
\end{tabular}



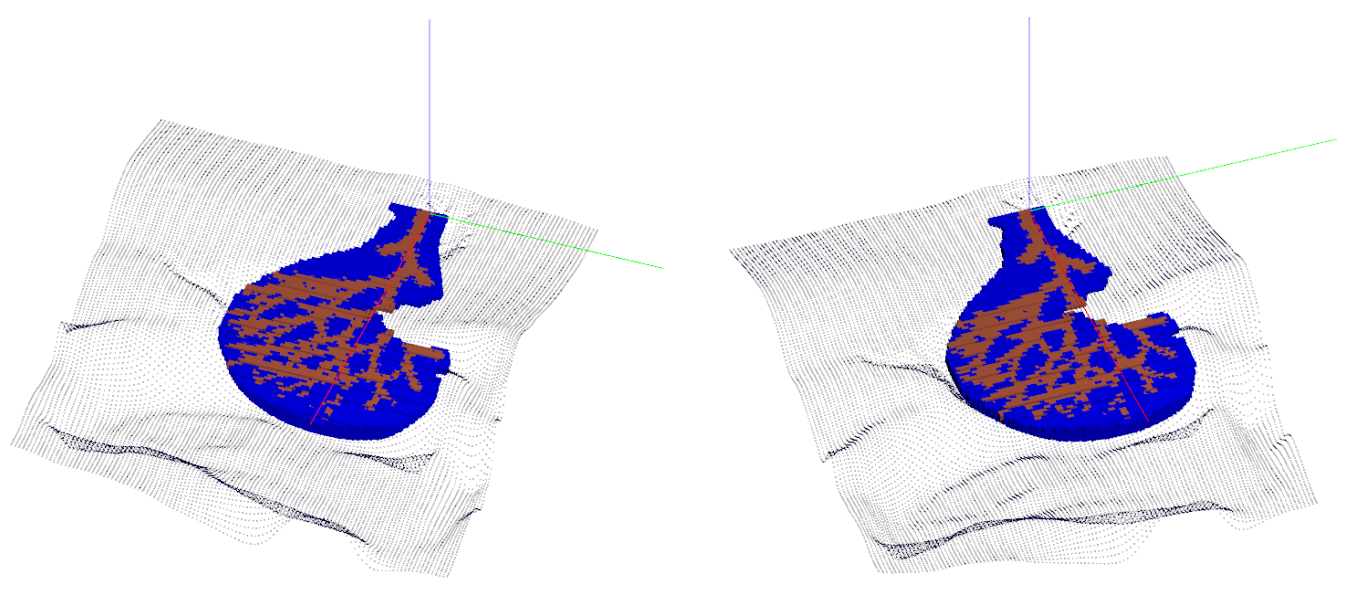

Figure 2.7: Image corresponds to table 2.1.

Table 2.2: Middle Lobe Parameters

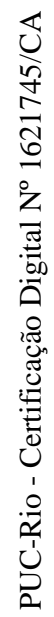

\begin{tabular}{cc}
\hline Parameter & Value \\
\hline Origin point & $(0,0,0)$ \\
$d$ & 0 \\
$w_{l}$ & 1.90 \\
$w_{r}$ & 4.47 \\
$t_{\text {in }}$ & 0.39 \\
$t_{\text {sup }}$ & 0.57 \\
$l$ & 8.19 \\
\hline
\end{tabular}
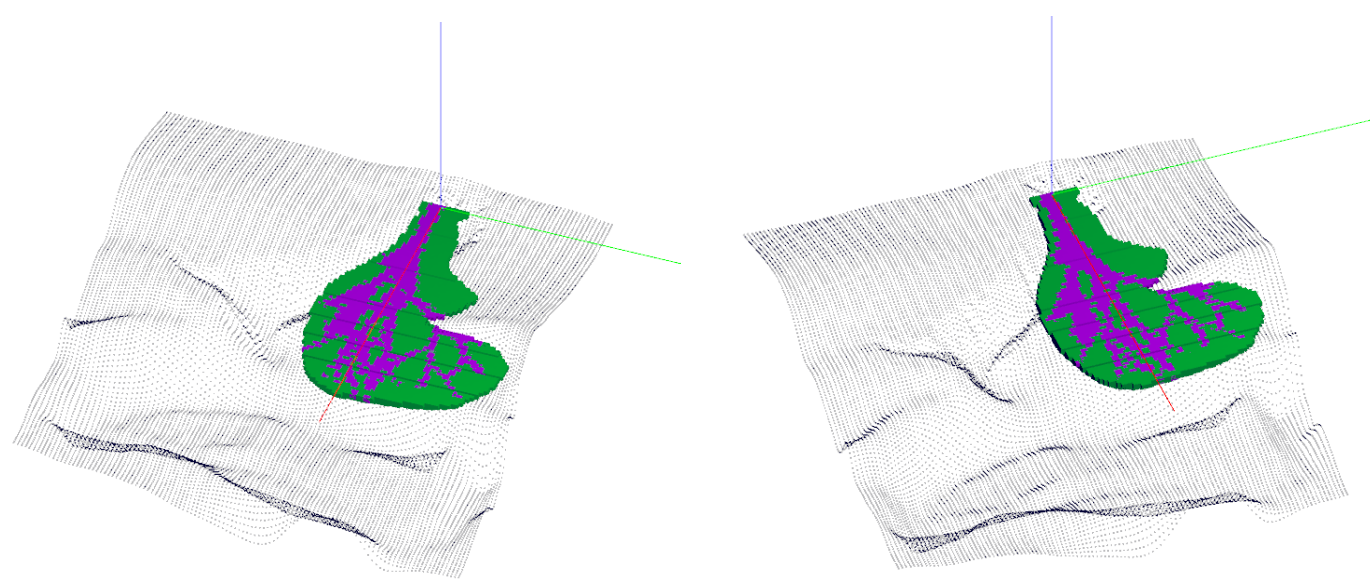

Figure 2.8: Image corresponds to table 2.2. 
Table 2.3: Upper Lobe Parameters

\begin{tabular}{cc}
\hline Parameter & Value \\
\hline Origin point & $(0,0,0)$ \\
$d$ & 0 \\
$w_{l}$ & 4.59 \\
$w_{r}$ & 1.23 \\
$t_{\text {in }}$ & 0.20 \\
$t_{\text {sup }}$ & 0.29 \\
$l$ & 6.47 \\
\hline
\end{tabular}
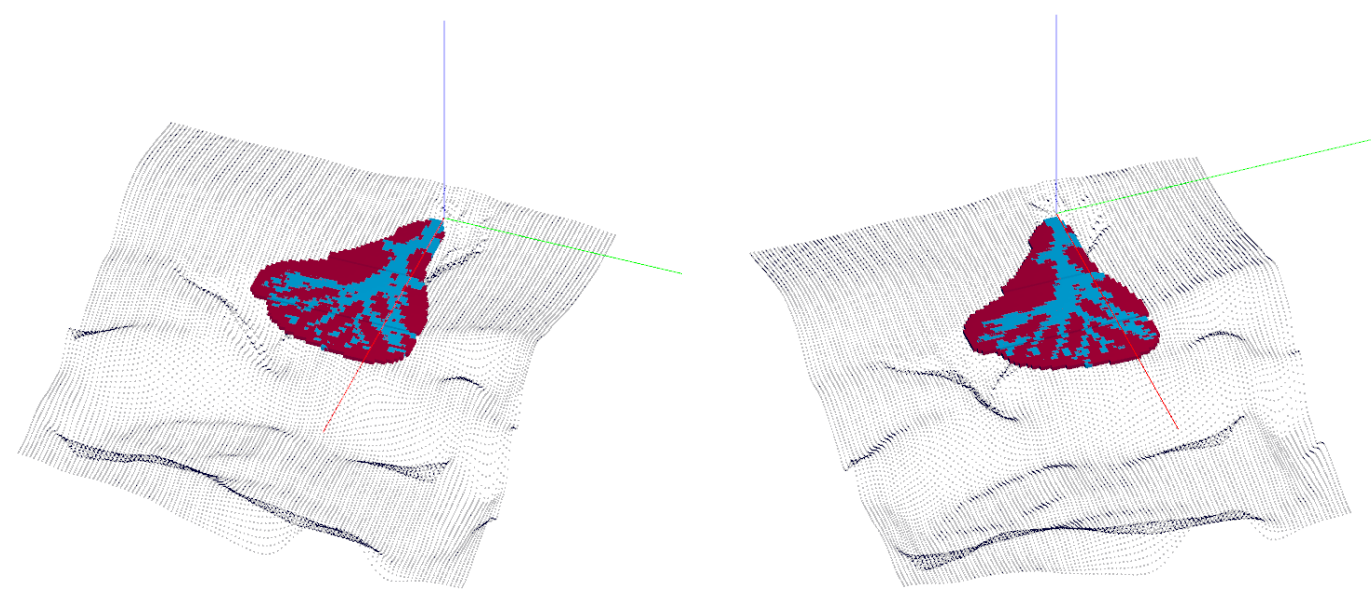

Figure 2.9: Image corresponds to table 2.3.

\subsection{2}

\section{Simulated Cases}

Three independent cases were considered for the simulation: the first case contains only one turbidite lobe and the image corresponding to this case is the same represented by lower lobe in the Fig. 2.7. For case 2, the depositional system is obtained by a composition of the lower and middle lobe, so that the middle lobe points overlap the lower lobe points. The illustration of this erosional process can be seen in the Fig. 2.10. In order to build a more realistic morphological complex for case 3, the upper lobe overlaps both the middle and lower lobe. In the Fig. 2.11, it is shown the composition of those geometric objects, building the geological environment with 3 layers. 

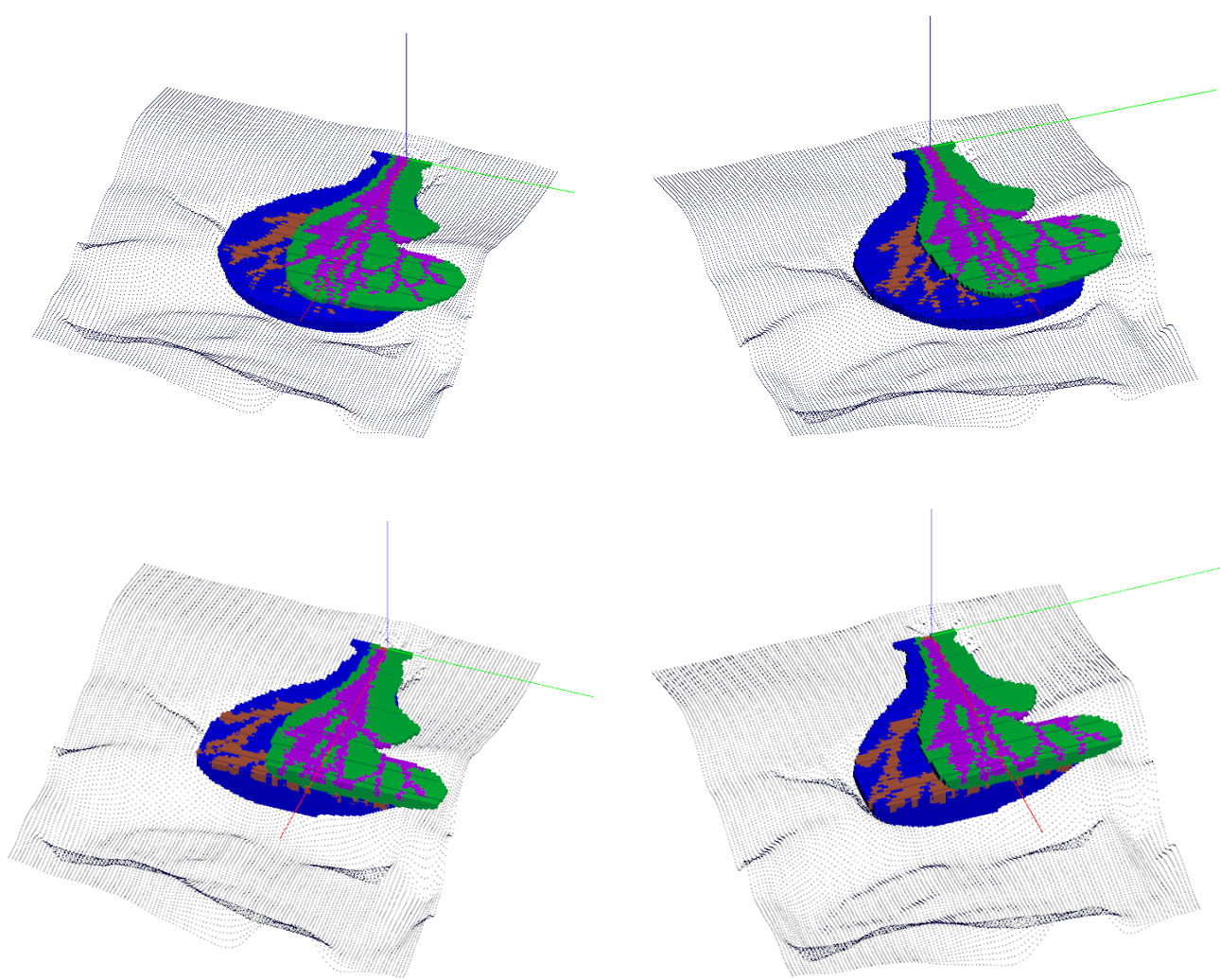

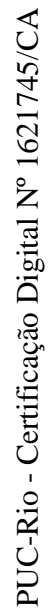

Figure 2.10: The depositional system with 2 layers.
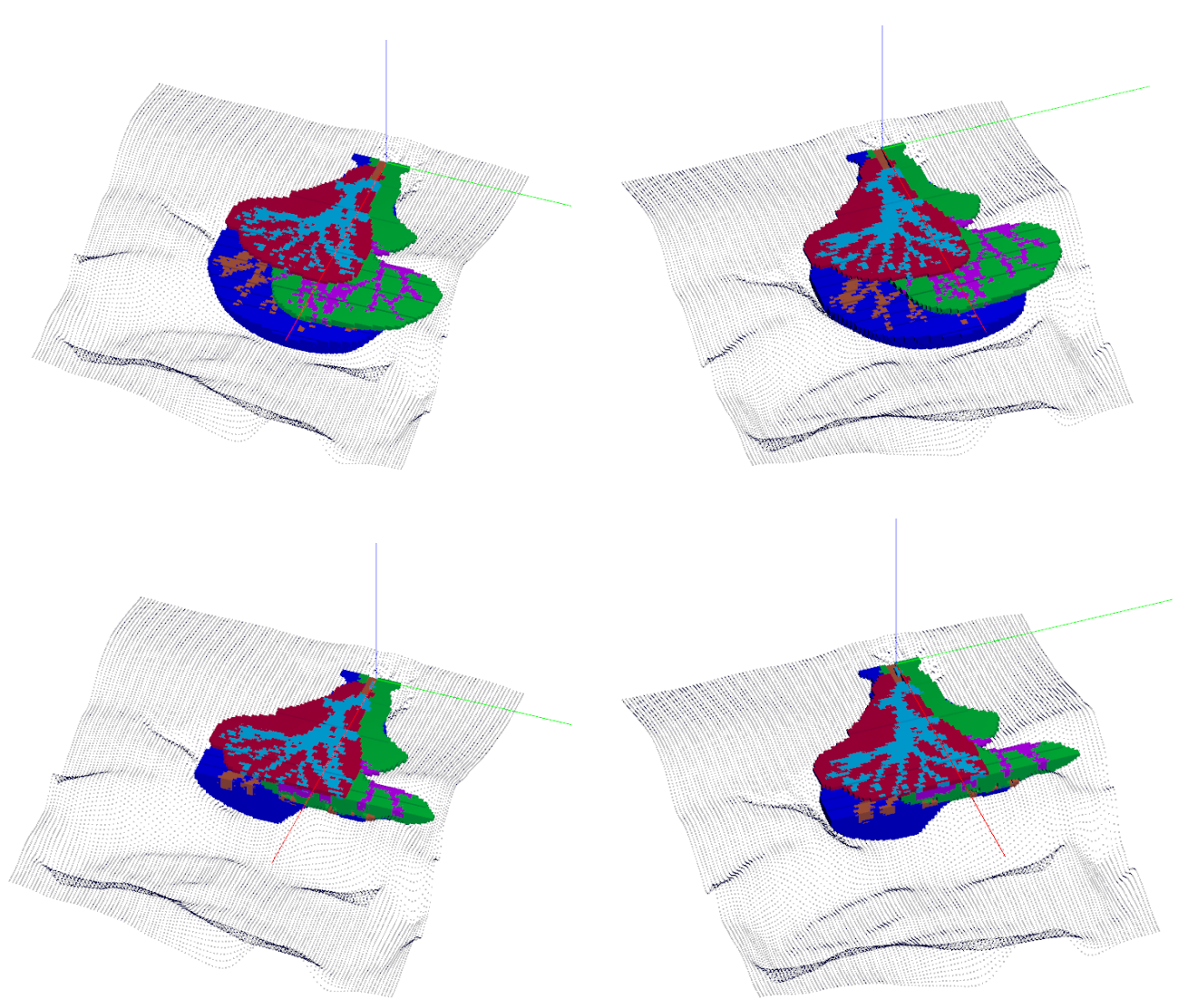

Figure 2.11: The depositional system with 3 layers. 


\section{3 \\ Petrophysical Characterization}

Thereafter the morphology has been constructed, the petrophysical properties within channels can be filled. In this chapter, we present how to model the petrophysical property into the turbidite channel system.

\section{1}

\section{Permeability}

For the study of the behavior of an oil reservoir, information on the properties of rocks are very important. Among the main properties present in an oil reservoir, the one chosen to be modeled in this work was permeability. Permeability is a quantitative measure that describes the ability of a porous medium to carry a fluid [8]. This is one of the most important property in fluid mechanics due to its huge impact on fluid displacement.

There are some methods for estimating permeability in a porous medium that can be made through a laboratory test using samples extracted from the formation or by pressure tests performed in the wells. The last one will be used to estimate the permeability values into simulated turbidite channels.

In addition to the hypothesis of a turbidite system, it is necessary to introduce flow conditions for an estimation of permeability close to the real. For this modeling, important hypothesis are considered: the porous medium (grains) is stationary, single-phase flow and heterogeneous anisotropic porous media.

As this property is a dynamic attribute, each edge of the skeleton will be associated to a distribution function. Although we use a three-dimensional regular grid for the simulation, we consider that the flow occurs in only two dimensions: horizontal and vertical. These flow directions define two independent permeabilities which are simulated separately and store in two different grids.

\section{2}

\section{Areal Permeability Distribution}

This is the property corresponding to the $\mathrm{x}-\mathrm{y}$ flow. For the areal permeability distribution, it is necessary to introduce marks to edges of 
the skeleton (see Fig. 3.1). These marks are associated to three distribution functions, one for each mark.

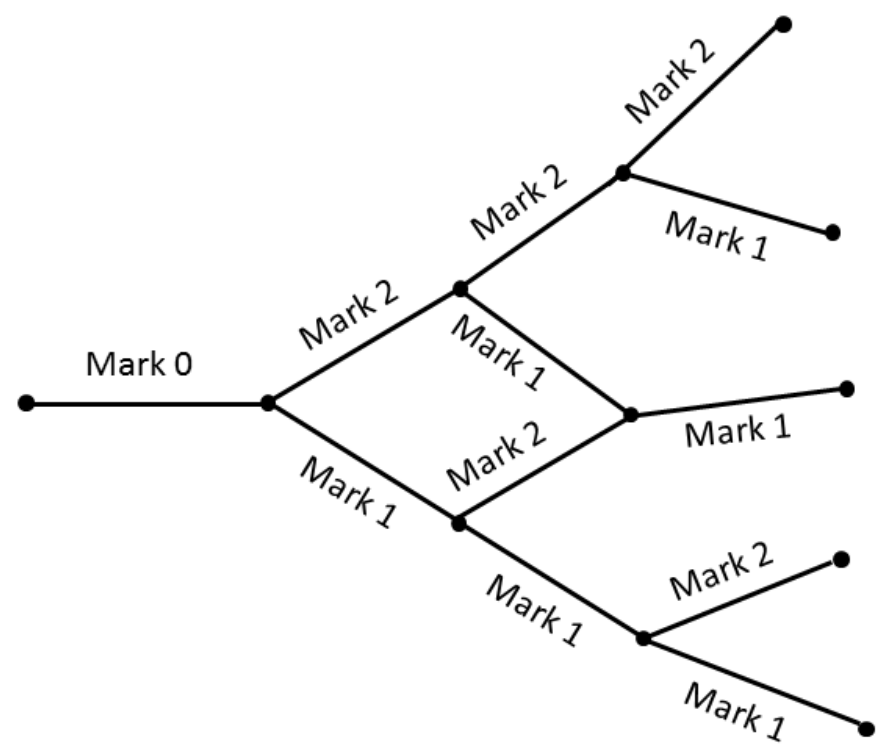

Figure 3.1: Marks inserts into the edges of Skeleton.

Our modeling of this attribute considers conditions for the flow similar to a fluvial channel: the point inside the channel that has the highest permeability value is in the direction of higher flow velocity, i.e., in the direction of the line vector associated to the channel edge, as shown in Fig. 3.2.

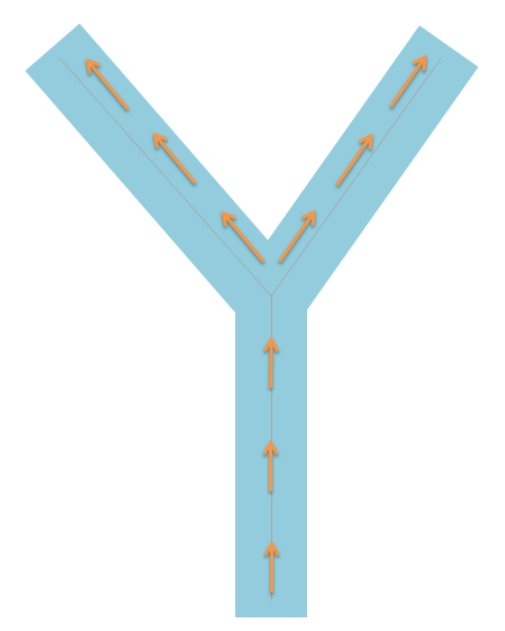

Figure 3.2: Areal flow illustration.

So, the choice of distribution functions needs to take into account these requirements. The function $f$ associated to mark 0 is a Gaussian function and it is just applied for the first edge of the skeleton. For mark 1 and 2, both functions $g$ and $h$ are associated to the edges according to the bifurcation angle. From the graphic of each function is possible to understand permeability behavior into the channel which was represented by figures 3.3, 3.4 and 3.5. 


$$
f(x)=e^{\frac{-(x-1)^{2}}{2}}
$$

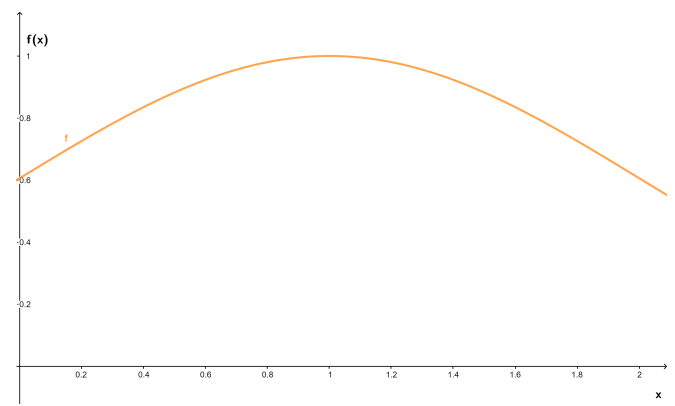

Figure 3.3: Graph of function $f$.

$$
g(x)=1.4 \frac{e^{\frac{-\ln ^{2}(-x+2)}{2}}}{(-x+2) \sqrt{2 \pi}}
$$

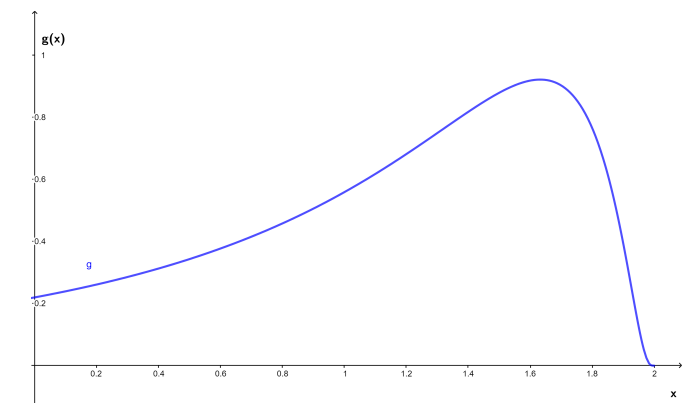

Figure 3.4: Graph of function $g$.

$$
h(x)=1.4 \frac{e^{\frac{-\ln ^{2}(x)}{2}}}{x \sqrt{2 \pi}}
$$

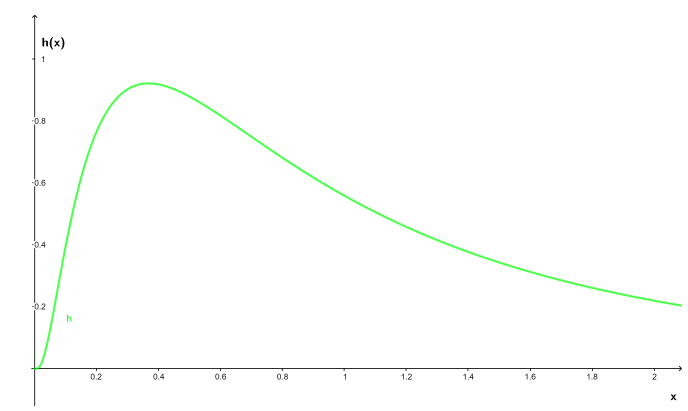

Figure 3.5: Graph of function $h$.

The three functions are defined in the domain $(0,2)$. The input function $x$ is the distance between the projection in the plane $x y$ of a point within the channel and the skeleton's edges associated to it. This point within the channel corresponds to a point in the center of a grid cell. Sometimes, we just refer to it as a grid point.

The range of these functions is a subset of the interval $(0,1)$, considering the minimum permeability value is reached when the output of the function is sufficiently close to zero and the maximum when is equal one. 


\section{3}

\section{Vertical Permeability Distribution}

For the vertical permeability distribution, it is also considered a fluvial like construction. But in this case, all edges of the skeleton receive the same distribution function. There are no marks in this case. In this direction, the greatest permeability value is at the bottom of the channel because, in general, the coarser grains are deposited in this channel region (see Fig. 3.6).

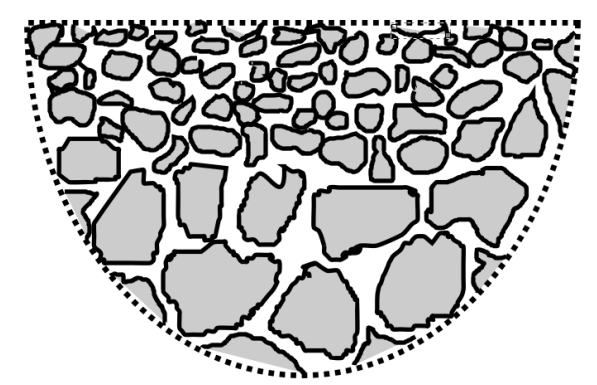

Figure 3.6: An example of grain depositions.

So, for that distribution it is considered the same function $g$ section 3.2, but in this case $x$ represents the distance between the plane $x y$ and the projection of a grid point in a plane $y z$ that contained the edge corresponding to the channel.

\section{4}

\section{Properties Generation}

The process begins by taking the Skeleton generated for the lower lobe. During the channel system generation process, we stored on each Skeleton's edge the dimension $\mathrm{w}$ and $\mathrm{h}$ used to define the half-ellipse associated to each channel formation (Fig. 3.7).

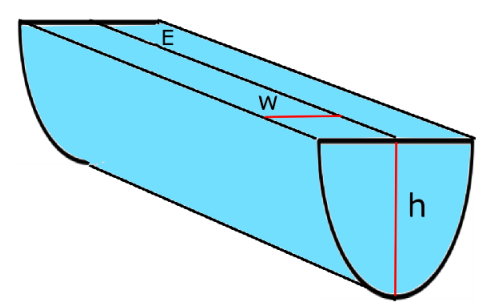

Figure 3.7: An example of a channel formed by an edge $\mathrm{E}$ with dimension $\mathrm{w}$ and $\mathrm{h}$.

In order to optimize the simulation time, we implement a bounding box in the grid using the lobe parameters. This process will be the same in all lobes. The points outside the lobe have zero permeability value. 
In the next step, for each grid point in the bounding box, we look for the channel on which this point is contained. Then, we locate this point in the domains of the areal and vertical permeability distribution functions and store the output function in two different grid, one for the areal permeability and other for the vertical permeability. After, we repeat the same process for middle and upper lobes. The Fig. 3.8 shows the areal permeability in one grid point.
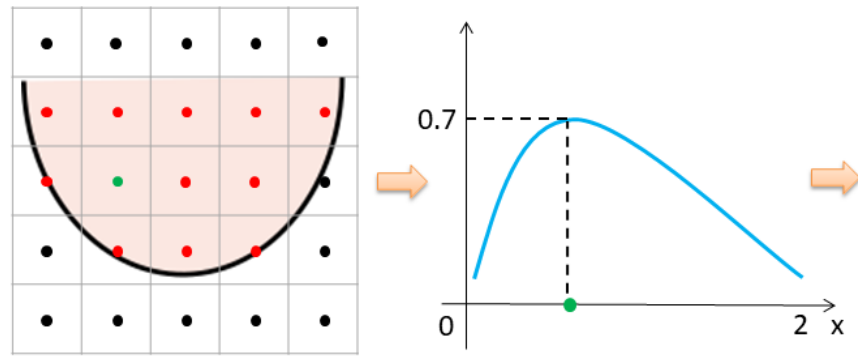

\begin{tabular}{|c|c|c|c|c|}
\hline 0 & 0 & 0 & 0 & 0 \\
\hline 0 & 0 & 0 & 0 & 0 \\
\hline 0 & 0.7 & 0 & 0 & 0 \\
\hline 0 & 0 & 0 & 0 & 0 \\
\hline 0 & 0 & 0 & 0 & 0 \\
\hline
\end{tabular}

Figure 3.8: Generation process of a grid with permeability.

The advantage of our model compared to image-based models [9] is that the skeleton contains information about the structure of the channel, such as its center axis, width and thickness. In models based on multiple-point geostatistics the result is an image, which does not contain structural information of the channel.

Besides the Skeleton contains information about the bifurcation point, it is also possible to introduce flow characteristics in the properties simulation in these points. For example, in the region of channel intersections (Fig. 3.9 (a)), we arbitrarily decide that the chosen permeability in this region is that associated to the channel more to the right of the bifurcation point (Fig. 3.9(b)).

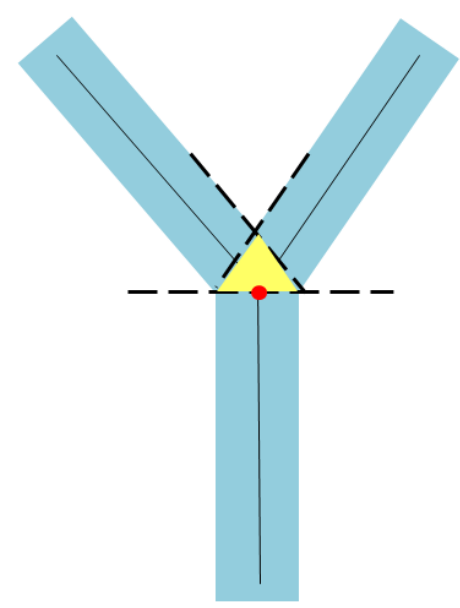

$3.9(\mathrm{a}):$

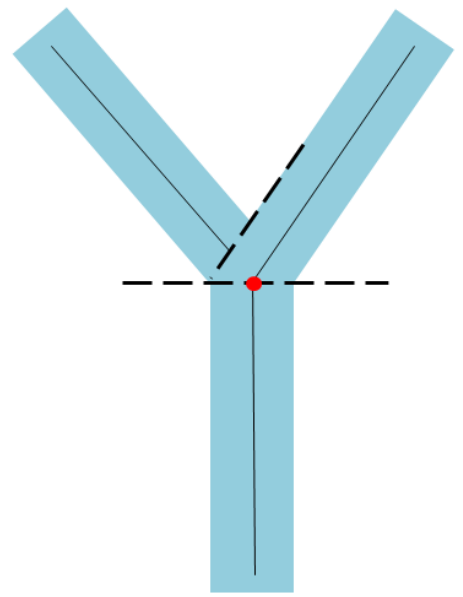

$3.9(\mathrm{~b})$ :

Figure 3.9: (a)Region of channel intersections. right of the bifurcation point overlaps the channel on the left. 


\subsection{1}

\section{The Areal Permeability Grid}

The output values of the areal permeability distribution functions are stored in a grid called $k_{h}$ by a voxelization process. In this way, each cell inside the channel will receive a value corresponding to the permeability. The cells that are not located inside a channel are given a value of zero. The Fig. 3.10 illustrates one example of the function $f$ applied to grid points.

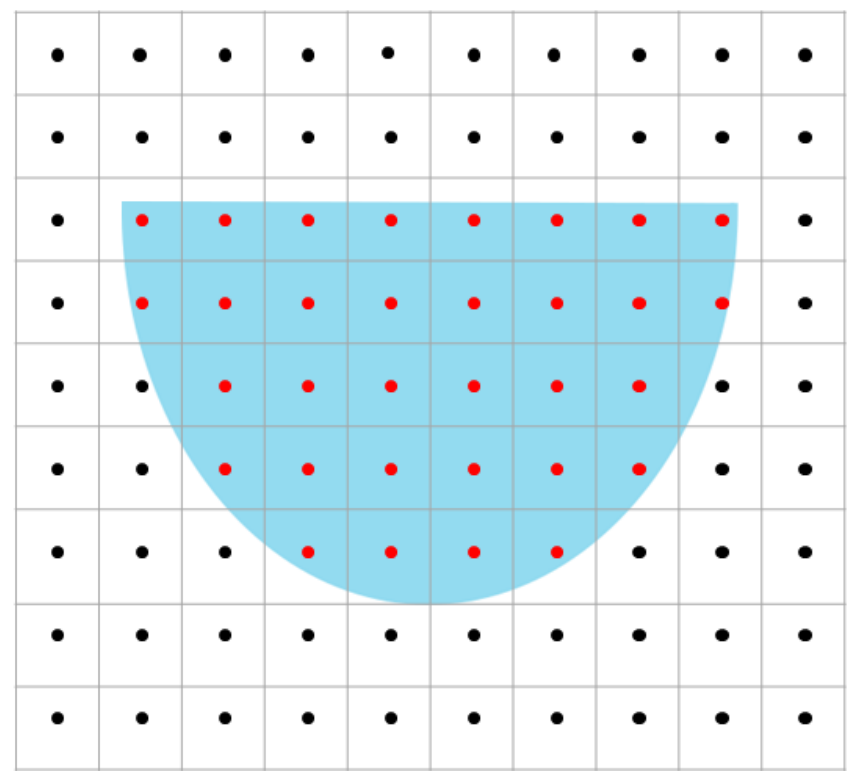

\begin{tabular}{|c|c|c|c|c|c|c|c|c|c|}
\hline 0 & 0 & 0 & 0 & 0 & 0 & 0 & 0 & 0 & 0 \\
\hline 0 & 0 & 0 & 0 & 0 & 0 & 0 & 0 & 0 & 0 \\
\hline 0 & 0.73 & 0.84 & 0.92 & 0.98 & 0.98 & 0.92 & 0.84 & 0.73 & 0 \\
\hline 0 & 0.73 & 0.84 & 0.92 & 0.98 & 0.98 & 0.92 & 0.84 & 0.73 & 0 \\
\hline 0 & 0 & 0.84 & 0.92 & 0.98 & 0.98 & 0.92 & 0.84 & 0 & 0 \\
\hline 0 & 0 & 0.84 & 0.92 & 0.98 & 0.98 & 0.92 & 0.84 & 0 & 0 \\
\hline 0 & 0 & 0 & 0.92 & 0.98 & 0.98 & 0.92 & 0 & 0 & 0 \\
\hline 0 & 0 & 0 & 0 & 0 & 0 & 0 & 0 & 0 & 0 \\
\hline 0 & 0 & 0 & 0 & 0 & 0 & 0 & 0 & 0 & 0 \\
\hline
\end{tabular}

Figure 3.10: An example of the areal permeability grid filled with output function given by Eq. 3.1.

From Fig. 3.11, it is possible to observe the behavior of areal permeability distribution into the channel associated to the functions given in (3.1), (3.2), 
(3.3), where the maximum permeability value is represented by the color red and the minimum by the color blue.

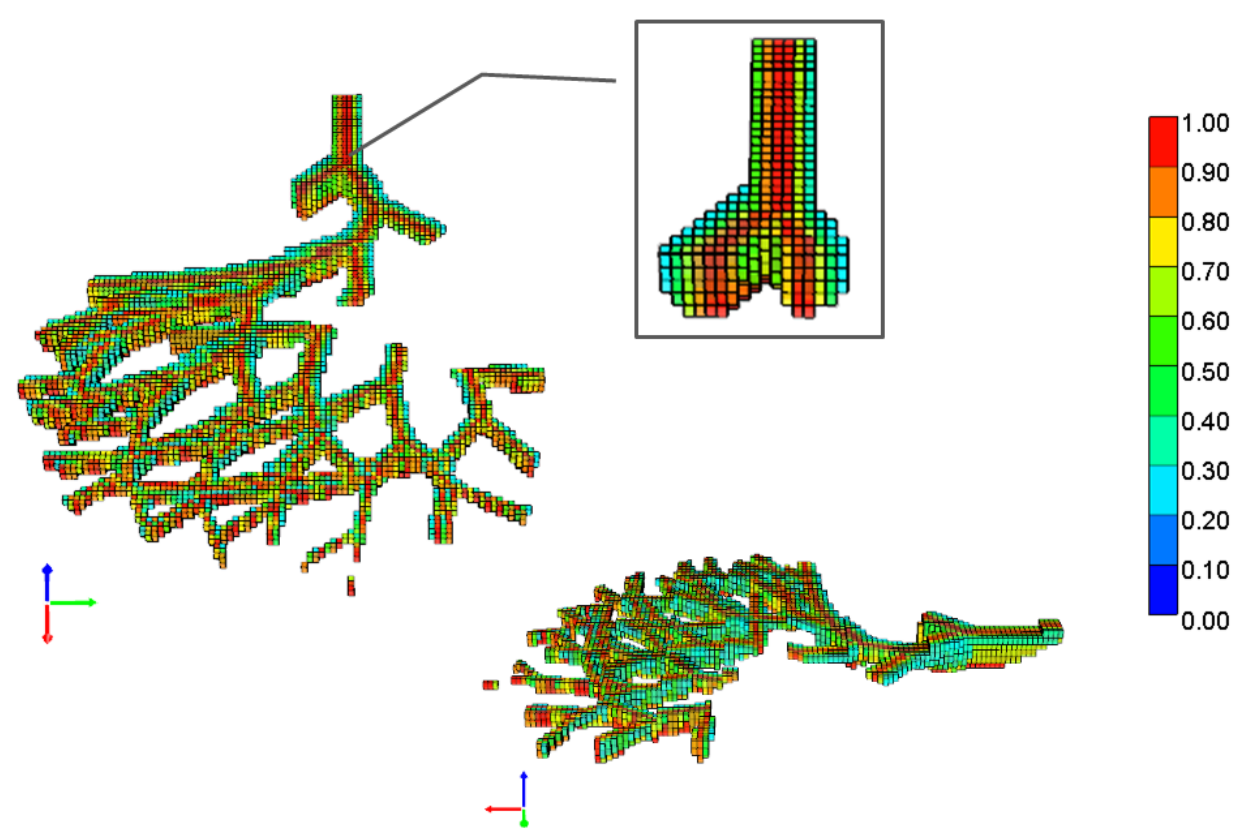

Figure 3.11: Permeability distribution function for the areal flow.

The knowledge of channel level is associated to the tag inserted in the skeleton's edges. This information is very important for the erosion process of the channel system, because the considered value for permeability in each channel corresponds to the permeability value of the newest channel, which means, the permeability value of the oldest channels are overlapped by the value of the newest ones, as can be observed in Fig. 3.12.
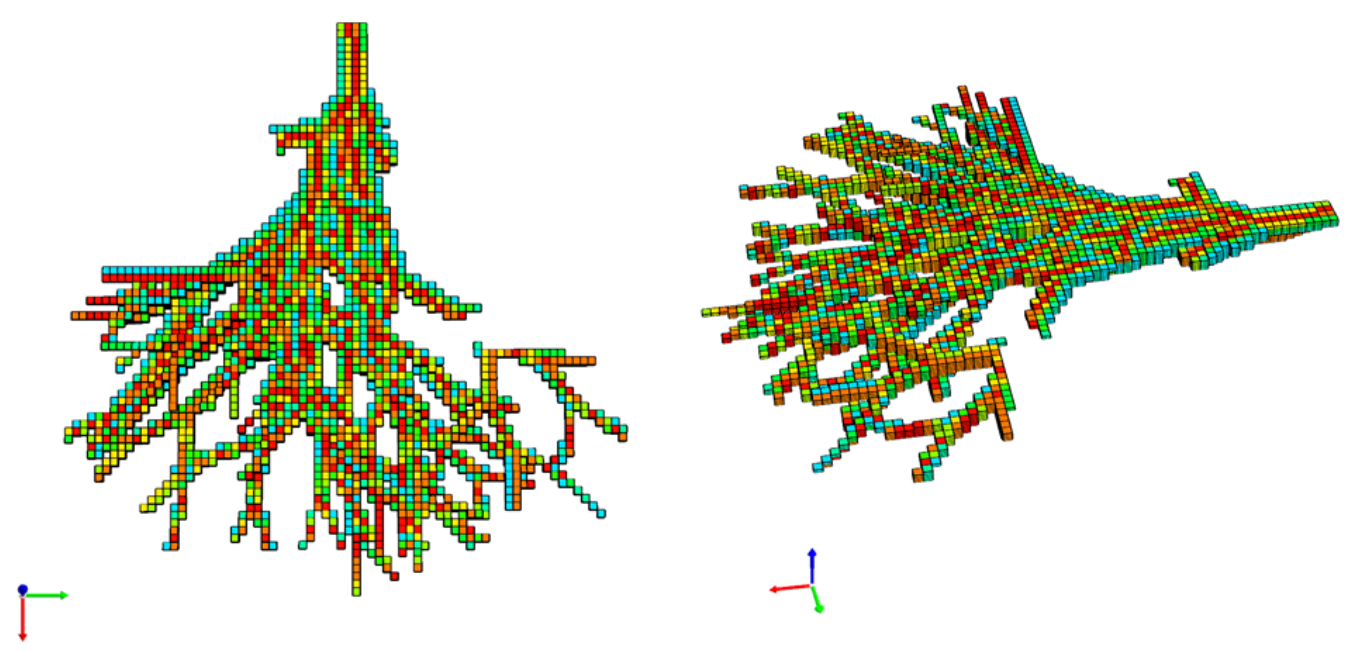

Figure 3.12: Three channel systems within the areal permeability data. 


\subsection{2}

\section{The Vertical Permeability Grid}

The output values of the vertical permeability distribution function are stored in a grid called $k_{v}$, an example of this grid is presented in the Fig. 3.13.

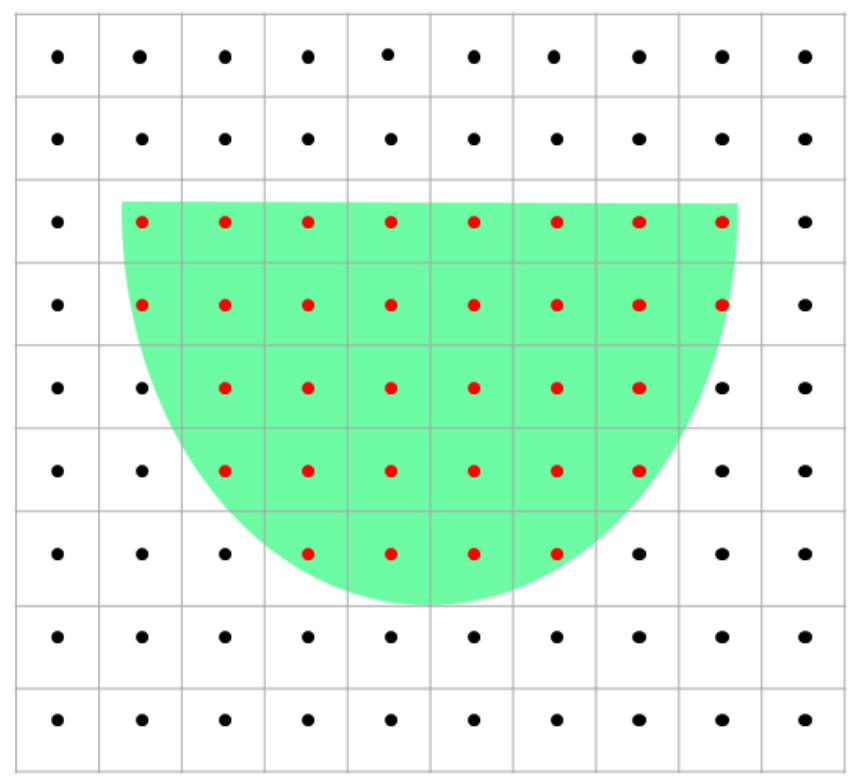

\begin{tabular}{|c|c|c|c|c|c|c|c|c|c|}
\hline 0 & 0 & 0 & 0 & 0 & 0 & 0 & 0 & 0 & 0 \\
\hline 0 & 0 & 0 & 0 & 0 & 0 & 0 & 0 & 0 & 0 \\
\hline 0 & 0.26 & 0.26 & 0.26 & 0.26 & 0.26 & 0.26 & 0.26 & 0.26 & 0 \\
\hline 0 & 0.38 & 0.38 & 0.38 & 0.38 & 0.38 & 0.38 & 0.38 & 0.38 & 0 \\
\hline 0 & 0 & 0.56 & 0.56 & 0.56 & 0.56 & 0.56 & 0.56 & 0 & 0 \\
\hline 0 & 0 & 0.82 & 0.82 & 0.82 & 0.82 & 0.82 & 0.82 & 0 & 0 \\
\hline 0 & 0 & 0 & 0.76 & 0.76 & 0.76 & 0.76 & 0 & 0 & 0 \\
\hline 0 & 0 & 0 & 0 & 0 & 0 & 0 & 0 & 0 & 0 \\
\hline 0 & 0 & 0 & 0 & 0 & 0 & 0 & 0 & 0 & 0 \\
\hline
\end{tabular}

Figure 3.13: An example of the vertical permeability grid filled with output function given by Eq. 3.2.

Similar to the area permeability distribution, the maximum vertical permeability value is also reached when the output of the function is equal to one and the minimum when it is sufficiently close to zero, the same color pattern is used to represent the variation of these values (see Fig. 3.14) and an 
equal erosion process is considered. In Fig. 3.15, is possible to see permeability conditioned to vertical distribution into the depositional system with 3 layers.

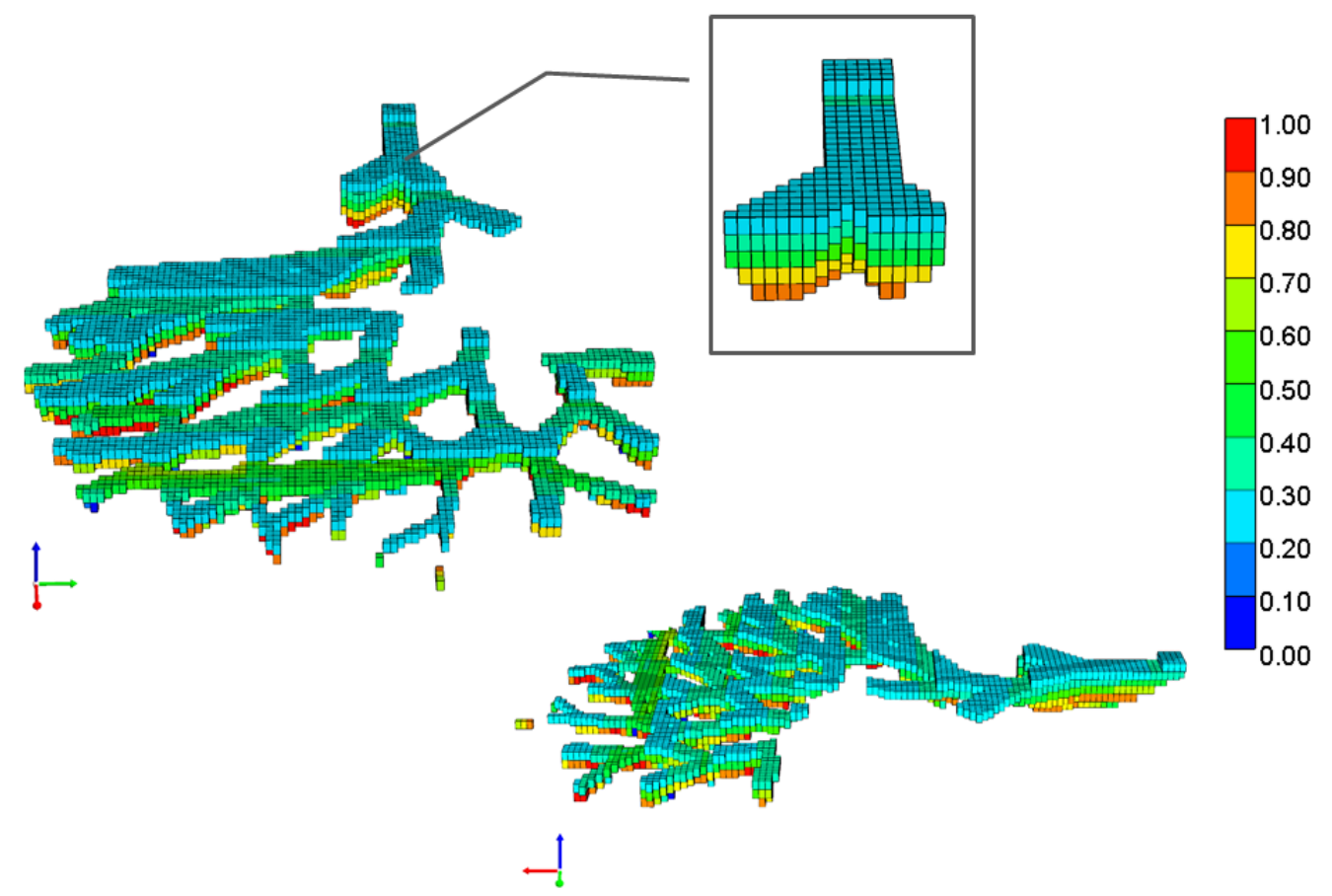

Figure 3.14: Permeability distribution function for the vertical flow.

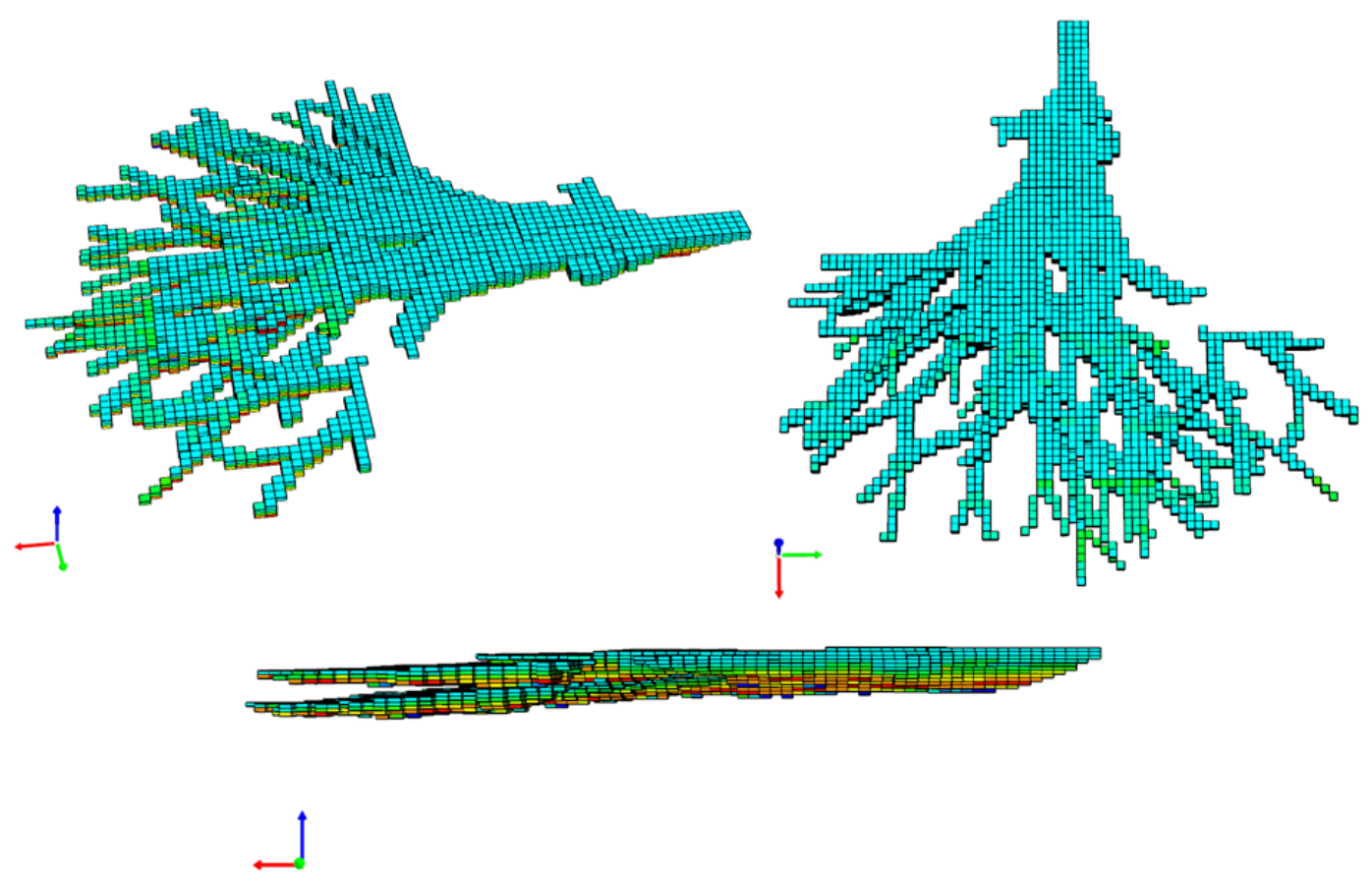

Figure 3.15: The channel system within the vertical permeability data. 


\section{4 \\ Permeability Adjust Constrained by Well Test Data}

After the permeability distribution have been inserted into the channels, the reference case is defined and the optimization process starts. The method used to compare the simulated data to the reference case will be explained in this chapter.

\section{1}

\section{Well-Testing}

The formation evaluation consists of the petrophysical properties study present in a reservoir formation [10]. In this way, it is responsible for the analysis of the results obtained in the well-testing in order to evaluate the reservoir properties and productivity characteristics of the formations.

The well-testing is an operation performed to acquire formation data, which aims to identify the fluids present in the formation, evaluating the production potential, determining the extension of the reservoir and its properties (porosity, permeability, etc.) and to determine the initial pressure and the average reservoir pressure [10].

From the analysis of the behavior of bottom-hole pressures recorded during the well tests, it is possible to obtain some information about the reservoir. These data are influenced by the following factors: reservoir characteristics, formation fluid type and its properties and flow history during the test [10].

The grid scene voxelization process presented in the previous chapter is important for exporting the permeability data to a flow simulator, which will provide information about simulated bottom-hole pressure. From this, it is possible to compare the behavior shown by the numerical derivative pressure curve of the simulated case to the curve of a reference case.

We will use initial pressure data $p_{i}$, the well bottom-hole pressure $p_{w f}$ for each time step and production log of each layer present in the reservoir to estimate the permeability values. The data extracted from real well tests can be reproduced by a conventional finite difference simulator developed by Computer Modelling Group Ltd. (IMEX - CMG) [11]. 


\section{2 \\ Input File IMEX}

In order to simulate a well test in IMEX, we have to build a base file (see Appendix A) containing the fluid and rock properties, such as: porosity, viscosity, fluid compressibility and permeability. Since the goal of this work is to estimate only the permeability values, the other properties associated to reservoir characterization were considered constant. And for simplification, these values will be the same for all example cases, except for the permeability data, which is the focus of this work.

Moreover, it is also necessary to insert some geometric characteristics in this file, such as: the grid dimension, the size of each cell and the location of the well related to the actual their coordinates in the grid. We only allocate one single well. This location depends on distribution of the skeleton's edges, where we find non-zero permeability values. Also, this location is important to identify the maximum permeability value $k_{\max }$ used in the calculus of the refinement radius and how many grid cells in the well correspond to each layer, determining the thickness of each lobe in the well. These thicknesses will be used to compute the production log of each layer.

The morphology of the channel is exported to a file called NULL.txt, which will be attached to the IMEX base file for well test simulation. This is a ONEs and ZEROs file that contains information about which cells belong to the channel and which not (see Appendix B). Therefore, the cell that is contained in a channel will receive the value 1 . The filling of this file is given according to the following conditions:

- If $K_{h}[i][j][k]=0$ or $K_{v}[i][j][k]=0$, so $N_{i, j, k}=0$;

- If $K_{h}[i][j][k]>0$ and $K_{v}[i][j][k]>0$, so $N_{i, j, k}=1$;

As well as the morphological modeling of the reservoir, this nullity file is generated only once, because these data, that represents the geometrical structure of the reservoir, do not change during the optimization process.

In addition to the file that contains the geometric data, another file with the reservoir permeability data will also be attached to the IMEX base file (PERM.txt). Since the range of the permeability distribution function is a subset of the interval $(0,1)$. These values are multiplied by a factor related to an average permeability in the well. An example of a cell block filled with these permeability values is presented in Appendix C. 


\subsection{1}

\section{Average Permeability}

In this work, we assign a single permeability value to represent the heterogeneous system of the reservoir. Since each grid cell received a different value of permeability, we use a method to compute the average permeability in the reservoir, for more detail see [8].

The average permeability $\bar{k}$ is calculated according to the equation for linear flow:

$$
\bar{k}=\frac{k_{1} \cdot h_{1}+k_{2} \cdot h_{2}+k_{3} \cdot h_{3}+\cdots+k_{n} \cdot h_{n}}{h_{t}},
$$

where

- $k_{1}, k_{2}, \ldots, k_{n}$ are absolute permeability,

- $h_{1}, h_{2}, \ldots, h_{n}$ are thickness,

- $h_{t}=h_{1}+h_{2}+h_{3}+\cdots+h_{n}$

- and $n$ is an amount of layers.

In this work, three cases are considered for simulation, each case with different numbers of lobe. In this way, $n$ represents numbers of lobes ( $n=1,2,3)$, which are ordered as: the lower lobe is associated to number one, the middle lobe to number two and the upper lobe to number three, $h_{i}$ is the thickness of each lobe in the well and $k_{i}$ corresponds to the permeability multipliers of each lobe. To define the average permeability of the reference case from the equation given by (4.1), we have three degrees of freedom. Thus, we first decided to define an average permeability value and then calculate the permeability multipliers of each layer according to production log.

So this is done as follows: we choose any value for $k_{1}, k_{2}$ and $k_{3}$ that satisfy the fixed average permeability. After, we run this case on IMEX and export a file containing the production log data in each grid cell related to well position for each time step. We only use the flow data in each layer of the last time step.

As the total flow $q_{t}$ is equal to sum of the flow in each layer, follows

$$
q_{t}=q_{1}+q_{2}+q_{3}+\cdots+q_{n} .
$$

Dividing both sides of Equation (4.2) by $q_{t}$, we obtain:

$$
1=\frac{q_{1}}{q_{t}}+\frac{q_{2}}{q_{t}}+\frac{q_{3}}{q_{t}}+\cdots+\frac{q_{n}}{q_{t}} .
$$


Then, the percentage of flow per layer is defined as

$$
R_{i}=\frac{q_{i}}{q_{t}}, \quad i=1,2,3, \ldots, n
$$

Furthermore, for calculating the radial flow in each layer, the Darcy law provides the following equation [8]:

$$
q_{i}=\frac{2 \pi \cdot k_{i} \cdot h_{i}}{\mu} \cdot\left(\frac{r \partial p}{\partial r}\right) \quad, \quad i=1,2,3, \ldots, n
$$

where

- $k_{i}$ is the absolute permeability of each layer,

- $h_{i}$ is the thickness of each layer,

- $\mu$ is viscosity

- and $\frac{r \partial p}{\partial r}$ is the pressure gradient.

Considering that the pressure gradient is equal in all layers, we consequently obtain that the total flow is given by:

$$
q_{t}=\frac{2 \pi \cdot \bar{k} \cdot h_{t}}{\mu} \cdot\left(\frac{r \partial p}{\partial r}\right)
$$

So, Eq. (4.5) divided by Eq. (4.6) and replacing (4.4), we can obtain the following relation:

$$
R_{i}=\frac{k_{i} \cdot h_{i}}{\bar{k} \cdot h_{t}}, \quad i=1,2,3, \ldots, n
$$

that implies

$$
k_{i}=\frac{\bar{k} \cdot h_{t} \cdot R_{i}}{h_{i}}, \quad i=1,2,3, \ldots, n .
$$

Therefore, to build the reference case, we fix a value for the average permeability and estimate the percentage of flow per layer in the well. Then, the values for $k_{1}, k_{2}, k_{3}$ are given by the Equation (4.8) and, in each lobe, all grid cells of $k_{h}$ and $k_{v}$ are multiplied by the permeability $k_{i}$ correspondent to this layer. Soon after, the file containing the areal and vertical permeabilities of all cells in the grid is generated and attached to the base file for the well test simulation.

For the simulated case, we use the same value for percentage of flow per layer of the reference case. However, we do not have a value for average permeability. Actually, it is the value that we want to estimate. Therefore, 
the simulated average permeability is calculated in each iteration during the optimization process, generating a new permeability field and resulting in a new well-testing pressure data, which is used to compare to the reference case.

\section{3}

\section{Output File IMEX}

After performing the well test simulation, we obtain the pressure data for each time step $t_{i}, i=1,2, \ldots, m$. Through these data, we calculate the pressure variation $\Delta p$ and the derivative of the pressure variation in respect to the natural logarithmic of time $\Delta p^{\prime}$. The pressure variation is equal to the difference between the initial pressure $p_{i}$ and the bottom-hole pressure $p_{w f}$, i.e. $\Delta p=p_{i}-p_{w f}$, and $\Delta p^{\prime}=\frac{d \Delta p}{d \ln t}$. The way to obtain the Bourdet derivative is described in [10]:

$$
\Delta p^{\prime}\left(t_{j}\right)=\frac{\Delta p\left(t_{j+1}\right)-\Delta p\left(t_{j}\right)}{\ln \left(\frac{t_{j+1}}{t_{j}}\right)} \frac{\ln \left(\frac{t_{j}}{t_{j-1}}\right)}{\ln \left(\frac{t_{j+1}}{t_{j-1}}\right)}+\frac{\Delta p\left(t_{j}\right)-\Delta p\left(t_{j-1}\right)}{\ln \left(\frac{t_{j}}{t_{j-1}}\right)} \frac{\ln \left(\frac{t_{j+1}}{t_{j}}\right)}{\ln \left(\frac{t_{j+1}}{t_{j-1}}\right)}
$$

For all simulated cases in this thesis, we consider 50 time steps, which corresponds to 4 production days. From the graphs $\Delta p \times t$ and $\Delta p^{\prime} \times t$ it is possible to analyze the consistence of the modeling proposed in this work. In the Fig. 4.1, an example of this curves in a graph with axes in logarithmic scale of base 10 is presented.

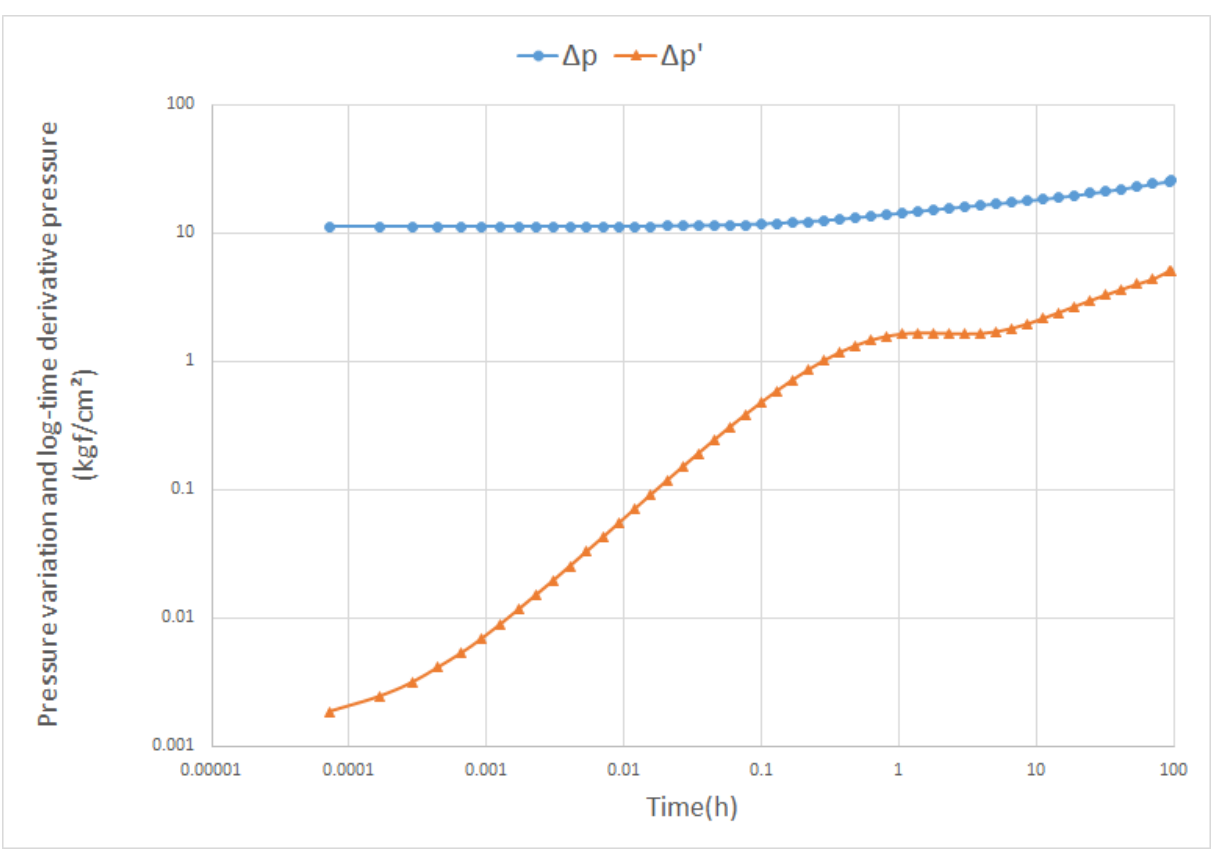

Figure 4.1: $\Delta p \times \Delta t$ and $\Delta p^{\prime} \times \Delta t$. 
From this figure, it is possible to observe some behaviors that correspond to the reservoir characterization. The first fact that draws attention to us is the behavior of the graph of $\Delta p^{\prime}$ in the initial times, which is very similar to a straight line with slope 1 . Over time, the curve stabilizes, approaching a horizontal line and presents a small rise to the end of the simulation.

The derivative pressure behavior at the beginning of the curve is due to a numerical storage problem caused by the size of the grid cell. When it reaches the horizontal line, the pressure begins to change as a radial flow regime, indicating that the model exhibits an infinite reservoir behavior and the small rise at the end of the graph indicates that the test has reached one of the channel limits.

Aiming to mitigate the numerical storage effect presented in the pressure data, a grid cell refinement is implemented in a well neighborhood. The method used to apply this refinement will be explained in the following subsection. In the Fig. 4.2, some images of the pressure variation of reservoir cells at the end of the well test are shown.

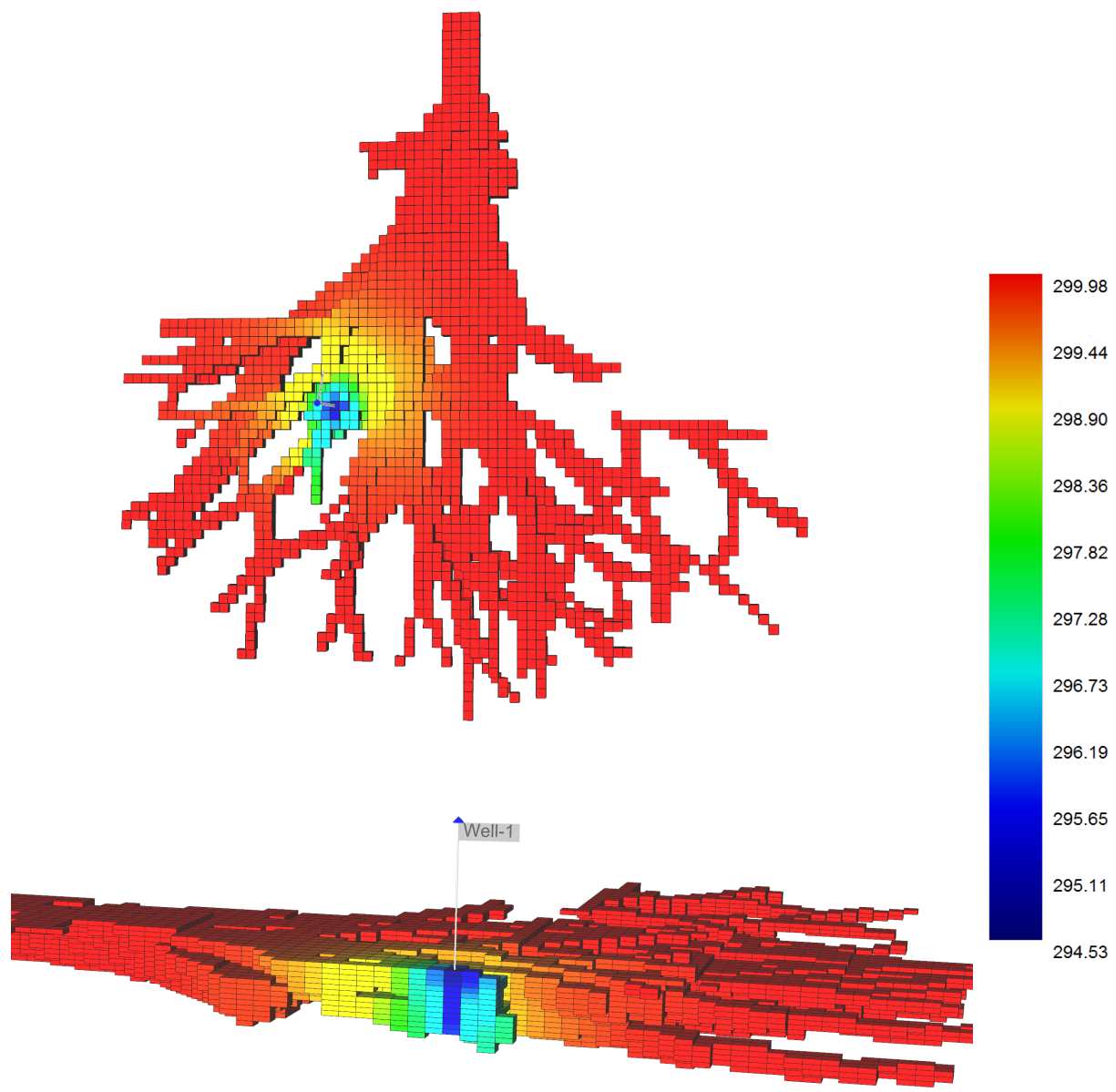

Figure 4.2: Pressure variation at the end of well test. 


\subsection{1}

\section{Effective Wellbore Radius}

In the reservoir modeling by numerical methods, it is necessary to minimize the numerical storage effect that happens when the grid blocks are much larger than the diameter of a well. Because of that, the simulated pressure data can not be associated to the well bottom-hole pressure, for more details about this effect, see [12].

In order to compare the simulated pressure data with the reference case, it was necessary to approximate the grid blocks of diameter of the well through a refinement process, proceeding the equivalent well-block radius defined in [10]:

$$
r=1.5 \frac{\sqrt{\alpha \cdot k_{\max } \cdot t_{p}}}{\phi \mu c_{t} d i}
$$

where,

- $\alpha$ is the system constant of units for time conversion $\alpha=0.0003484$;

- $k_{\max }$ corresponds to the maximum permeability value in the well;

- $t_{p}$ is the production time prior to buildup in hours;

- $\phi$ is porosity;

- $\mu$ is viscosity;

- $c_{t}$ is the total compressibility that is defined as follows:

$$
c_{t}=c_{w} \cdot s_{w i}+c_{o} \cdot\left(1-s_{o r}\right)+c_{r}
$$

$c_{w}$ is the compressibility of water, $s_{w i}$ is the irreducible water saturation, $c_{o}$ is the oil compressibility, $\left(1-s_{\text {or }}\right)$ is the residual oil saturation and $c_{r}$ is the rock compressibility;

- and $d_{i}$ is a cell dimension in the direction $\mathrm{i}$.

This refinement process is done in the grid mesh, then the value considered for $r$ is the largest integer near the value of $r$. We consider that each grid parallelepiped within the radius of refinement will be subdivided into 9 cells. The Fig. 4.3 shows some images of the pressure variation of reservoir cells at the end of the well test after this refinement. 


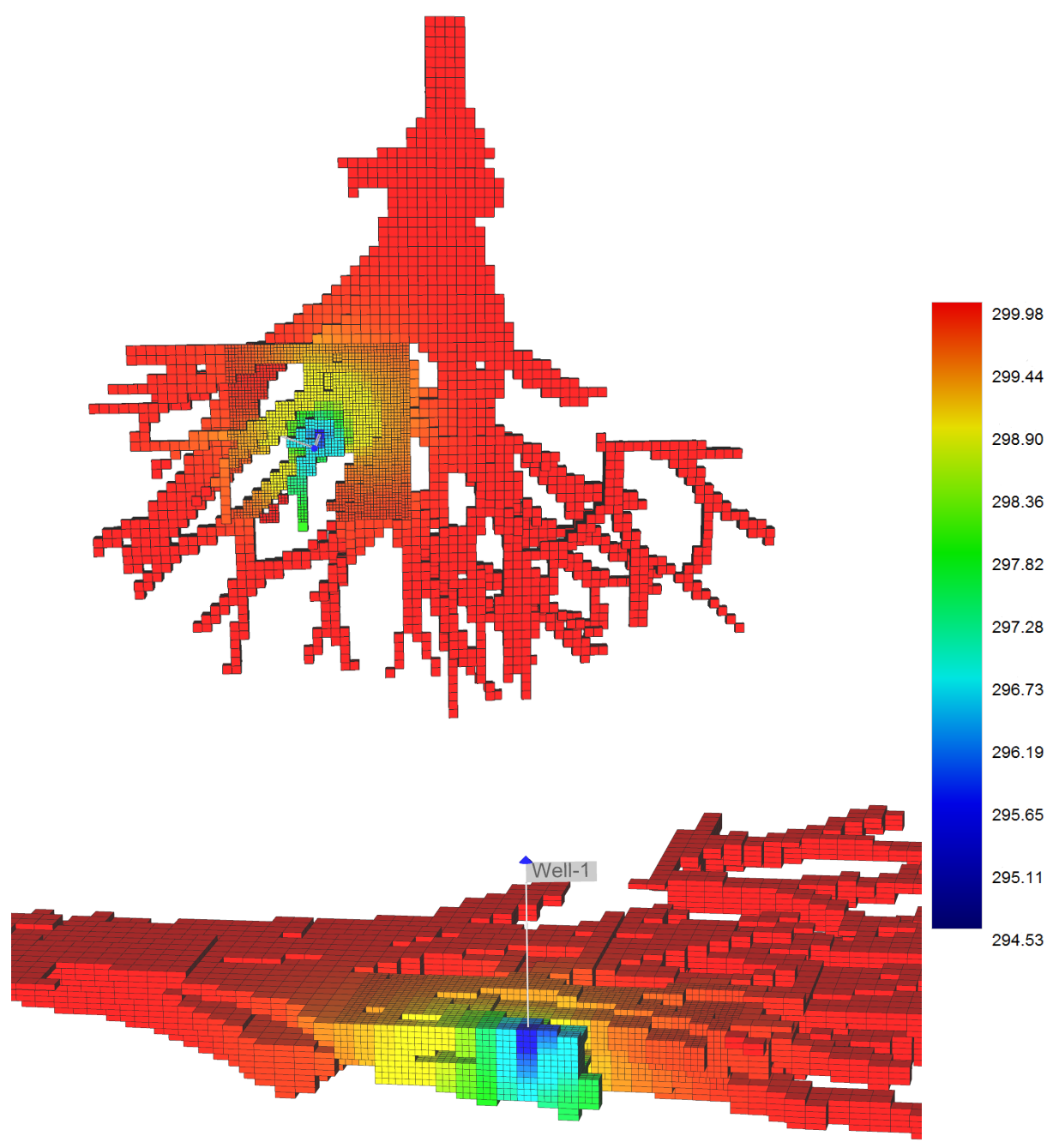

Figure 4.3: An example of the refinement process result.

Finally, the result of this refinement process can be observed in Fig. 4.4, which presents a graph with the answers obtained in the refinement of the case shown in the section 4.3. The series in blue represents the variation of the pressure at the bottom of the well, which is the same for the comparison of the two cases. But, from the results with refinement in color green, it is possible to see that derivative pressure curve reached the behavior similar to horizon line before the case without refinement in color orange.

Due to this impact on the derivative pressure results, all tests performed in this thesis consider turbidite channels models with refinement around the well. 


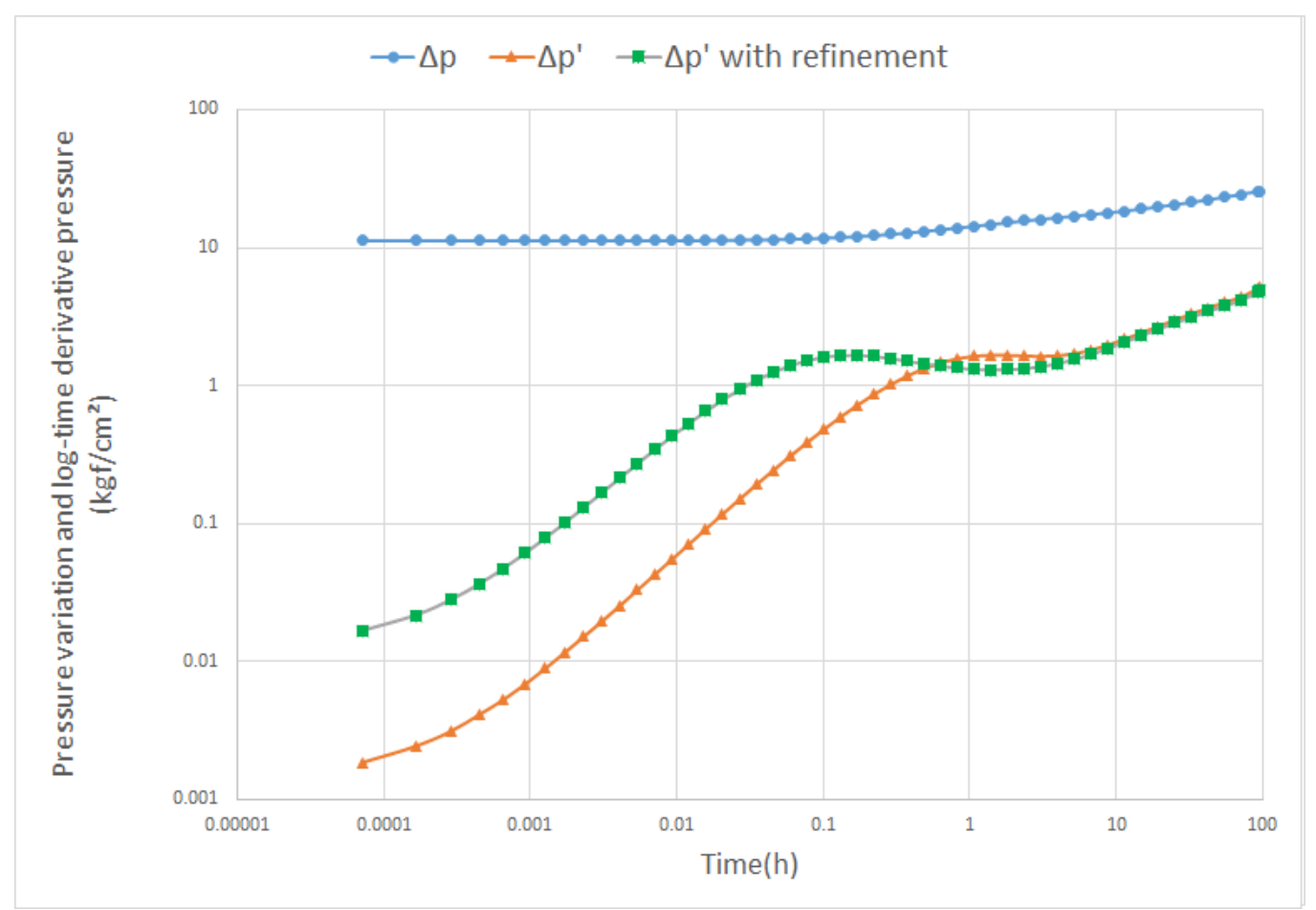

Figure 4.4: Graph of $\Delta p, \Delta p^{\prime}$ and $\Delta p^{\prime}$ with refinement.

\section{4}

\section{Optimization Process}

In this section we will explain how we estimate the permeability data constrained by pressure data obtained in well-testing. To compare the simulated case to the reference case, we implement an objective function that measures the difference between the pressure derivative curves of this respective cases.

In addition to the objective function, an auxiliary function function is implemented, which is used to check if the curve of the simulated case is above or below the reference case curve. When the objective function value does not satisfy the stop condition, the auxiliary function is used to calculate a new permeability value that will be tested through a classic optimization method.

\subsection{1}

\section{Objective Function}

The objective function used in this thesis is based on function $M$, defined by Hamdi and Sousa in [13]:

$$
M=\sum\left(\frac{\log \left(\Delta p^{\text {truth }}\right)-\log \left(\Delta p^{\text {sim }}\right)}{\overline{\log \left(\Delta p^{\text {truth }}\right)}}\right)^{2}+\sum\left(\frac{\log \left(\Delta p_{\text {der }}^{\text {truth }}\right)-\log \left(\Delta p_{\text {der }}^{\text {sim }}\right)}{\overline{\log \left(\Delta p_{\text {der }}^{\text {truth }}\right)}}\right)^{2}
$$


We define the following objective function:

$$
f_{o b j}=\sum\left(\frac{\log \left(\Delta p_{\text {der }}^{\text {truth }}\right)-\log \left(\Delta p_{d e r}^{\text {sim }}\right)}{\log \left(\Delta p_{d e r}^{\text {truth }}\right)}\right)^{2}
$$

where:

- the superscripts ${ }^{\text {truth }}$ and ${ }^{\text {sim }}$ corresponding to the well test response of the reference and the simulated cases respectively;

- the bar sign is the arithmetic mean;

- and $\Delta p_{d e r}$ is the Bourdet derivative.

Since,

$$
\Delta p^{\prime}=\frac{d \Delta p}{d \ln (t)}=t \cdot \frac{d \Delta p}{d t}
$$

it is redundant to use both terms of equation (4.9).

Due to the easy way of checking the consistency of the model from the graph pressure derivative, we only use the second term of (4.9). The behavior of this graph, in addition to inferring about the permeability data, can also provide information about the channel width. However, our research is not aimed at estimating the geometric parameters of the turbidite channels.

\subsection{2}

\section{Auxiliary Function and Secant Method}

The focus of this work is to estimate permeabilities in turbidite channels constrained by well-testing, more precisely constrained by the well bottom-hole pressure obtained in this kind of test. Therefore, we generated a reference case to compare the pressure data obtained to the simulated case data. In order to minimize the difference between these data and improving the quality of the modeling proposed in this work, we used a method that searches for the permeability value closest to the reference case.

The auxiliary function is the same function described in [4]:

$$
f_{\text {aux }}=\sum \frac{\log \left(\Delta p_{\text {der }}^{\text {truth }}\right)-\log \left(\Delta p_{\text {der }}^{\text {sim }}\right)}{\log \left(\Delta p_{\text {der }}^{\text {truth }}\right)}
$$

This function is calculated by a similar way as the objective function, but in this case the difference of the logarithms of $\Delta p^{\prime}$ is not squared.

As mentioned, the estimation process of the permeability within the channels is summarized in the average permeability estimation. Because from 
this information, it is possible to calculate the permeability multiplier for each layer of the depositional system. We have chosen to use a classical method in the literature which is the Secant Method. The algorithm of this method is defined by the following recurrence relation [14]:

$$
x[i+1]=x[i]-\frac{x[i]-x[i-1]}{f[i]-f[i-1]} \cdot f[i]
$$

The method uses the value of the last two iterations to approximate the function $f$ to a root $x^{*}$. From these values, a line is constructed by passing through the points $\left(x_{i}, f\left(x_{i}\right)\right)$ and $\left(x_{n}, f\left(x_{n}\right)\right)$ and the value $x_{i+1}$ is obtained by the the point where this line meet $\mathrm{x}$-axis. A geometric representation of this method is shown in the Fig. 4.5.

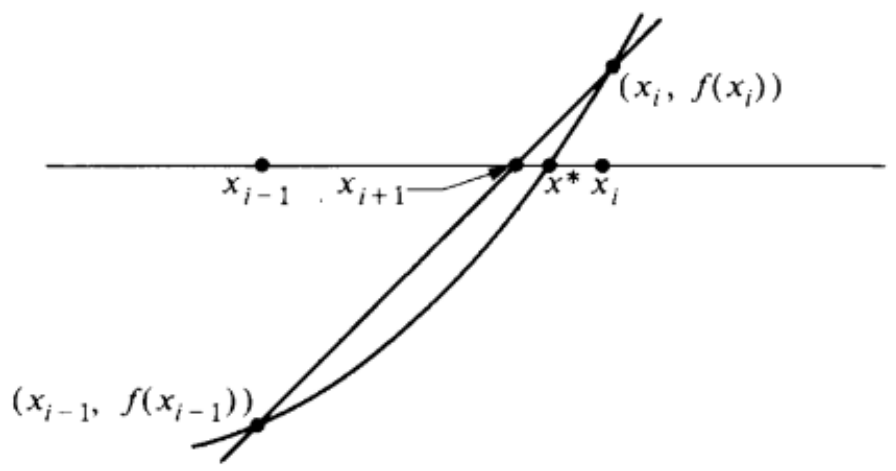

Figure 4.5: The Secant Method [14]

The root-finding algorithm provided by the secant method is used to compute the average permeability values that will be simulated as follows:

$$
\bar{k}[i+1]=\bar{k}[i]-\frac{\bar{k}[i]-\bar{k}[i-1]}{f_{\text {aux }}[i]-f_{\text {aux }}[i-1]} f_{\text {aux }}[i]
$$

From the found average permeability value $\bar{k}$, we calculate the permeability multipliers of each layer $\left(k_{1}, k_{2}, k_{3}\right)$ following the equation (4.8). After, we generate the areal and vertical permeability data corresponding to these multipliers and attach them to the input file. Then, we compare the obtained pressure data to the reference case.

Because the convergence condition of the secant method depends on the two initial values tested, we choose the values for the first two iterations so that the permeability of the reference case is contained in the range defined by them. The results obtained from this method will be presented in the next chapter. 


\section{Results}

In this chapter, we present the results related to simulated cases with 1 , 2 and 3 lobes considering uniform pressure data. In addition to these cases, we made a modification in the data of the reference case, adding a noise in the pressure data extracted from the IMEX. In this way, we can verify if the used method is able to estimate the permeability from non-uniform data.

To simplify the simulations, we used the same values in the necessary parameters to compute the refinement radius in all cases, which are:

\begin{tabular}{|c|c|c|}
\hline Parameters & Value & Unit (Brazilian) \\
\hline$\phi$ & 0.30 & - \\
\hline$\mu$ & 4.00 & $c p$ \\
\hline$S_{w i}$ & 0.00 & - \\
\hline$S_{o r}$ & 0.00 & - \\
\hline$c_{w}$ & $4.04 \times 10^{-05}$ & $\left(\mathrm{kgf} / \mathrm{cm}^{2}\right)^{-1}$ \\
\hline$c_{o}$ & $1.14 \times 10^{-04}$ & $\left(\mathrm{kgf} / \mathrm{cm}^{2}\right)^{-1}$ \\
\hline$c_{r}$ & $8.00 \times 10^{-05}$ & $\left(\mathrm{kgf} / \mathrm{cm}^{2}\right)^{-1}$ \\
\hline$t_{p}$ & 96.00 & $\mathrm{hours}$ \\
\hline
\end{tabular}

Also we define the dimensions of the grid cell in the $i, j$, and $k$ directions as $50 \mathrm{~m}, 50 \mathrm{~m}$, and $15 \mathrm{~m}$ respectively. The maximum permeability value in the well $k_{\max }$ is obtained by the geometric average of the maximum values of areal and vertical permeability in the grid cells contained in the well. We choose to use the same refinement radius calculated for the reference case in the simulated cases.

\section{1}

\section{Approximation to the Reference Case}

In this section we will analyze the results obtained in the simulations constrained by well-testing pressure data comparing them to reference case. The stop condition is the same in all cases: the objective function value must be less than or equal to $1.0 \times 10^{-04}$ for the optimization process stops.

For the reference case in the one-lobe system, we choose the average permeability value as $500 \mathrm{mD}$ and, consequently, the permeability multiplier of 
this layer has the same value, $500 \mathrm{mD}$. Because the percentage of the flow in this layer is equal to 1 . The table 5.1 shows the obtained values for permeability and objective function at each iteration. In this case, the objective function achieves the stop condition in just 6 iterations. We can observe the behavior of the approximations at each iteration in the graphs of the Fig. 5.1.

Table 5.1: Case with 1 lobe

\begin{tabular}{ccc}
\hline Iteration & Permeability $(\mathrm{mD})$ & $f_{\text {obj }}$ \\
\hline 1 & 100.00 & $7,510.84$ \\
2 & $1,000.00$ & $1,294.11$ \\
3 & 736.00 & 427.96 \\
4 & 378.74 & 219.92 \\
5 & 527.91 & 9.72 \\
6 & 502.00 & $8.42 \times 10^{-06}$ \\
\hline
\end{tabular}

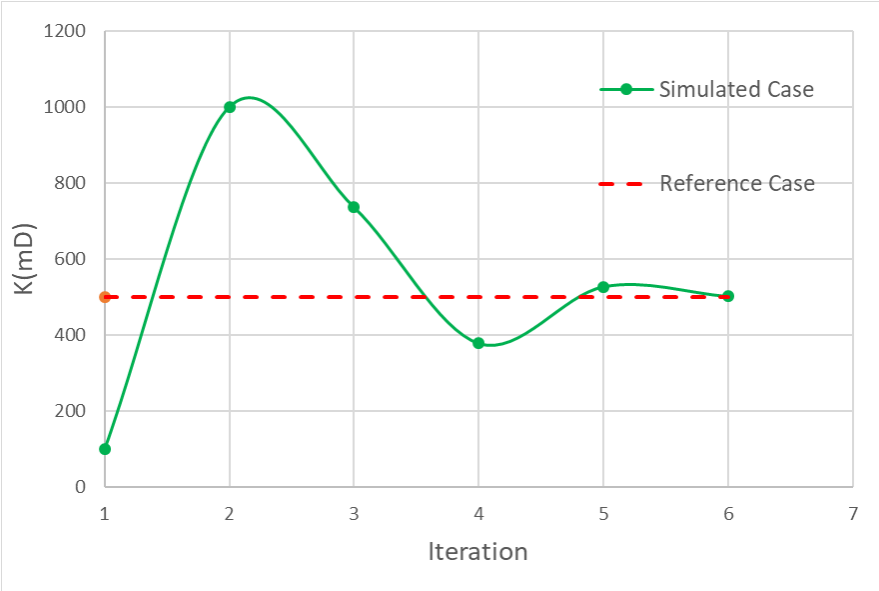

(a) $\bar{k} \times$ iteration

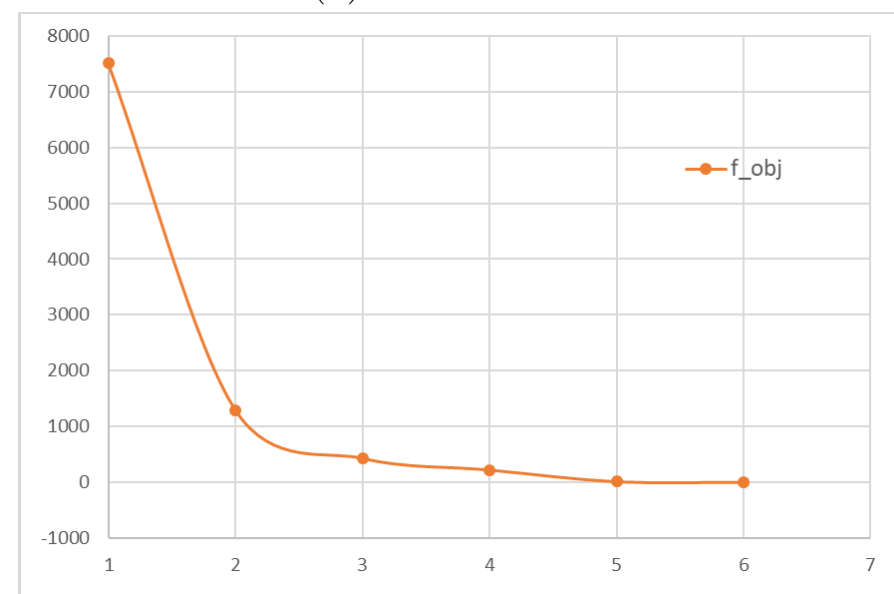

(b) $f_{o b j} \times$ iteration

Figure 5.1: Graphs correspond to Table 5.1. 
Moreover, we can observe the log-time pressure derivative curve of each iteration in the Fig. 5.2. It is observed from the third iteration, the curves of the simulated cases are close to the reference case. In the last iteration, the values are so close that the curves almost match.

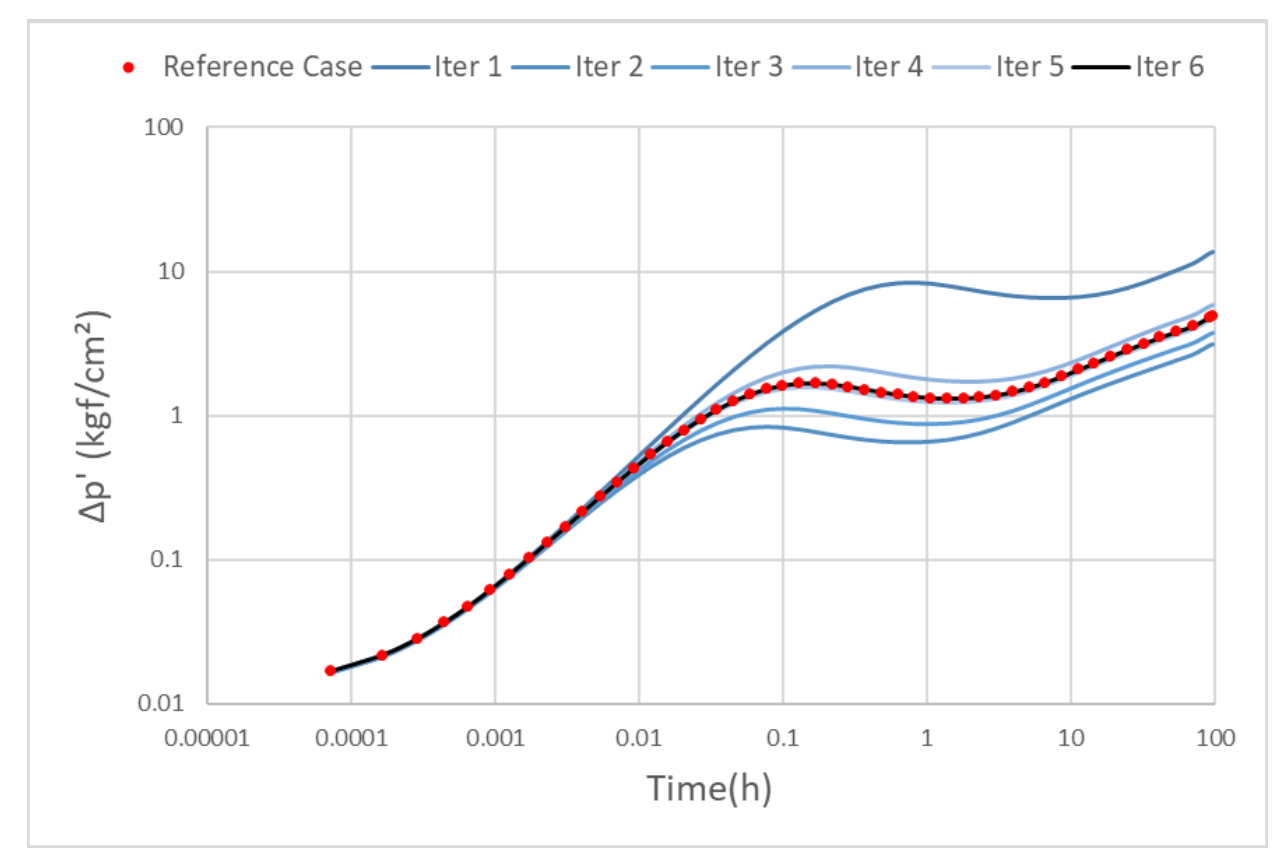

Figure 5.2: $\quad \Delta p^{\prime} \times$ Time for each iteration.

In this case, it is easy to verify that the distribution of permeabilities in the simulated case is similar to the reference case (see Fig. 5.3). Since the difference between the estimated permeability through the secant method and the reference case is less than $0.5 \%$. The average permeability of the reference case was $500 \mathrm{mD}$ and the permeability estimated in the simulation was $502.003 \mathrm{mD}$.

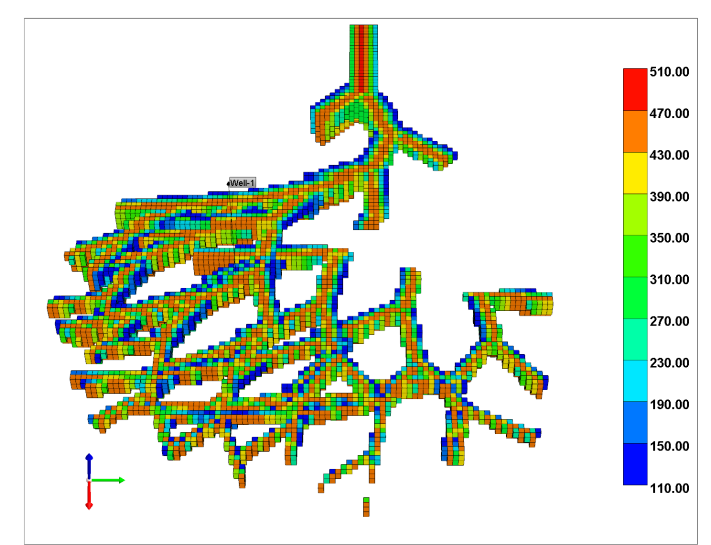

(a) Reference case.

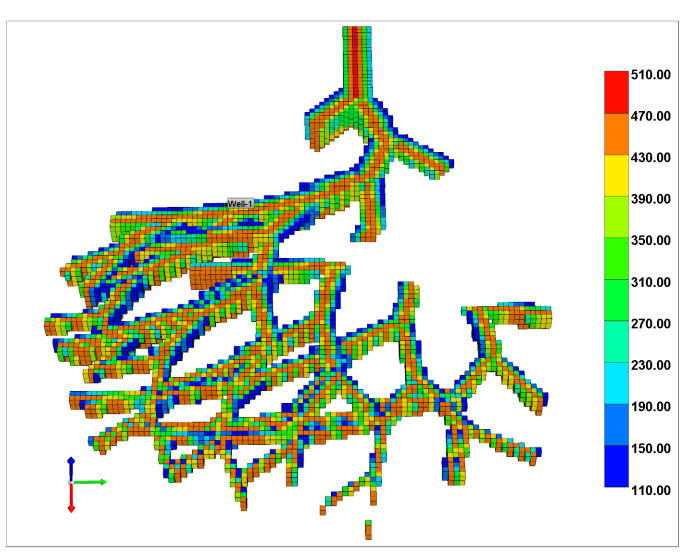

(b) Simulated case.

Figure 5.3: Areal permeability distribution. 
The same results were obtained in the vertical permeability (Fig. 5.4).

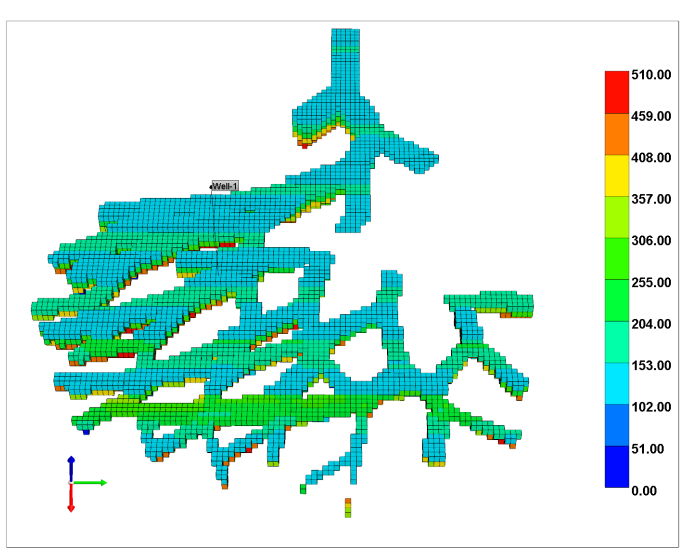

(a) Reference case.

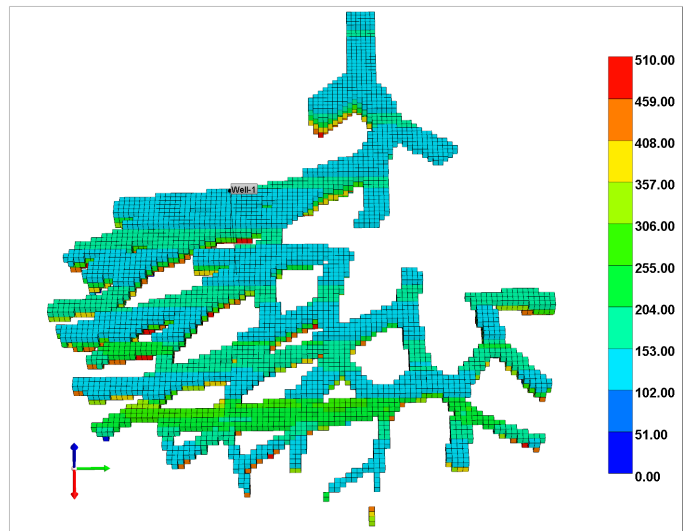

(b) Simulated case.

Figure 5.4: Vertical permeability distribution.

For the case with 2 layers, we consider that the average permeability value of the reference is $600 \mathrm{mD}$. The parameters used to define the multipliers permeability of each lobe are presented in the following tables.

\begin{tabular}{|l|l|l|}
\hline \multicolumn{3}{|c|}{ Lobe 1} \\
\hline$h_{1}$ & $R_{1}$ & $k_{1}$ \\
\hline $30 \mathrm{~m}$ & 0.22 & $861.4 \mathrm{mD}$ \\
\hline
\end{tabular}

\begin{tabular}{|l|l|l|}
\hline \multicolumn{3}{|c|}{ Lobe 2} \\
\hline$h_{2}$ & $R_{2}$ & $k_{2}$ \\
\hline $165 \mathrm{~m}$ & 0.78 & $552.5 \mathrm{mD}$ \\
\hline
\end{tabular}

The values of $k_{1}$ and $k_{2}$ were computed from Eq. (4.8) presented in the previous chapter. The obtained results for the simulations are presented in Table 5.2. The values of the multipliers $k_{1}$ and $k_{2}$ for each iteration can also be calculated through Eq. (4.8), using the same values of $R_{1}$ and $R_{2}$ chosen to the reference case. In addition, the thickness $\mathrm{h} 1$ and $\mathrm{h} 2$ are also the same, since we did not change the morphology of the turbidite channels in the simulated cases. 
Table 5.2: Case with 2 lobes

\begin{tabular}{ccc}
\hline Iteration & Permeability $(\mathrm{mD})$ & $f_{\text {obj }}$ \\
\hline 1 & 100.00 & 22.38 \\
2 & $1,000.00$ & 16.90 \\
3 & $6,967.81$ & 482.21 \\
4 & 374.55 & 5.09 \\
5 & 988.75 & 15.93 \\
6 & 596.33 & $5.38 \times 10^{-03}$ \\
7 & 588.99 & $1.96 \times 10^{-03}$ \\
8 & 591.75 & $8.36 \times 10^{-03}$ \\
9 & 586.39 & $7.27 \times 10^{-04}$ \\
10 & 584.14 & $2.62 \times 10^{-03}$ \\
15 & 601.49 & $6.49 \times 10^{-04}$ \\
16 & 901.69 & 9.87 \\
17 & 603.90 & $1.46 \times 10^{-04}$ \\
18 & 605.04 & $4.40 \times 10^{-03}$ \\
19 & 603.65 & $2.29 \times 10^{-03}$ \\
20 & 600.02 & $1.29 \times 10^{-05}$ \\
\hline
\end{tabular}

As the value of the objective function is close to zero, the simulated average permeability approaches the reference case, showing that the method used to estimate the permeability multipliers provides good results for the case with two lobes. It is possible to verify this behavior from the graphs corresponding to Table 5.2, shown in figures 5.5 and 5.6.

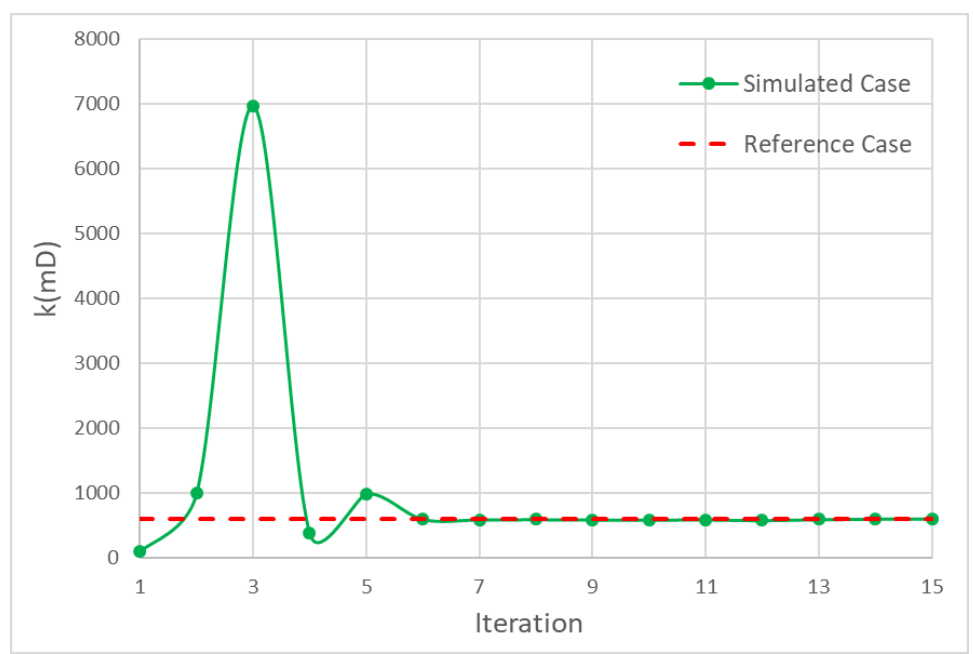

Figure 5.5: $\quad \bar{k} \times$ iteration . 


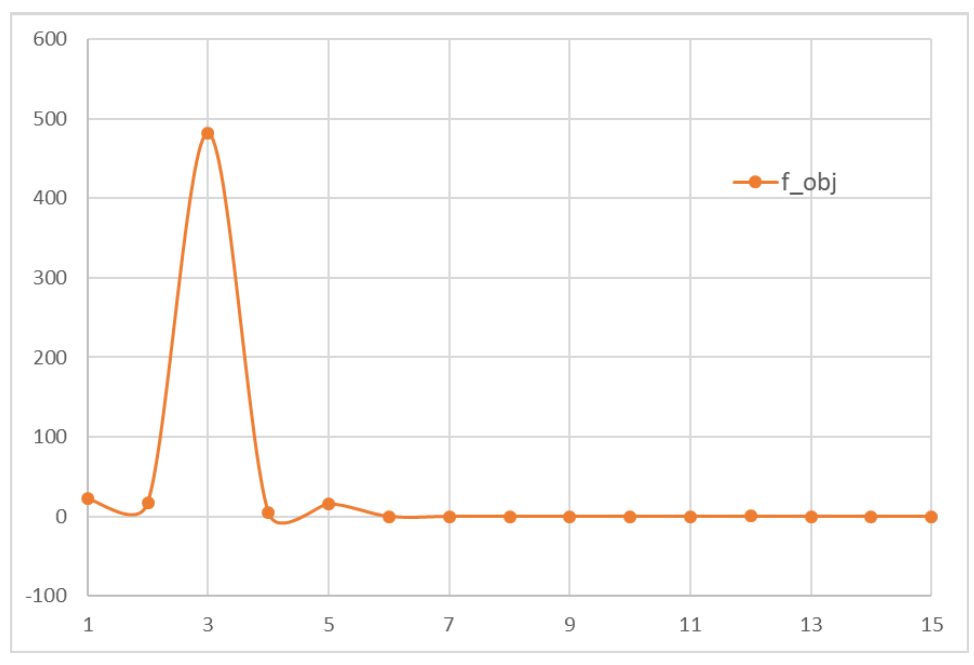

Figure 5.6: $f_{o b j} \times$ iteration .

The production log of each layer is shown in Fig. 5.7 as follows: the layers in color dark blue belong to lobe 2 of the simulated case and the layers in color light blue are related to the same lobe but of the reference case. This pattern is repeated for lobe 1 in color red: the simulated case is in color dark red and the reference case is in color light red. Each layer has the same thickness, 15m, because this is the dimension of the grid cell with respect to $k$. If we compare the flow data if estimated to the reference, we can see that the difference between them in each layer is very little, showing that the estimated model satisfies the imposed production log.

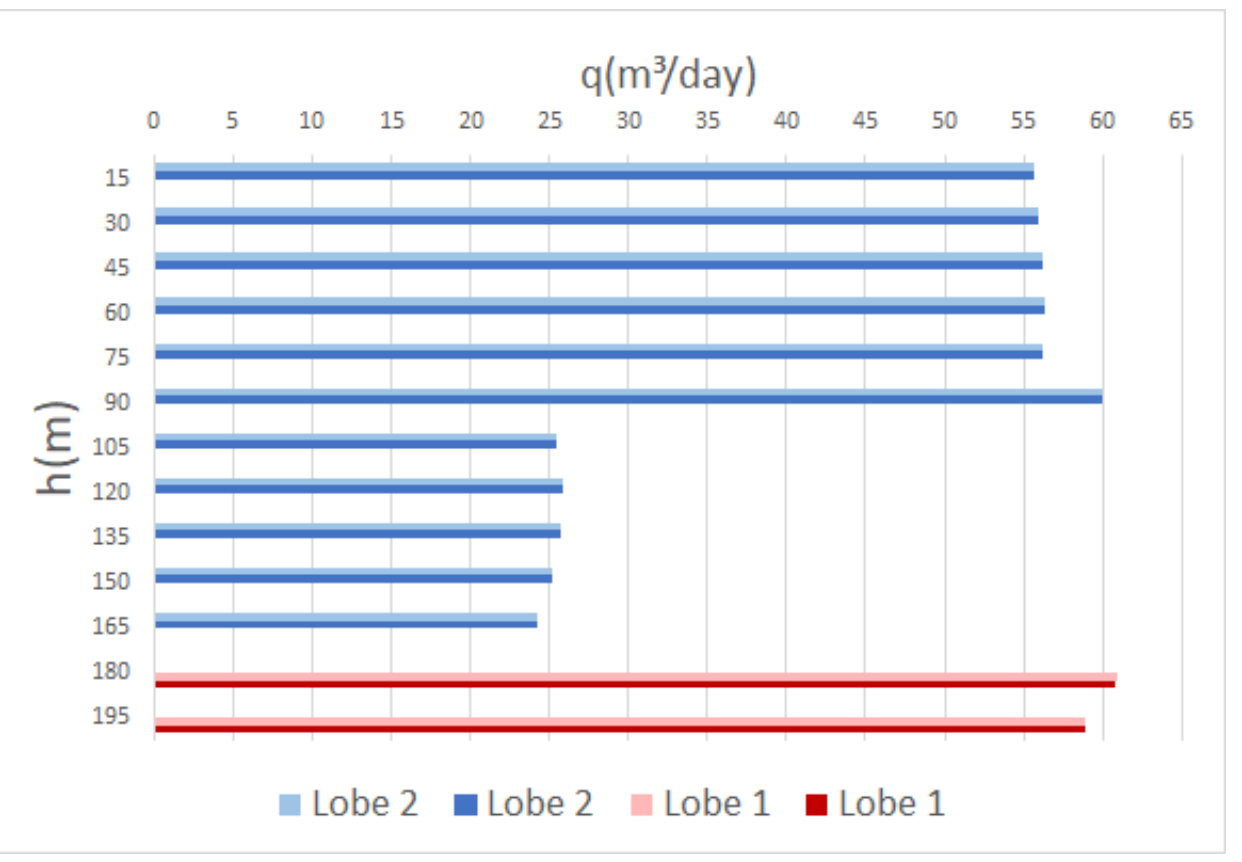

Figure 5.7: Production log of the case with 2 lobes. 
Due to the number of iterations performed by the secant method in the case with 2 lobes, we choose to show only the log-time pressure derivative curves corresponding to the iterations 1, 2 and 15 (last iteration) in the Fig. 5.8.

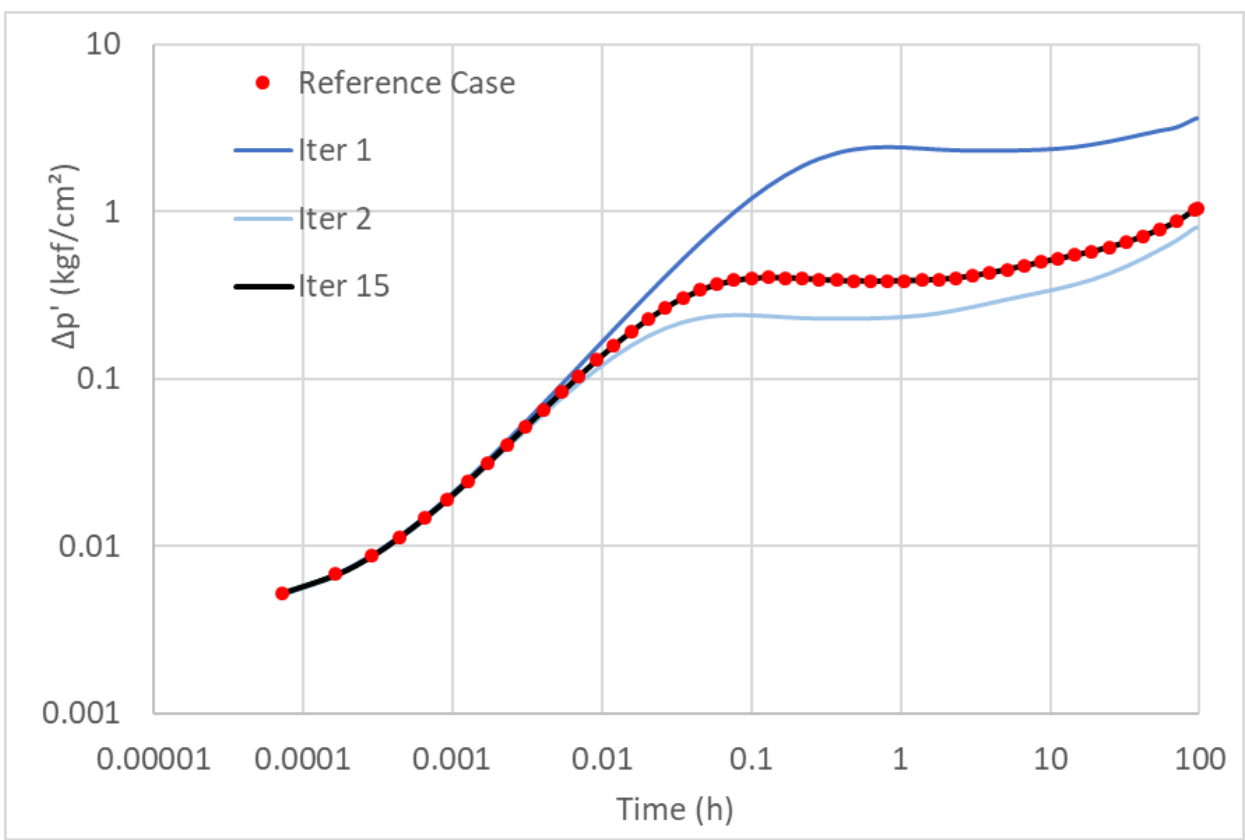

Figure 5.8: $\Delta p^{\prime} \times$ Time.

Both the areal and vertical permeability distributions have the same configuration: the lobe 2 has permeability values lower than those of the lobe 1 (see Fig. 5.9 and Fig. 5.10). This is due to the fact that the lobe 2 has a great thickness and percentage of flow, implying in a small value of permeability multiplier $\left(k_{2}\right)$.

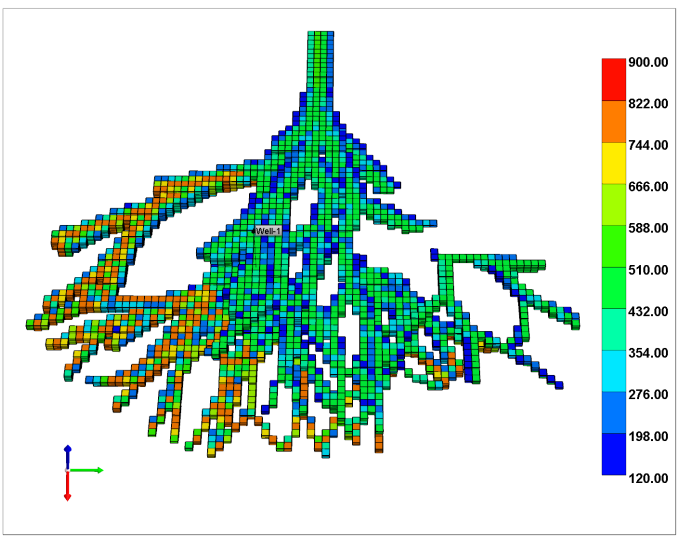

(a) Reference case.

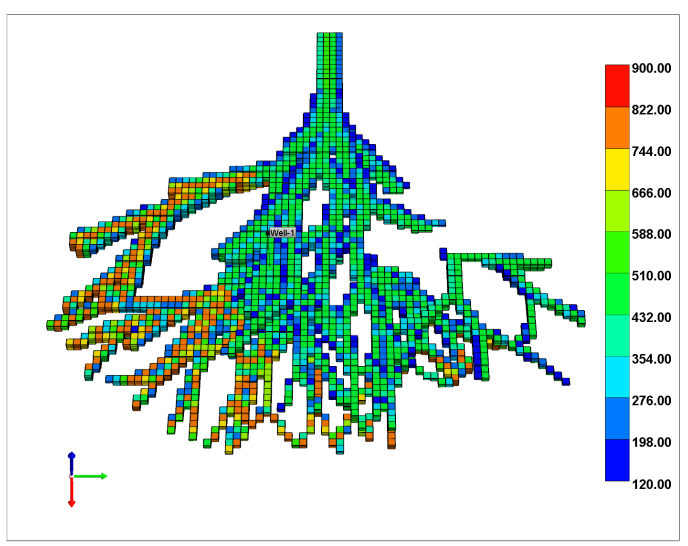

(b) Simulated case.

Figure 5.9: Areal permeability field. 


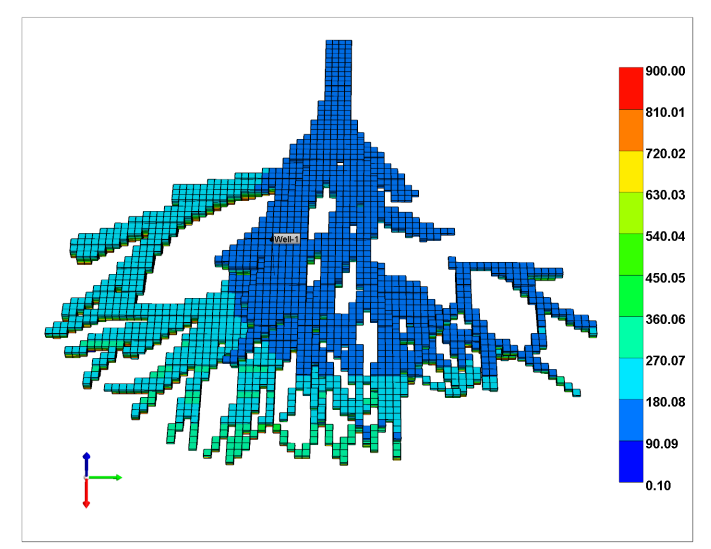

(a) Reference case.

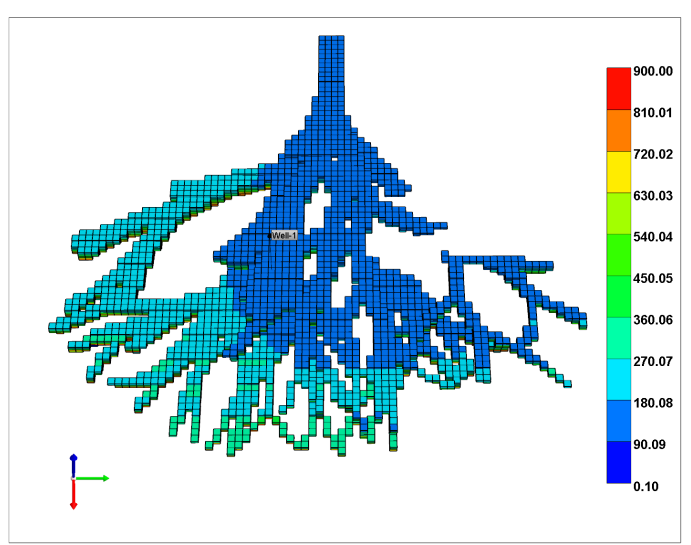

(b) Simulated case.

Figure 5.10: Vertical permeability field.

In the case with 3 layers, as in the case with 2 layers, we consider the permeability of the reference case equal to $600 \mathrm{mD}$. However, the well is located in other position. So the thickness of each lobe are different, the production log changed and, consequently, the permeability multipliers of each lobe are distinct. The used parameters for each lobe in the reference case will be given in the following tables.

\begin{tabular}{|l|l|l|}
\hline \multicolumn{3}{|c|}{ Lobe 1} \\
\hline$h_{1}$ & $R_{1}$ & $k_{1}$ \\
\hline $45 \mathrm{~m}$ & 0.17 & $413.5 \mathrm{mD}$ \\
\hline
\end{tabular}

\begin{tabular}{|l|l|l|}
\hline \multicolumn{3}{|c|}{ Lobe 2} \\
\hline$h_{2}$ & $R_{2}$ & $k_{2}$ \\
\hline $90 \mathrm{~m}$ & 0.35 & $424.2 \mathrm{mD}$ \\
\hline
\end{tabular}

\begin{tabular}{|l|l|l|}
\hline \multicolumn{3}{|c|}{ Lobe 3} \\
\hline$h_{3}$ & $R_{3}$ & $k_{3}$ \\
\hline $45 \mathrm{~m}$ & 0.47 & $1138.1 \mathrm{mD}$ \\
\hline
\end{tabular}

The Table 5.3 presents the results obtained in the permeability estimation by secant method in the case with 3 lobes. Although the method reaches the stop condition in the eleventh iteration, the value obtained in the sixth iteration is already reasonable because the objective function has a value lower than 0.002. This performance is also observed in the graphs of Fig. 5.11. 
Table 5.3: Case with 3 lobes

\begin{tabular}{ccc}
\hline Iteration & Permeability $(\mathrm{mD})$ & $f_{\text {obj }}$ \\
\hline 1 & 100.00 & $5,395.25$ \\
2 & $1,000.00$ & 361.12 \\
3 & 815.02 & 133.01 \\
4 & 529.43 & 24.62 \\
5 & 615.33 & 0.73 \\
6 & 602.70 & 0.01 \\
7 & 602.21 & $3.09 \times 10^{-03}$ \\
8 & 605.59 & $3.29 \times 10^{-04}$ \\
9 & 606.26 & $1.44 \times 10^{-04}$ \\
10 & 607.56 & 0.02 \\
11 & 606.37 & $7.36 \times 10^{-05}$ \\
\hline
\end{tabular}

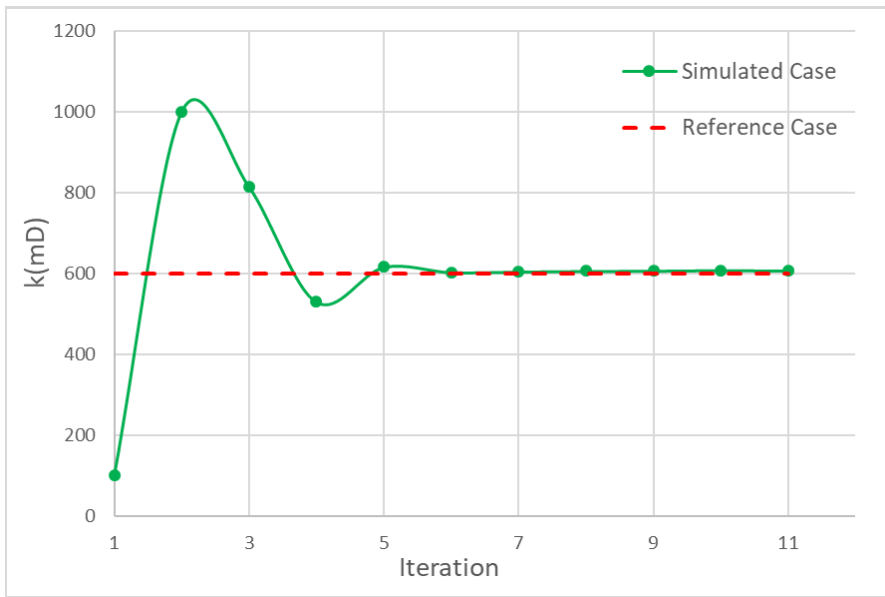

(a) $\bar{k} \times$ iteration

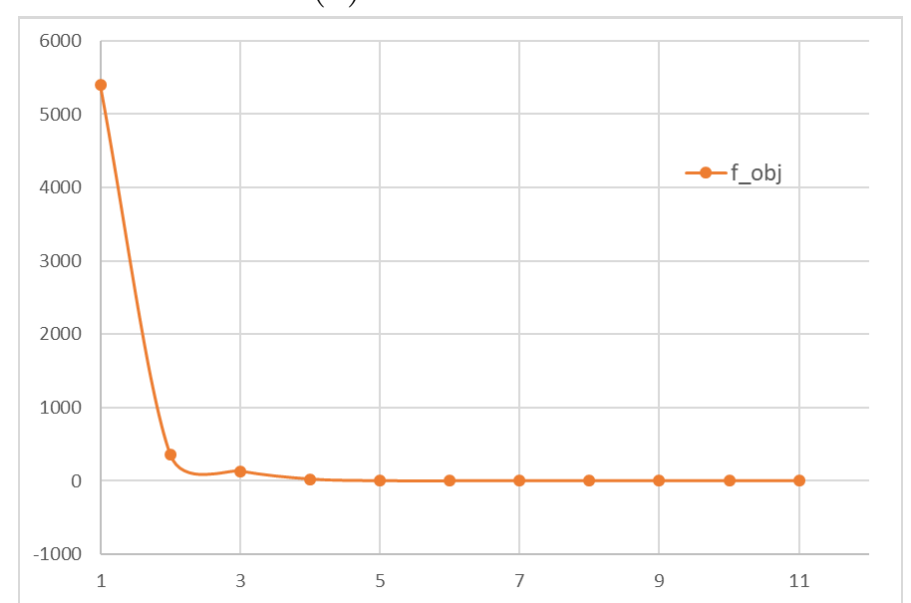

(b) $f_{o b j} \times$ iteration

Figure 5.11: Graphs correspond to Table 5.3. 
The production log of each layer in the well is shown in Fig. 5.12. The layers presented in dark red, dark blue and dark green colors correspond to lobes 1, 2 and 3 of the simulated case respectively. The lobes 1, 2 and 3 of the reference case have their layers presented in light colors. From the graph we can observe that the lobe 1 presented greater variation in the production profile, however this variation was still very small.

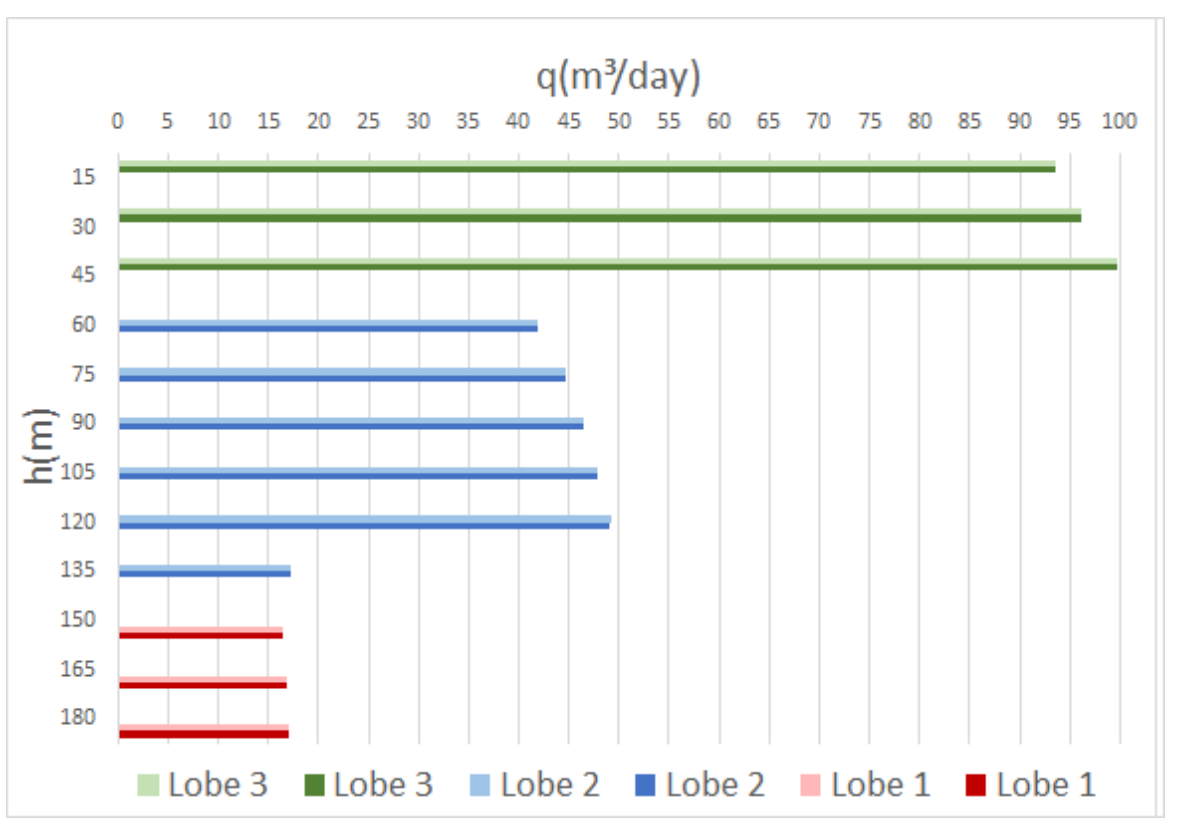

Figure 5.12: Production log of the case with 3 lobes.

From the Fig. 5.13 it is possible to analyze the log-time pressure derivative curves.

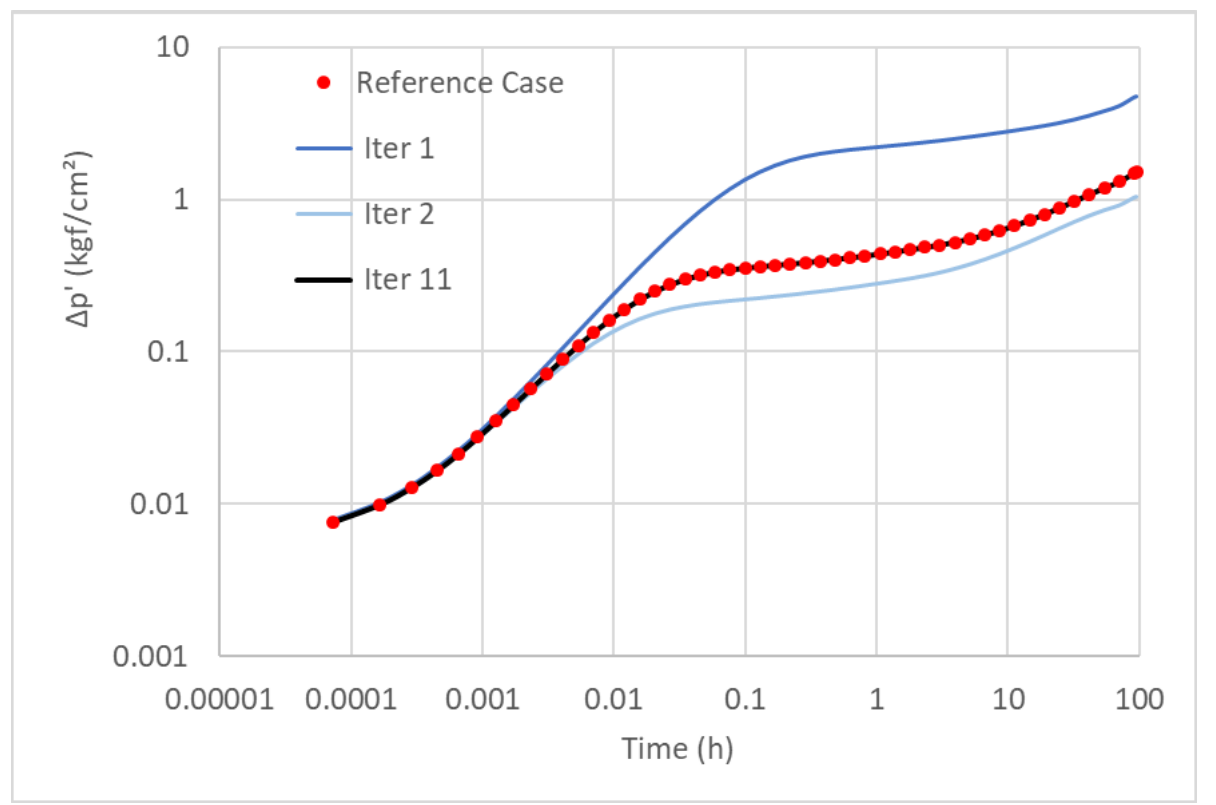

Figure 5.13: $\Delta p^{\prime} \times$ Time. 
The distribution of areal and vertical permeability can be checked in the figures 5.14 and 5.15 .

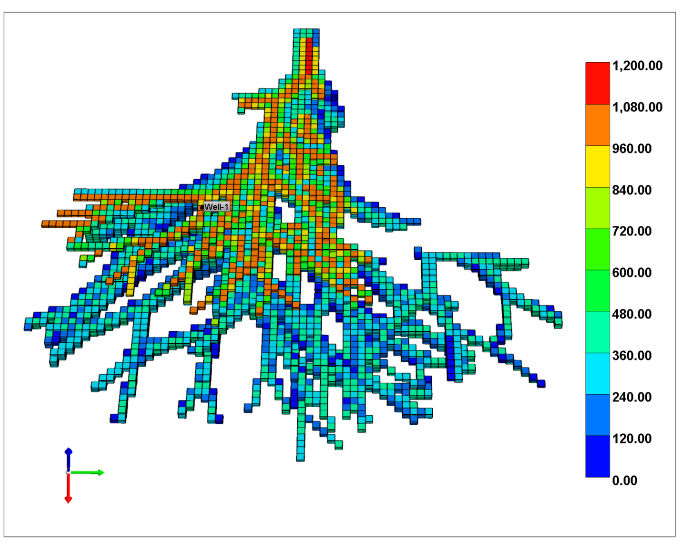

(a) Reference case.

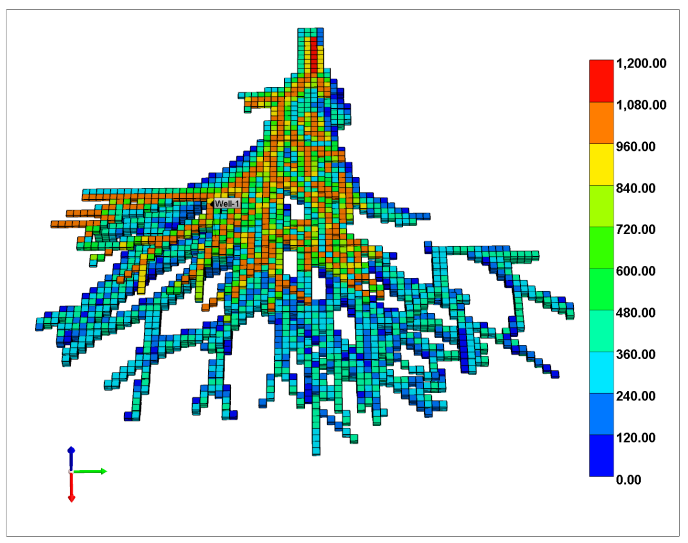

(b) Simulated case.

Figure 5.14: Areal permeability distribution.

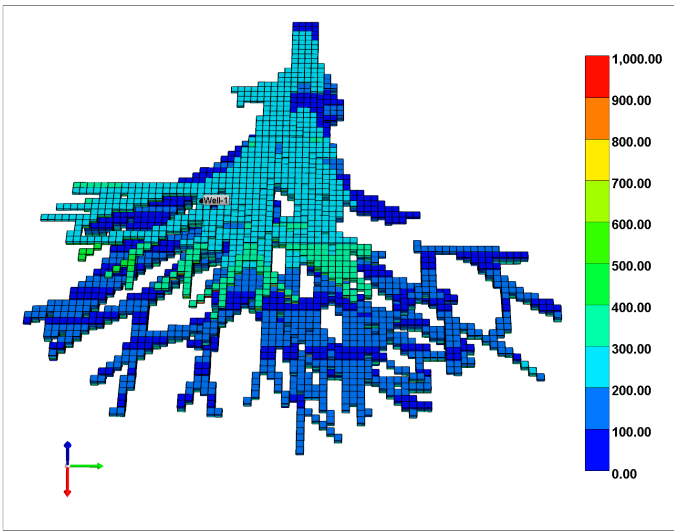

(a) Reference case.

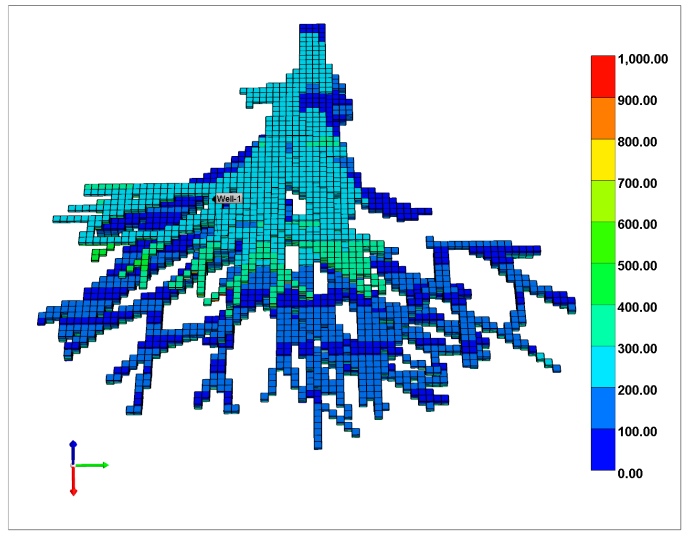

(b) Simulated case.

Figure 5.15: Vertical permeability distribution.

\section{2}

\section{Approximation to the Reference Case with Noise}

For each case presented in the previous section, we include a noise in the pressure data. The non-uniform pressure variation $\Delta p^{*}$ is given by:

$$
\Delta p^{*}(t)=\alpha \cdot \sin (t) \cdot \Delta p(t)
$$

where,

- $\Delta p$ is pressure variation without noise,

- $\alpha$ is a constant chosen for each case,

- and $t$ is the time step in hours. 
The choice of this sinusoidal noise is due to the fact that the behavior of this function is similar to the tidal effect, which occurs in offshore well tests. After some simulations with this disturbance in the pressure variation data, we modified the stopping condition of the cases with noise to 5.0e-02. That also corresponds to a relatively small error for the pressure data.

For the case with 1 lobe, we choose $\alpha$ equal to 0.25 . The results obtained in each iteration are in the Table 5.4.

Table 5.4: Case with 1 lobe

\begin{tabular}{ccc}
\hline Iteration & Permeability $(\mathrm{mD})$ & $f_{\text {obj }}$ \\
\hline 1 & 100.00 & $8,692.64$ \\
2 & $1,000.00$ & 227.69 \\
3 & 874.63 & 158.29 \\
4 & 245.77 & 667.87 \\
5 & 668.72 & 51.76 \\
6 & 576.61 & 14.28 \\
7 & 474.70 & 3.68 \\
8 & 509.01 & 0.17 \\
9 & 503.00 & 0.02 \\
\hline
\end{tabular}

It is possible to observe average permeability simulation in each iteration is similar to case without noise (Fig. 5.16(a)). For objective function the same happens (see Fig. 5.16(b)).

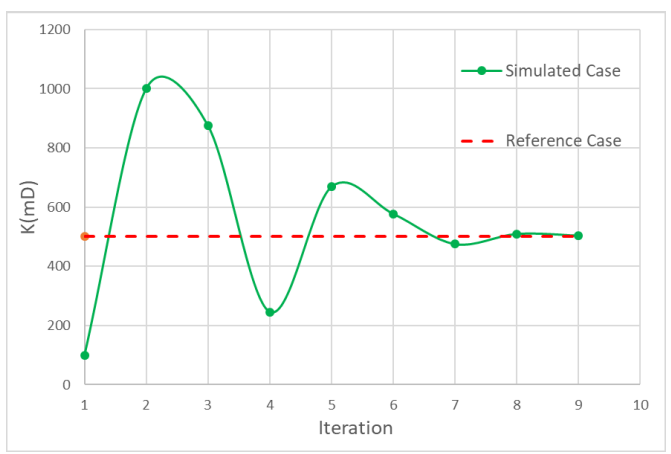

(a) $\bar{k} \times$ iteration.

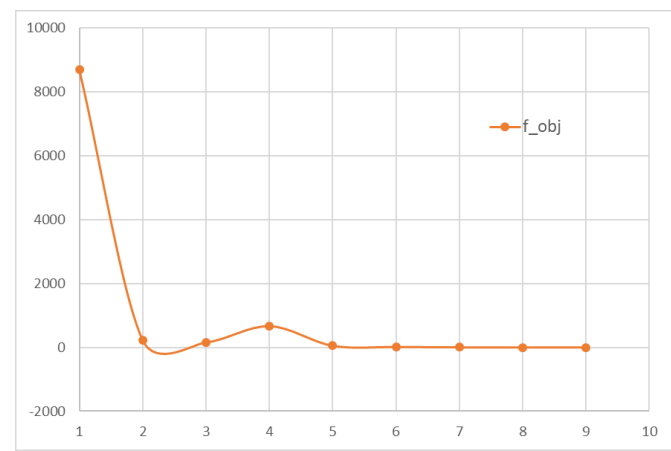

(b) $f_{o b j} \times$ iteration.

Figure 5.16: Graphs correspond to table 5.4.

In the Fig. 5.17, we can observe that the log-time pressure derivative stared the simulated log-time pressure derivative of the reference case. In addition, there was not much variation for the areal and vertical permeability distribution of the simulated case from noisy data, as shown in Fig. 5.18 and 5.19. 


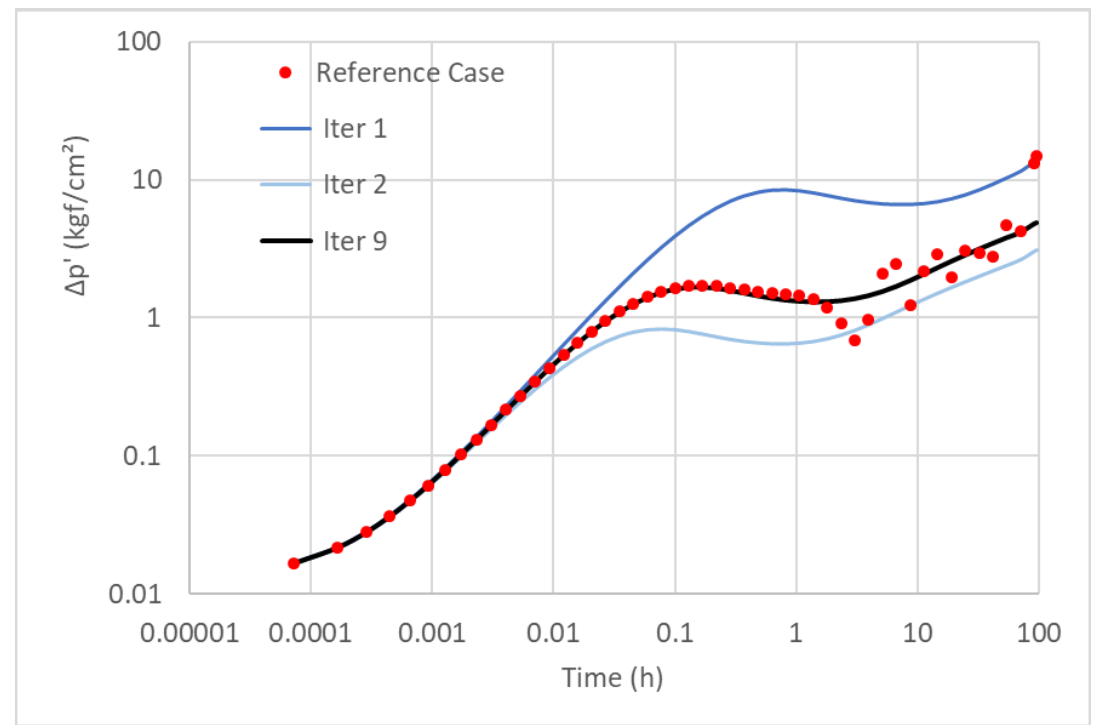

Figure 5.17: $\Delta p^{* \prime} \times$ Time.

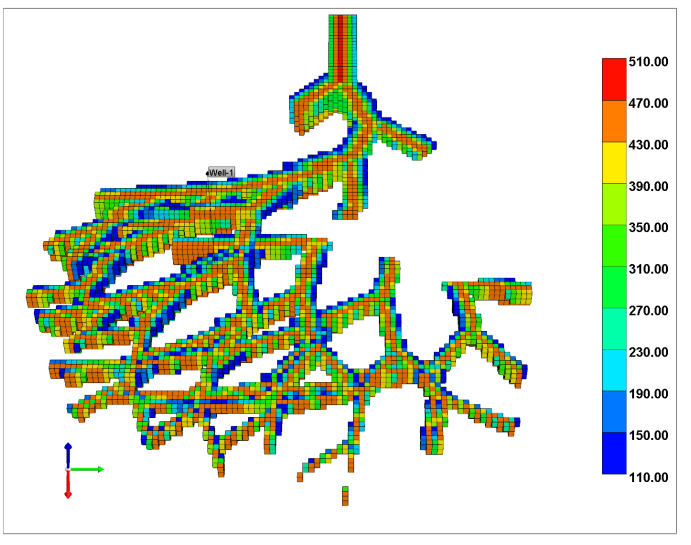

(a) Reference case.

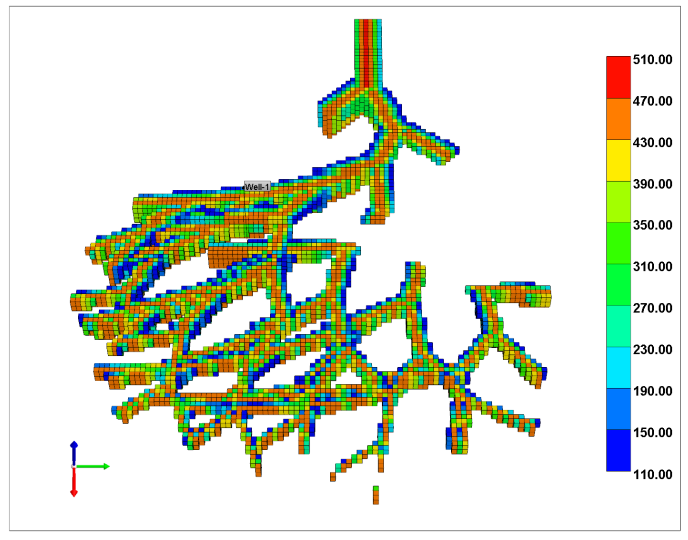

(b) Simulated case.

Figure 5.18: Areal permeability distribution.

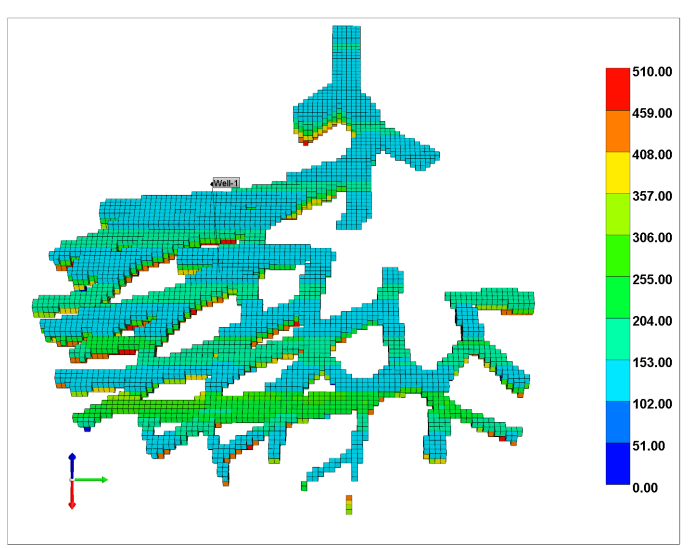

(a) Reference case.

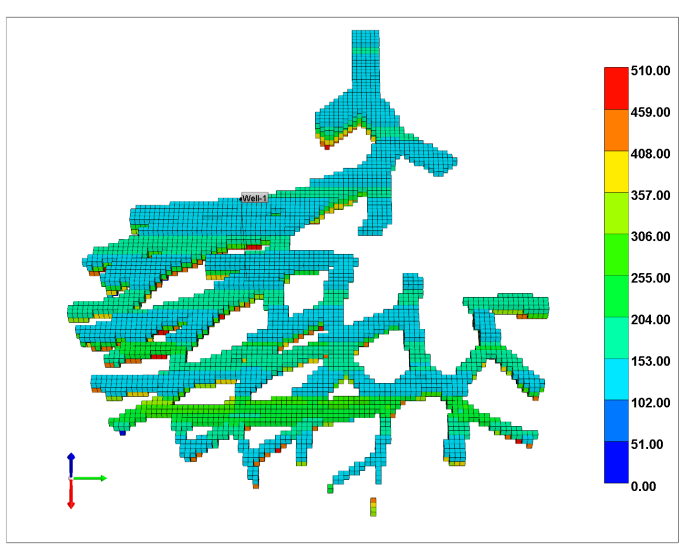

(b) Simulated case.

Figure 5.19: Vertical permeability distribution. 
The $\alpha$ value in cases with 2 and 3 lobes is the same, $\alpha=0.1$. The choice of this value was motivated by the analysis of the behavior of the log-time pressure derivative data after the inclusion of noise in pressure data with higher $\alpha$ values.

In the case with 2 lobes, the objective function achieved the stopping condition in less iterations and also with a lower value than case without noise (see Table 5.5). However, the difference between the estimated permeability and the reference permeability is greater.

Table 5.5: Case with 2 lobes

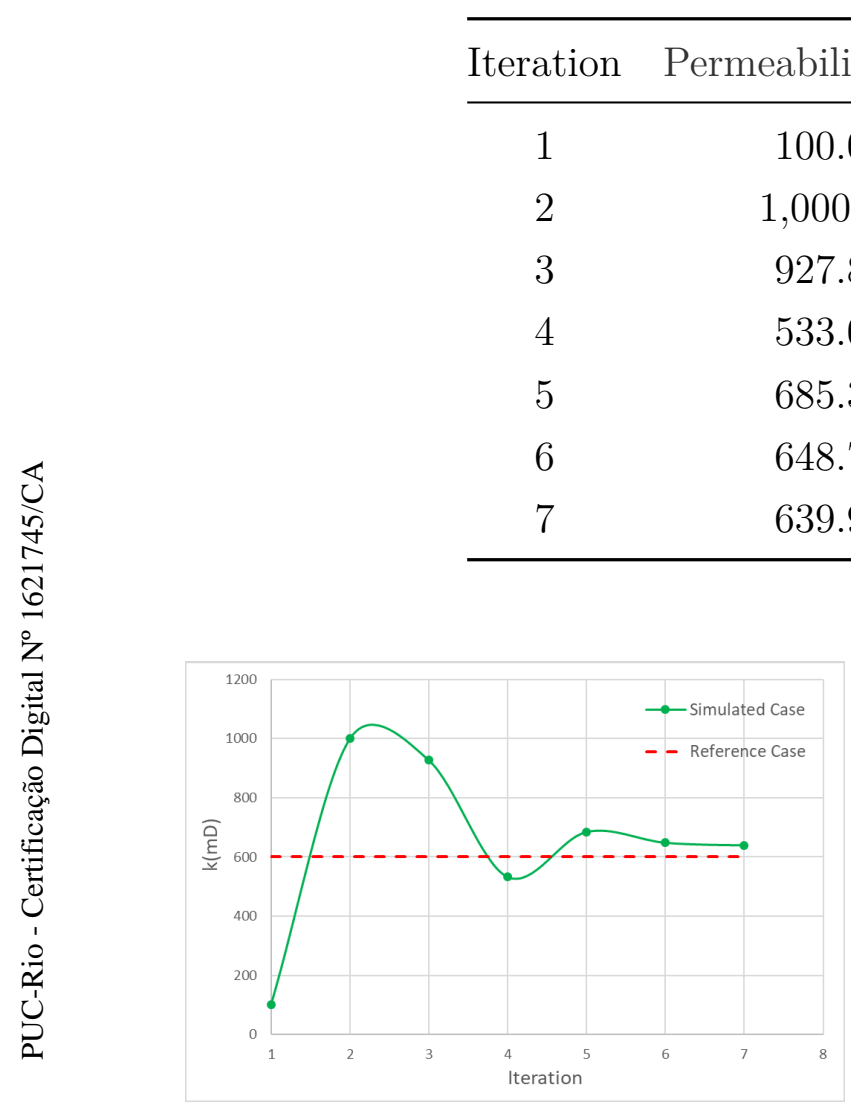

(a) $\bar{k} \times$ iteration

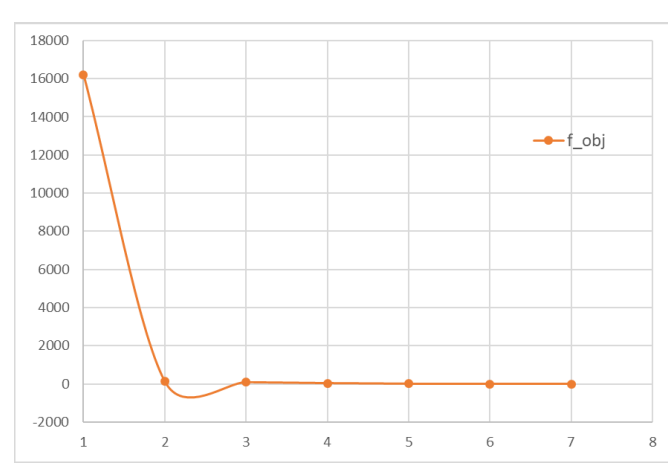

(b) $f_{o b j} \times$ iteration.

Figure 5.20: Graphs correspond to table 5.5.

The variation in the pressure data of the reference case has meant that the flow data in each layer were not so similar, as shown in Fig. 5.21. 


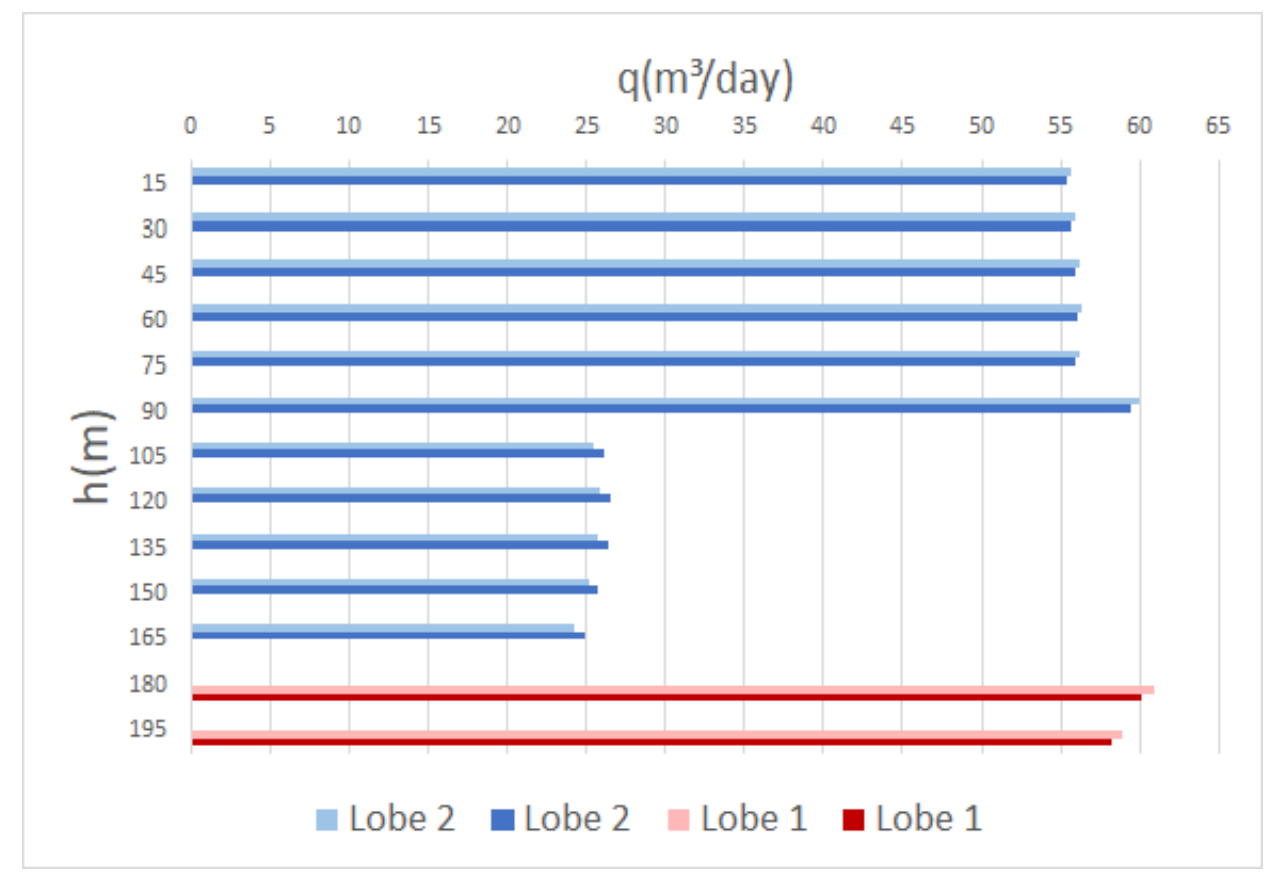

Figure 5.21: Production log of the case with 2 lobes and noise.

Despite this, the log-time pressure derivative curve shows a satisfactory behavior, considering the non-uniformity in the data (Fig. 5.22).

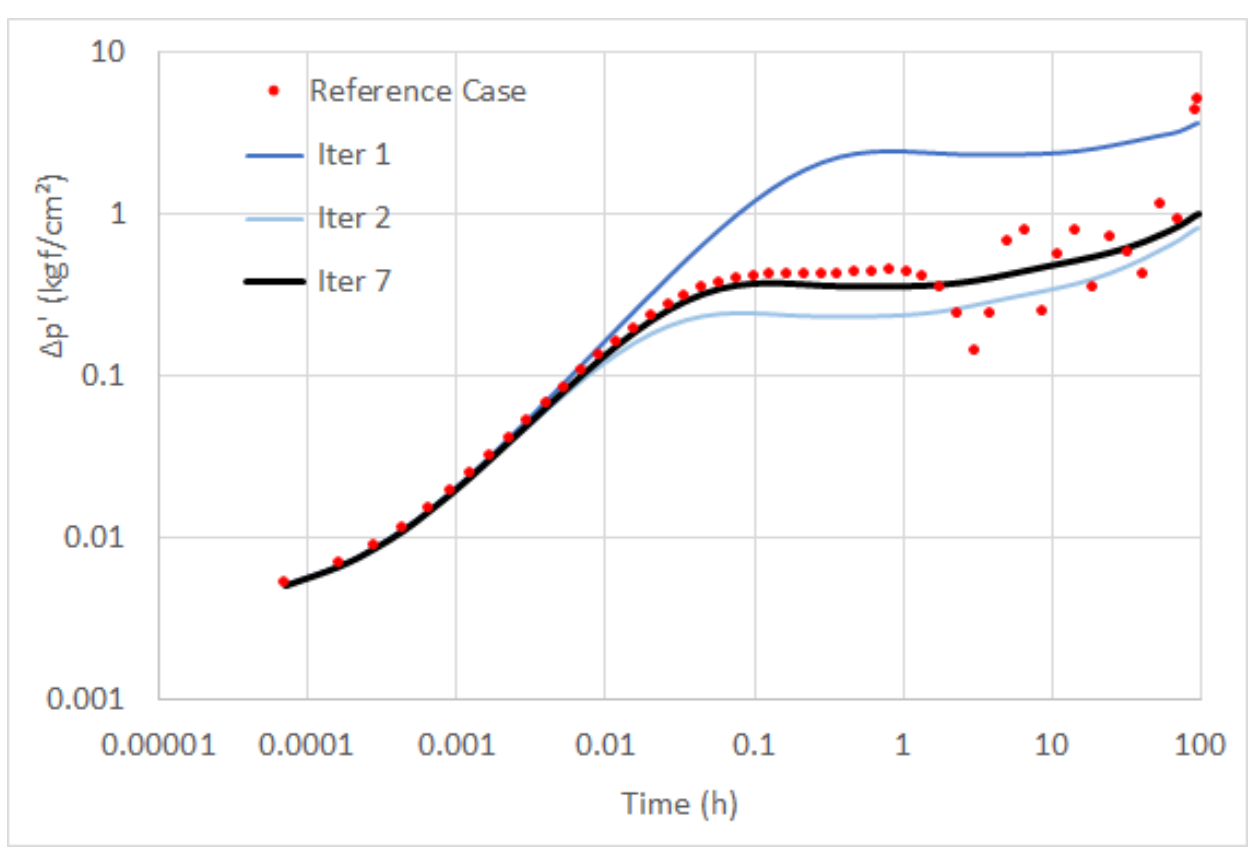

Figure 5.22: $\Delta p^{* \prime} \times$ Time.

As well as the distributions of areal and vertical permeability, presented in Fig. 5.23 and 5.24. 


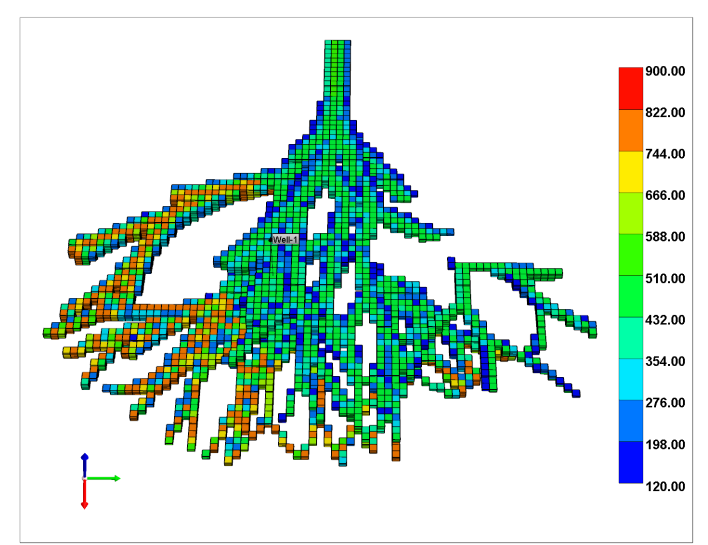

(a) Reference case.

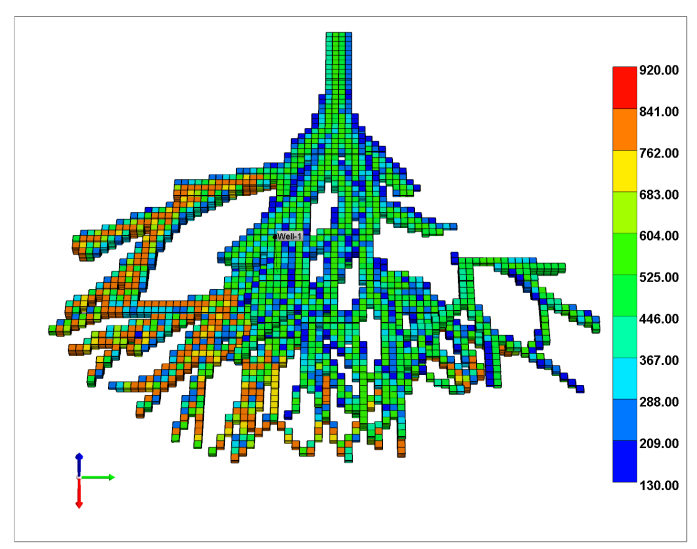

(b) Simulated case.

Figure 5.23: Areal permeability distribution.

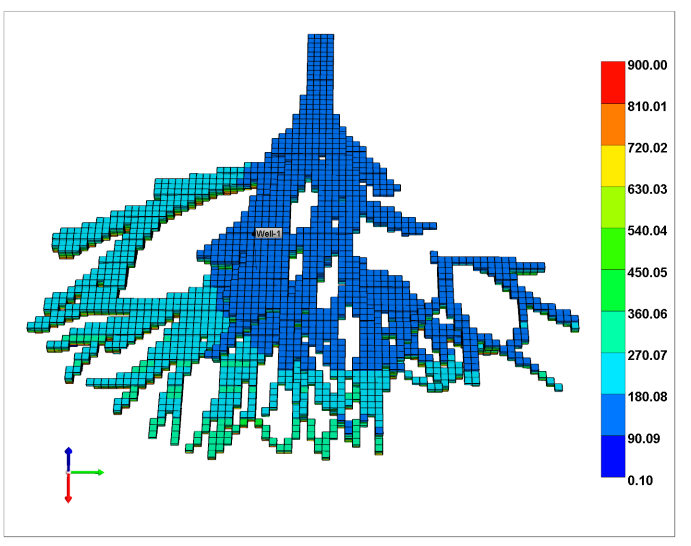

(a) Reference case.

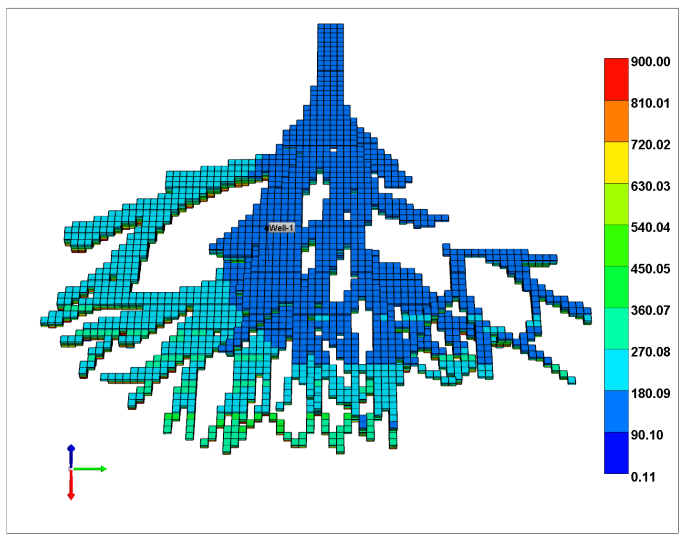

(b) Simulated case.

Figure 5.24: Vertical permeability distribution.

The results for case with 3 lobes are presented in Table 5.6.

Table 5.6: Case with 3 lobes

\begin{tabular}{ccc}
\hline Iteration & Permeability $(\mathrm{mD})$ & $f_{o b j}$ \\
\hline 1 & 100.00 & $12,112.30$ \\
2 & $1,000.00$ & 148.35 \\
3 & 910.32 & 104.82 \\
4 & 437.49 & 124.74 \\
5 & 684.19 & 10.28 \\
6 & 629.16 & 0.57 \\
7 & 612.16 & 0.05 \\
8 & 616.14 & 0.06 \\
9 & 614.13 & 0.03 \\
10 & 609.79 & 0.09 \\
11 & 612.59 & $5.54 \times 10^{-03}$ \\
\hline
\end{tabular}


From the sixth iteration the permeability values approximate to the $600 \mathrm{mD}$ (Fig. 5.25(a)). The objective function also presents the same configuration (see Fig. 5.25(b)).

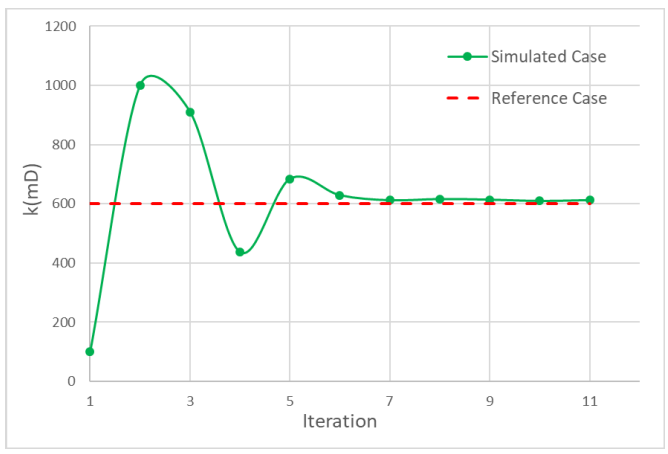

(a) $\bar{k} \times$ iteration

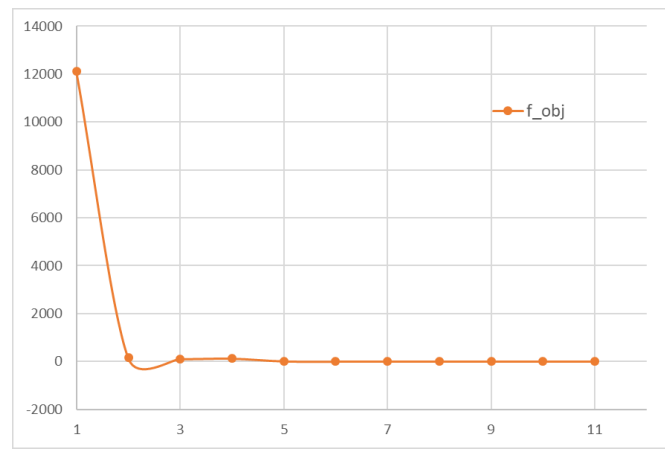

(b) $f_{o b j} \times$ iteration.

Figure 5.25: Graphs correspond to table 5.6.

The percentage of flow per each layer also presented a variation compared to the reference values, mainly in the lobe 1 as shown in Fig. 5.26.

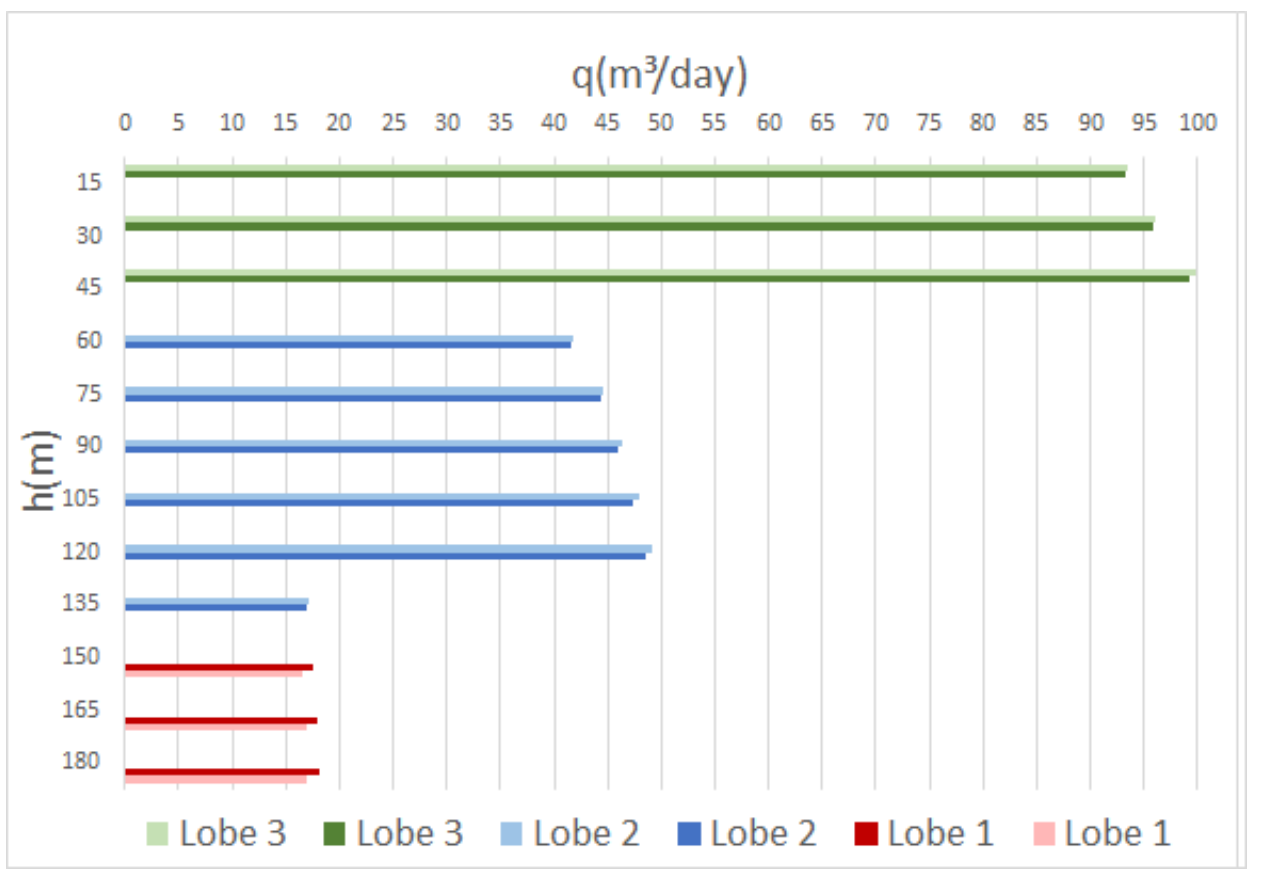

Figure 5.26: Production log of the case with 3 lobes and noise.

The log-time pressure derivative data with noise are illustrated in the Fig. 5.27. From the curve corresponding to the simulated case, we can observe the perturbation caused by noise in the pressure data. However, this effect is not clear in the data from the permeability distribution (see Fig. 5.28 and Fig. 5.29). 


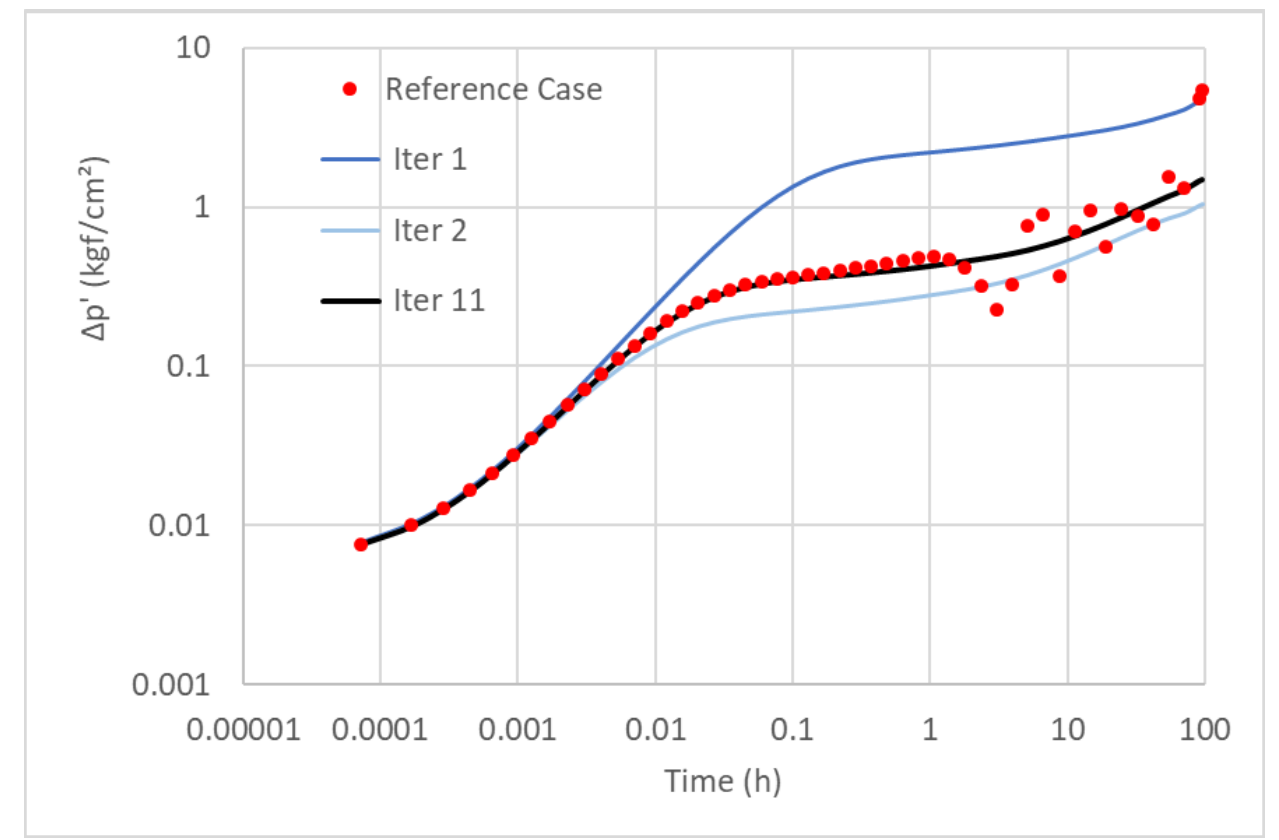

Figure 5.27: $\Delta p^{* \prime} \times$ Time.

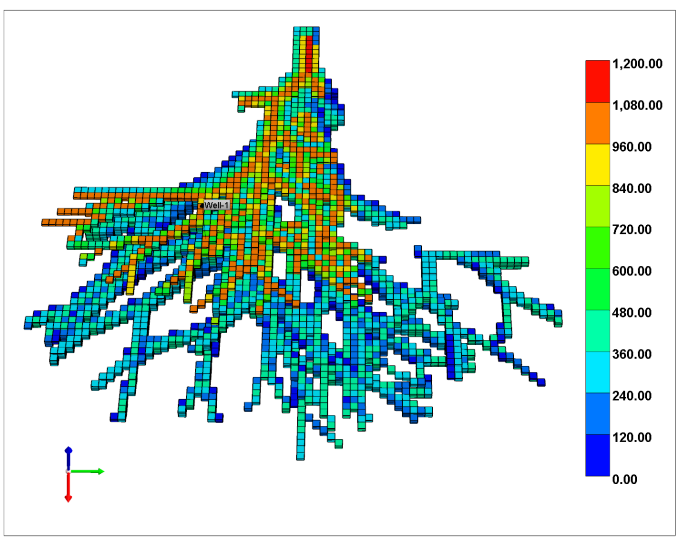

(a) Reference case.

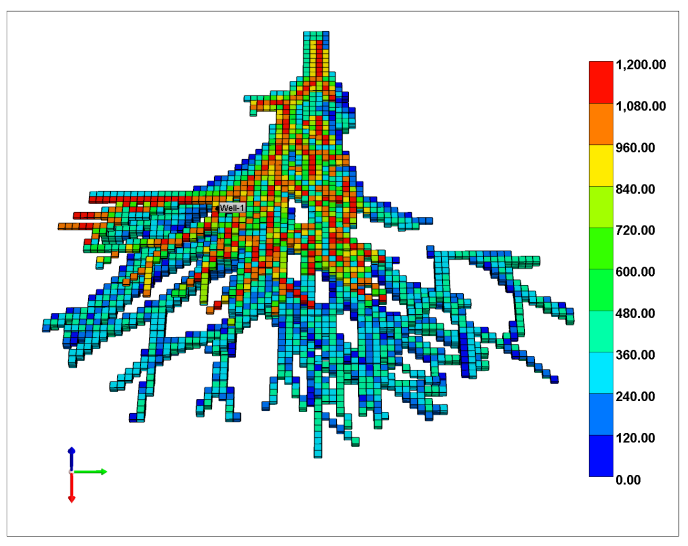

(b) Simulated case.

Figure 5.28: Areal permeability distribution.

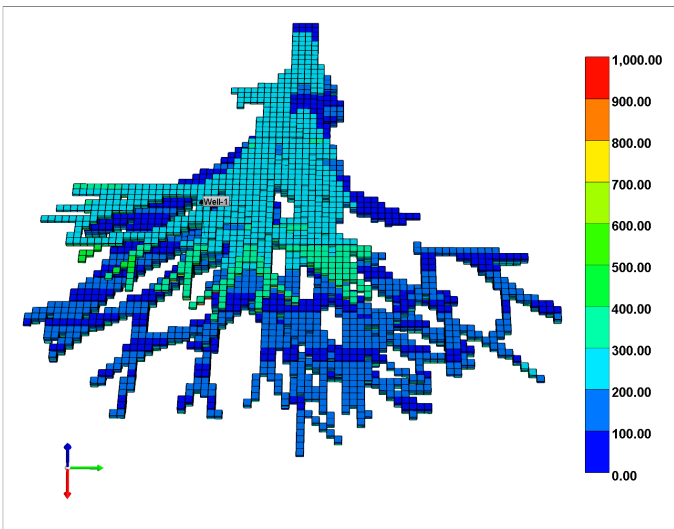

(a) Reference case.

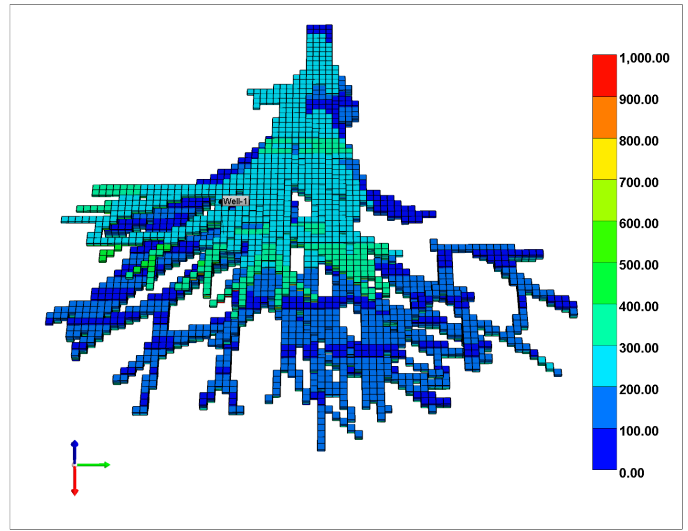

(b) Simulated case.

Figure 5.29: Vertical permeability distribution. 
Finally, comparing the results of the simulations to the reference case, we analyzed that the pressure data and the production profile per layer were sufficient to estimate the permeabilities in reservoirs of turbidite channels with 1, 2 or 3 lobes. Although th eresults obtained for the noisy cases present some dispersion, it is possible to verify that the estimation method used in this work generates accurate results.

Although the Secant Method provides good results in a few iterations, its convergence is conditioned to a good choice for the first two iterations. In a future research, it should be interesting to investigate other methods to estimate the average permeability constrained by well-testing simulations. 


\section{Conclusions}

The methodology proposed in this thesis provides advantages for a reservoir model based on turbidity currents, providing a better comprehension of flow behavior in a depositional system composed by turbidite channels. In a future research, this model can be used to predict other rock properties, such as porosity.

Since the permeability can be estimated by pressure measurements obtained during the well-testing, these data were used to compare the simulation to a reference case through an objective function. So, permeability was estimated as an inverse problem. The secant method was chosen to approximate the average permeability of the simulated case to the average permeability of the reference case.

In the chapter 5 , it is possible confirm that the method used to estimate the permeability filed in each lobe of the simulated depositional system provides consistent results and, after addition of a noise to the pressure data, the results also were good.

Some challenges were found in the optimization process, such as: the choice of the well's location could not be arbitrary. For its position is conditioned by two factors: he well to drill a channel and the thickness of each lobe in the well can not be zero. Because it is necessary to provide information about the production log in each lobe to estimate the permeability multiplier corresponding to it.

Furthermore, the use of a regular Cartesian grid is not condition for obtaining a effective distribution of this data. However, it necessary to choose the mesh size large enough to replicate geological properties into the channels and small enough to optimize the simulation time.

For future works, it should be interesting the reservoir modeling constrained by other data that contents informations about reservoir characterizations such as: well log or proportion curve, proportion map based on seismic data and new permeability models. These data can be used to construct a modeling with characteristics close to reality. 


\section{Bibliography}

[1] DIAS, J. A., Correntes Turbidíticas (versão preliminar). CORRENTES TURBIDÍTICAS. 2004.

[2] BOGGS, S., Principles of Sedimentology and Stratigraphy, 2011, p. 1689-1699.

[3] CARDOnA, Y. A., Object-based Modeling of Turbidite Lobes using Single-valued B-Splines. 2016. Dissertação de Mestrado. Departamento de Matemática, Pontifícia Universidade Católica do Rio de Janeiro.

[4] SILVA, T. M. D., Modelagem Assistida de Lobos Turbidíticos Baseadas em Dados de Teste de Formação. 2017. Dissertação de Mestrado. Departamento de Matemática, Pontifícia Universidade Católica do Rio de Janeiro.

[5] GRAJALES, V. L. V., Image Based Simulation Methods for Depositional Systems Modeling. 2017. Tese de Doutorado. Departamento de Matemática, Pontifícia Universidade Católica do Rio de Janeiro.

[6] HAUGE, R.; SYVERSVEen, A. R.; MACDOnALD, A. C., Modeling Facies Bodies and Petrophysical Trends in Turbidite Reservoirs, SPE Journal, 2003.

[7] SHEPARD, D., A Two-dimensional Interpolation Function for Irregularity-spaced data. Proceedings of the 1968 23rd ACM National Conference, ACM' 68, p. 517-524, New York, USA, 1968.

[8] Rosa, A. J.; CARvalho, R. S.; Xavier, J. A. D., Propriedades das Rochas. Engenharia de Reservatório de Petróleo, p. 104-174. Editora Interciência, 2006.

[9] MARIETHOZ, G.; CAERS, J., Multiple-point Geostatistics: stochatisc modeling with training images. John Wiley \& Sons, 2014. 
[10] BARRETO, A., Notas de aula do professor Abelardo Barreto Teoria dos Testes de Pressão em Poços. 2016. Pontifícia Universidade Católica do Rio de Janeiro. Rio de Janeiro, Brasil.

[11] COMPUTER MODELING GROUP LTD., User's Gruide IMEX: Advanced Oil/ Gas Reservoir Simulator, 2010. Calgary, Canadá.

[12] PEACEMAN, D. W., Interpretation of Well-block Pressures in Numerical Reservoir Simulation with Nonsquare Grid Blocks and Anisotropic Permeability. SPE Journal, 1983.

[13] HAMDI, H.; SOUSA, M. C., Calibrating Multi-Point Geostatistical Models Using Pressure Transient Data. SPE Journal, 2016.

[14] GOLUB, G. H.; ORTEGA, J. M., Scientific Computing and Differencial Equations: an Introduction to Numerical Methods. Elsevier, 2014. 
A

\section{Example of Input File}

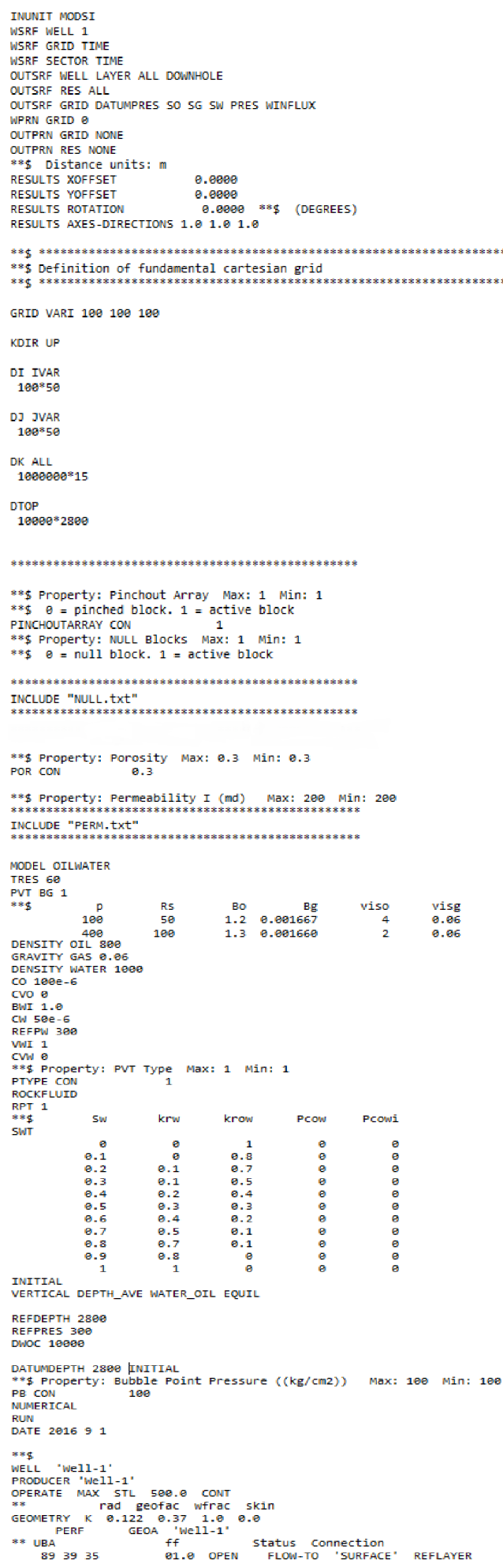




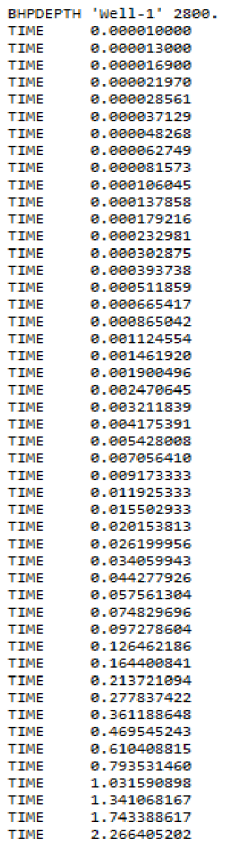

RESULTS SPEC 'Bubble point pressure RESLITS RESULTS SPEC REGIONTYPE 'REGION_TABLE' RESULTS SPEC LAYERMUMB

RESULTS SPEC CON 100

RESULTS SPEC SPECKEEPMOD 'YES

RESULTS SPEC 'Permeability I'

RESULTS SPEC S $S$ EEAT

RESULTS SPEC REGION "All Layers (Whole Grid)'

RESULTS SPEC LAYERNUMB
PORTYPE 1

RESULTS SPEC CON $20 \Theta$
RESULTS SPEC SPECKEEPMOD 'YES"

RESULTS SPEC 'Permeability $]$ '

RESULLS SPEC SPECNOTCALVIAL - 99999
RESULTS SPEC REGION "AII Layers (whole Grid)"

RESULTS SPEC REGIONTYPE 'REGION_WHOLEGRID'

RESULTS SPEC LAYERNUMB

RESULTS SPEC CON 260
RESULTS SPEC SPECKEPMOD ' $Y$ EES

RESULTS SPEC STOP

RESULTS SPEC 'Permeability K'

RESULTS SPEC REGION "All Layers (whole Grid)

'EESULTS SPEC PEGTOUTYPE 'PEGTON (WhOLEGTD'

RESULTS SPEC LAYERNUMB

RESULTS SPEC CON 2
RESULTS SPEC SPECKEEPMOD "YES"

RESULTS SPEC STOP

RESULTS SPEC "POrOsity"

RESULTS SPEC SPECNOTCALCVAL - 9999

RESULTS SPEC REGION 'All Layers (Whole Grid)

RESULTS SPEC REGIONTYPE '

RESULTS SPEC LAYERNUMB

RESULTS SPEC CON 0.3

RESULTS SPEC SPECKEEPMOD 'YES'

RESULTS SPEC STOP

RESULTS SPEC "PVT TYPe"

RESULTS SPEC SPECNOTCALCVAL - 9999

RESULTS SPEC REGION 'All Layers (Whole Grid)'

RESULTS SPEC REGIONTYPE 'REGION_WHOLEGRID'

RESULTS SPEC LATERTVMB

RESULTS SPEC PORTYPE

RESULTS SPEC SPECKEEPMOO 'YES'

RESULTS SPEC STOP

RESULTS SPEC "Grid Thickness'

RESULTS SPEC SPECNOTCALCVAL -99999

RESULTS SPEC REGION All Layers (Whole Grid) "

RESULTS SPEC REGIONTYPE 'REGION_WHOLEGRID'

RESULTS SPEC LAYERMUMB

RESULTS SPEC PORTYPE

RESULTS SPEC SPECKEEPMOD 'YES'

RESULTS SPEC STOP

RESULTS SPEC "Grid TOP"

RESULTS SPEC SPECNOTCALCVAL -99999

RESULTS SPEC REGION 'Layer 1 - Whole layer'

RESULTS SPEC REGIONTYPE 'REGION_LAYER'

RESULTS SPEC LAYERNUMB

RESULTS SPEC PORTYPE

RESULTS SPEC CON 2800

RESULTS SPEC SPECKEEPMOO 'YES' 
B
NULL.txt

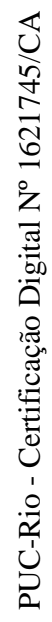

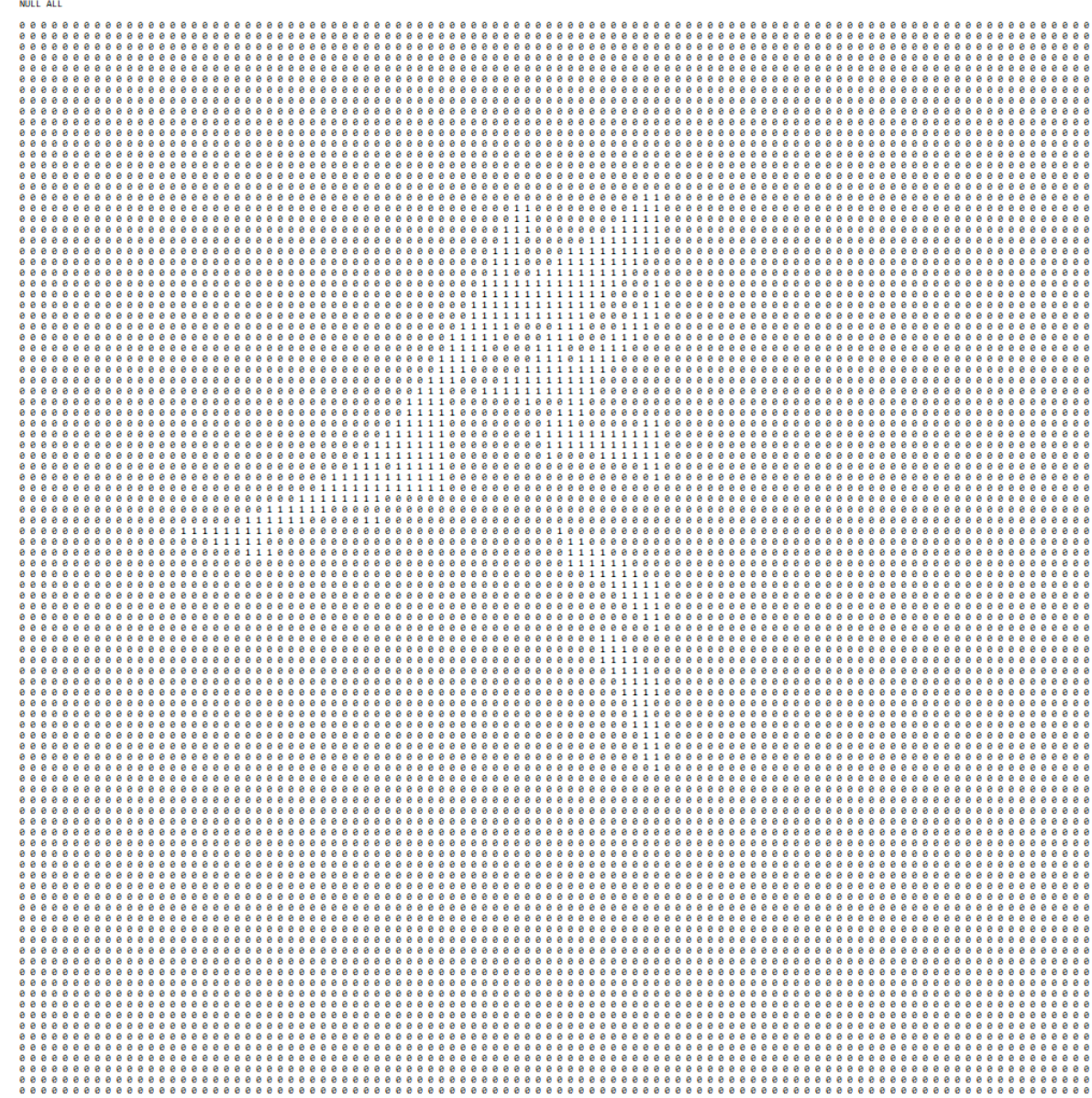


C

PERM.txt

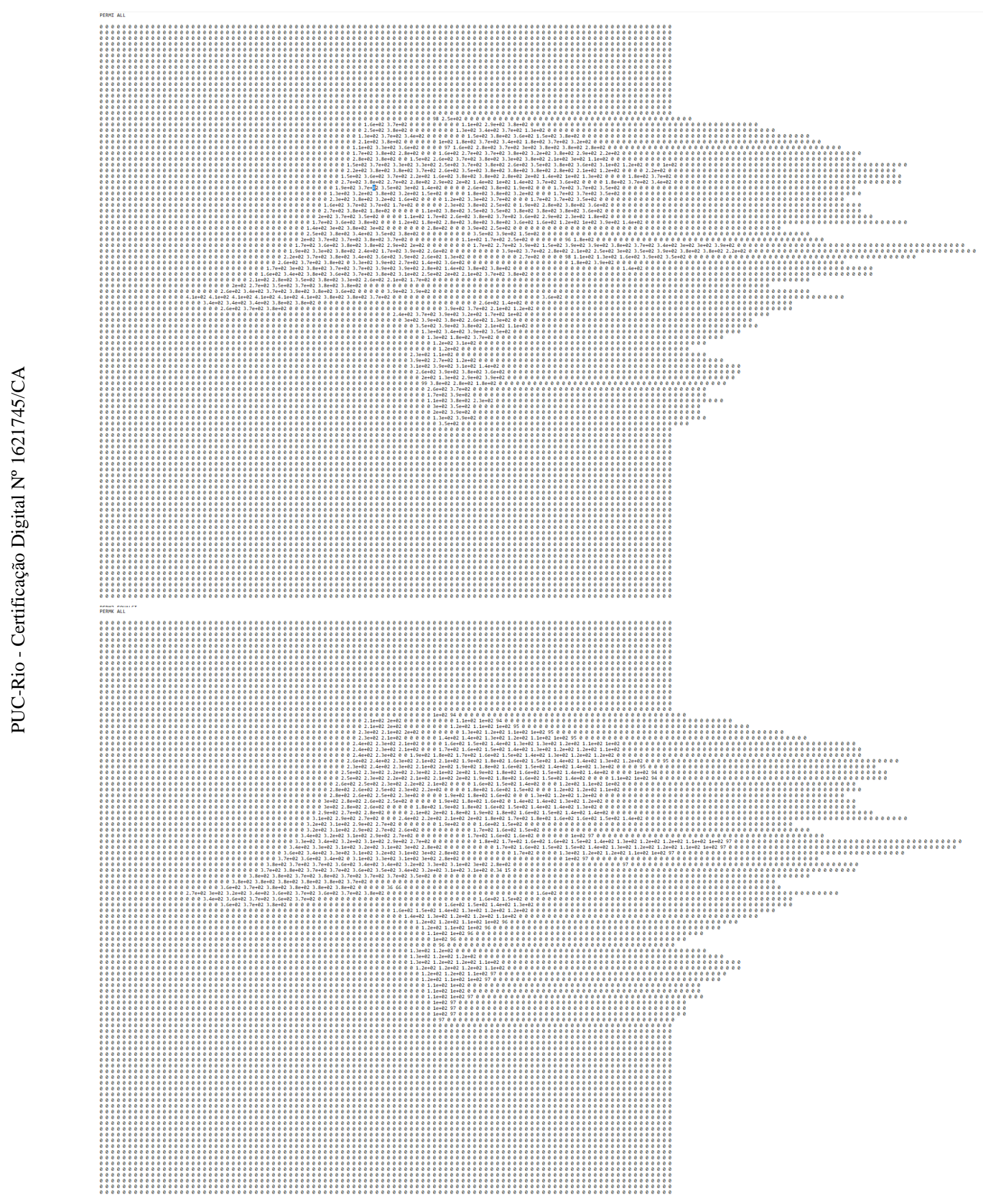

